\title{
Kingdom of Lesotho: Poverty Reduction Strategy Paper- National Strategic Development Plan
}

This poverty reduction strategy paper (PRSP): National Strategic Development Plan 2012/132016/17 was prepared by authorities of the Kingdom of Lesotho. PRSPs are prepared by member countries in broad consultation with stakeholders and development partners, including the staffs of the World Bank and the International Monetary Fund. Updated every three years, with annual progress reports, they describe the country's macroeconomic, structural, and social policies in support of growth and poverty reduction, as well as associated external financing needs and major sources of financing. This country document for the Kingdom of Lesotho, dated March 2012, is being made available on the IMF website by agreement with the member country as a service to users of the IMF website.

\author{
Copies of this report are available to the public from \\ International Monetary Fund • Publication Services \\ $70019^{\text {th }}$ Street, N.W. • Washington, D.C. 20431 \\ Telephone: (202) 623-7430 • Telefax: (202) 623-7201 \\ E-mail: publications@imf.org Internet: http://www.imf.org
}

\section{International Monetary Fund Washington, D.C.}




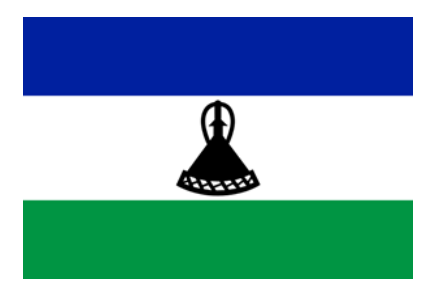

\title{
National Strategic Development Plan 2012/13 - 2016/17
}

\author{
Growth and Development \\ Strategic Framework
}

"Towards an accelerated and sustainable economic and social transformation"

Government of Lesotho

March 2012 



\section{Preface}

This National Strategic Development Plan (NSDP), which will be implemented from the fiscal year $2012 / 13$ to $2016 / 17$, succeeds the Poverty Reduction Strategy Paper (PRSP) and the Interim National Development Framework (INDF). Like the PRSP and the INDF, it will also serve as an implementation strategy for the National Vision 2020 for the next five years.

The Ministry of Finance and Development Planning prepared the NSDP with the invaluable assistance of Technical Working Groups (TWGs), composed of technical staff, mainly from line Ministries and with participation by resident UN offices and other cooperating partners. The contribution of the private sector, civil society, academia and other stakeholders was solicited mainly through nine Cluster Groups that were configured around the NSDP key strategic areas. The Clusters reviewed the work done by the TWGs. The NSDP secretariat consolidated the inputs of the Clusters and other stakeholders to produce an advanced draft of the NSDP, which was considered by Cabinet. Thereafter, district consultation meetings were held, which had wide representation of stakeholders. This Growth and Development Strategic Framework is based on all of these inputs.

The NSDP is organized into eight chapters. Chapter 1 covers the background, providing a brief development review based on National vision 2020 targets and the Millennium Development Goals (MDGs) and the Plan objectives. Chapter 2 provides the context within which the plan was developed, mainly highlighting key population dynamics, natural setting, economic performance, international outlook and major challenges and opportunities facing Lesotho. Chapter 3 defines the growth strategy, including the growth diagnostics, 
growth strategy, sources of growth and economic growth scenarios. Chapter 4 presents the macroeconomic framework and compares simulations of the three growth scenarios and key economic projections up to 2020, which is the last year of implementation for National Vision 2020. Chapter 5 shifts to the strategic framework which outlines the main sector or thematic area objectives and strategic actions under the six NSDP strategic goals. Chapter 6 brings out key cross-cutting issues. Chapter 7 sets out the implementation strategy. 


\section{Table of Contents}

List of Acronyms

Executive Summary . i

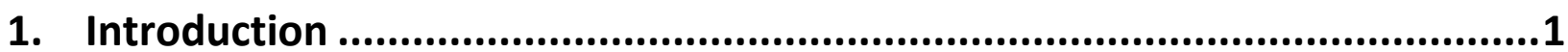

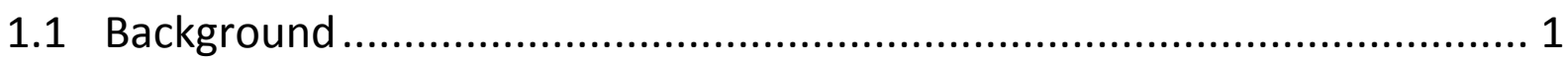

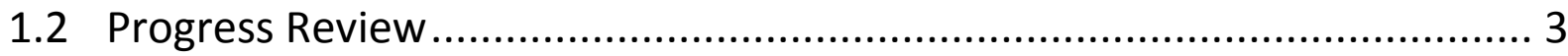

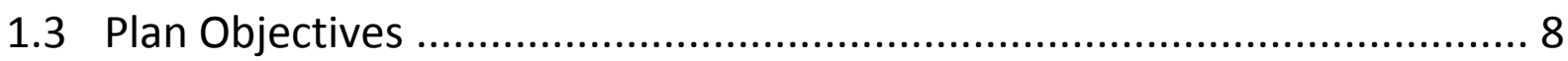

2. Context, Challenges and Opportunities....................................................11

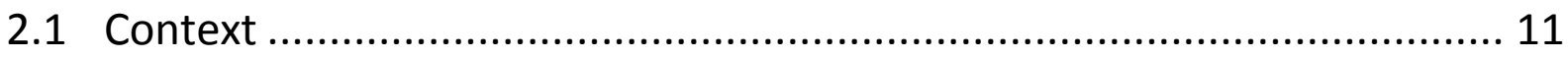

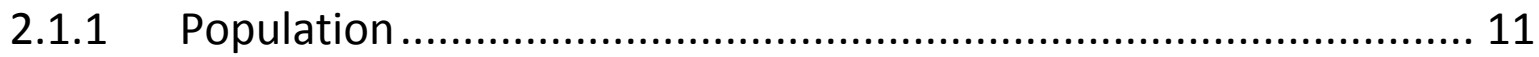

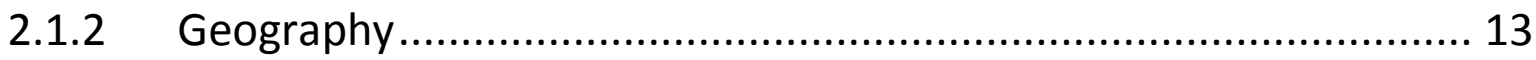

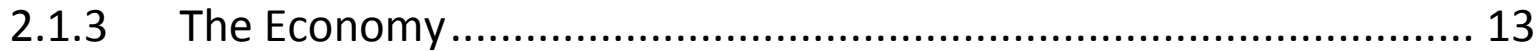

2.1.4 International Economic Outlook ................................................... 20

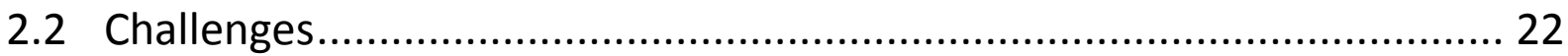

2.2.1 Poverty, Unemployment and Inequality .................................. 22

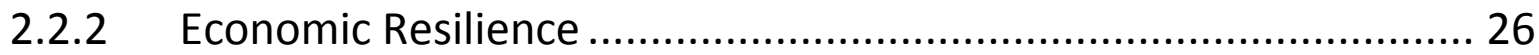

2.2.3 Vulnerability to natural disasters and climate change .................. 26

2.2.4 Health, HIV and AIDS ............................................................ 27

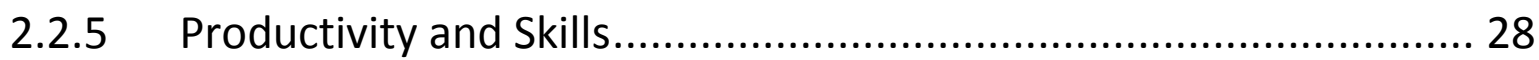

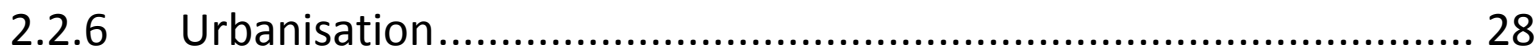

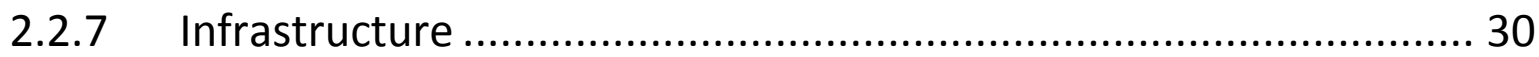

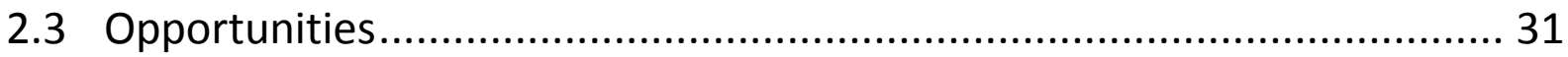

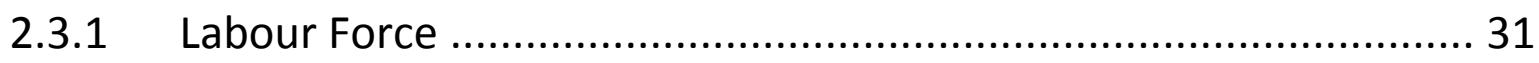

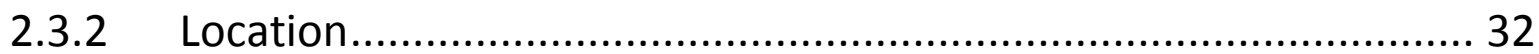

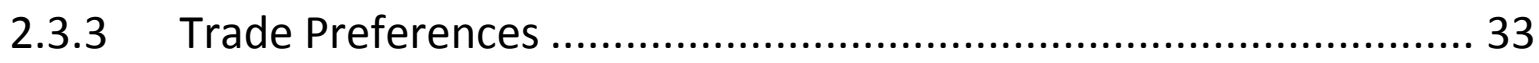

2.3.4 Clean Energy and Green Technologies........................................... 34

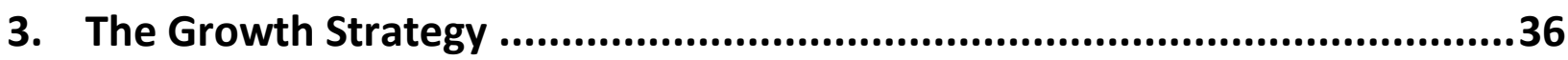

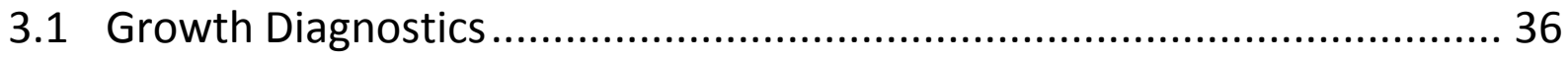

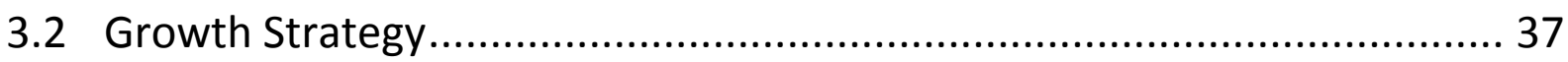




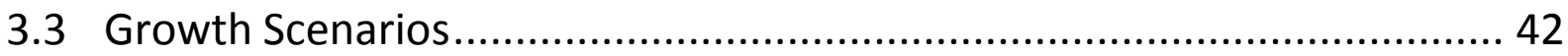

3.3.1 Low Growth Scenario ............................................................. 43

3.3.2 Moderate Growth Scenario and Growth Accelerators................... 45

3.3.3 Plan Scenario and Growth Generators ........................................ 48

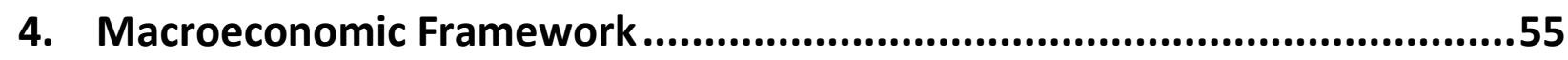

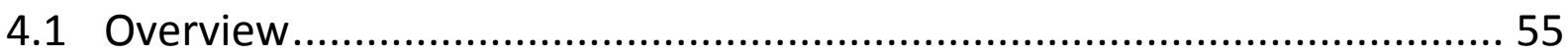

4.1.1 Recent Economic Performance................................................... 55

4.1.2 Recent Fiscal Trends ................................................................. 56

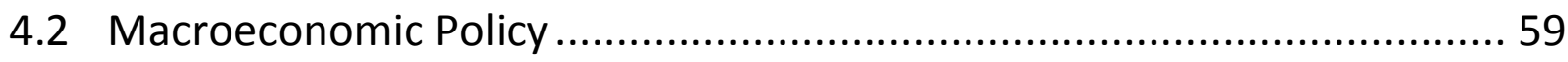

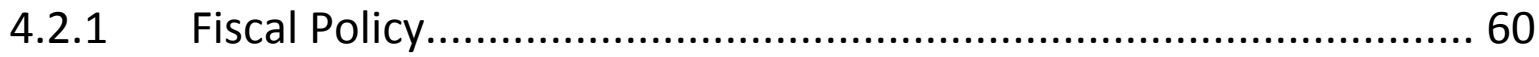

4.2.2 Monetary Policy and External Sustainability................................... 61

4.3 Economic Projection for the Plan Period .................................................. 64

4.4 Fiscal Framework, 2011/12 - 2016/17 …............................................. 67

4.5 Economic Projection beyond the Plan period ....................................... 71

4.6 Managing downside risks .................................................................. 72

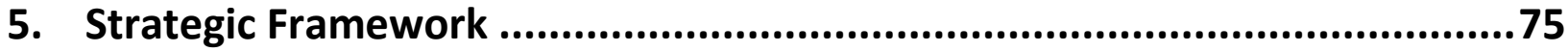

5.1 Create High, Shared, and Employment Generating Growth .................... 75

5.1.1 Investment Climate .................................................................. 75

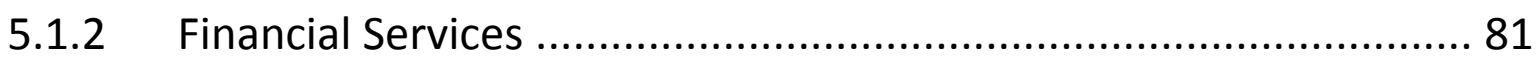

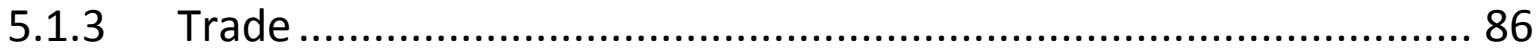

5.1.4 Agriculture and the Rural Economy ............................................ 89

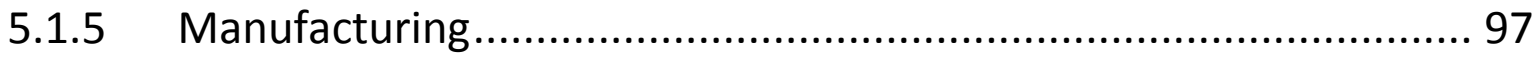

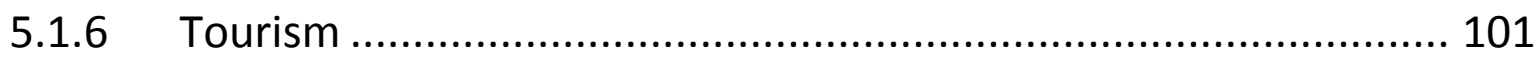

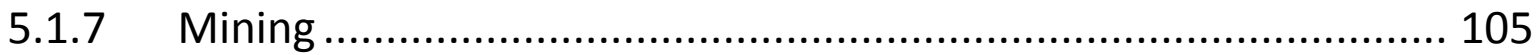

5.1.8 Micro, Small and Medium Enterprises (MSMEs).......................... 107

5.2 Develop Key Infrastructure ................................................................ 109

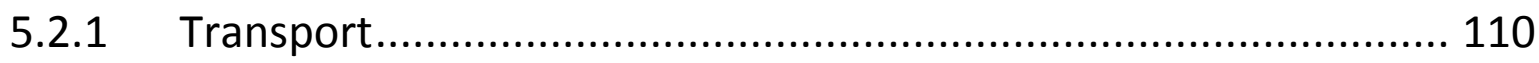

5.2.2 Water and Sanitation ............................................................ 113

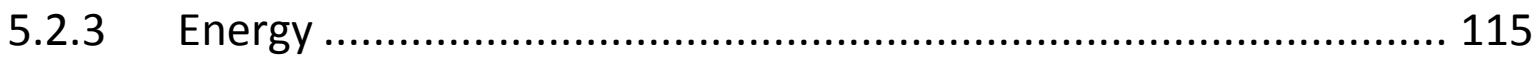

5.2.4 Information and Communications Technology (ICT) ................... 117 
5.2.5 Shelter and Property Development ......................................... 120

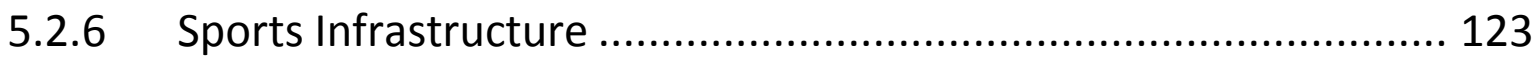

5.2.7 Public Asset Development and Management .............................. 124

5.3 Enhance Skills Base, Technology adoption and Foundation for

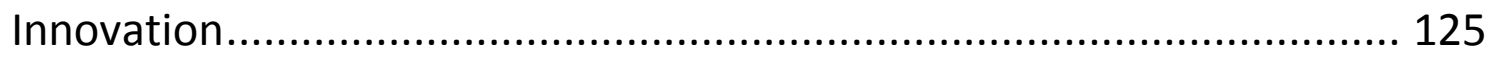

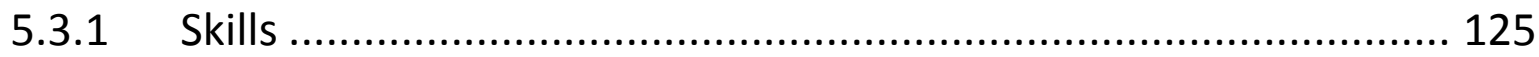

5.3.2 Technology and Innovation ..................................................... 131

5.4 Improve Health, Combat HIV and AIDS and Reduce Vulnerability.......... 133

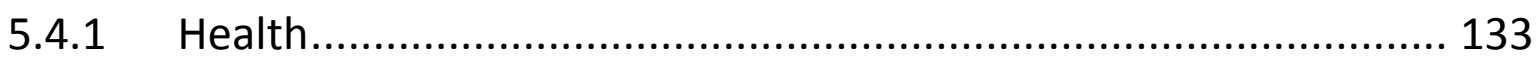

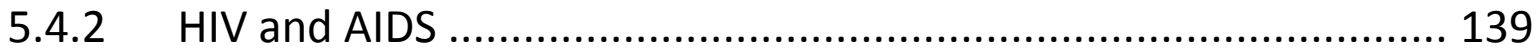

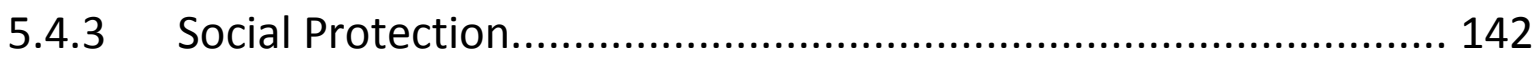

5.5 Reverse Environmental Degradation and Adapt to Climate Change....... 144

5.6 Promote Peace, Democratic Governance and Effective Institutions ...... 149

5.6.1 Stability and Democracy .......................................................... 149

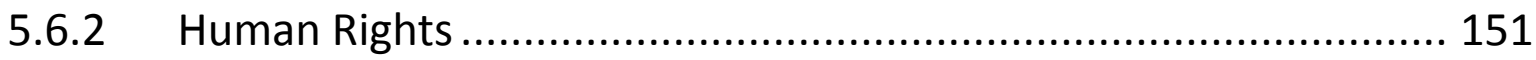

5.6.3 Law Enforcement and Administration of Justice.......................... 152

5.6.4 Policy, Planning and Public Financial Management ..................... 155

5.6.5 Public Administration and Service Delivery ............................... 158

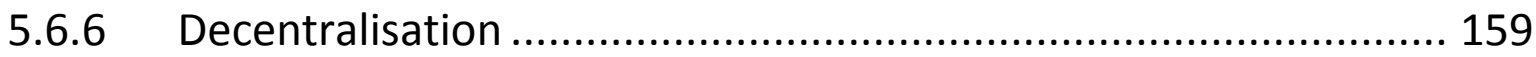

5.6.7 Regional Integration, International Relations and Cooperation.... 160

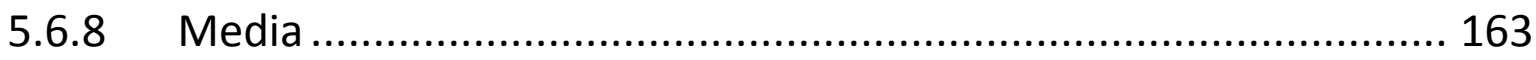

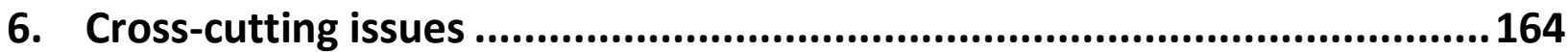

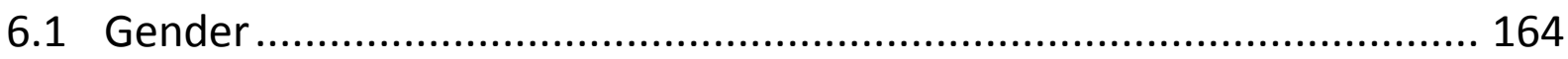

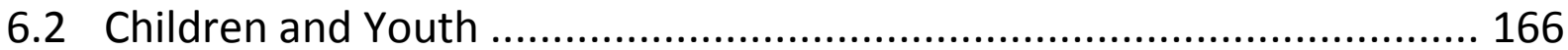

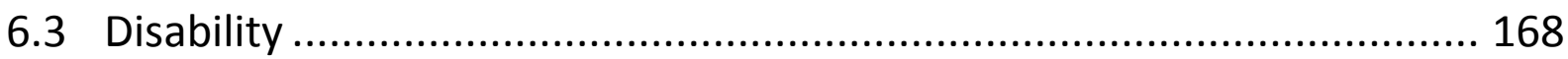

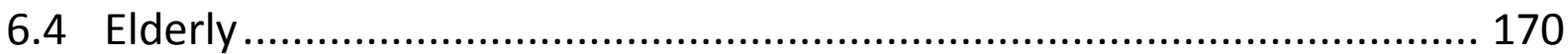

7. Implementation Strategy.....................................................................171 



\section{List of Acronyms}

$\begin{array}{lll}\text { AGOA } & - & \text { Africa Growth and Opportunity Act } \\ \text { AIDS } & - & \text { Acquired Immune Deficiency Syndrome } \\ \text { ALAFA } & - & \text { Apparel Lesotho Alliance to Fight AIDS } \\ \text { ART } & - & \text { Anti-Retroviral Therapy } \\ \text { ARV } & - & \text { Anti-Retroviral } \\ \text { AU } & - & \text { African Union } \\ \text { CBL } & - & \text { Central Bank of Lesotho } \\ \text { CDR } & - & \text { Crude Death Rate } \\ \text { CGPU } & - & \text { Child and Gender Protection Unit } \\ \text { CMA } & - & \text { Common Monetary Area } \\ \text { CMT } & - & \text { Cut Make and Trim } \\ \text { DA } & - & \text { District Administrator } \\ \text { DBI } & - & \text { Doing Business Indicators } \\ \text { DCEO } & - & \text { Directorate of Corruption and Economic Offences } \\ \text { DDPR } & - & \text { Directorate of Dispute Prevention \& Resolution } \\ \text { DSL } & - & \text { Digital Subscriber Line } \\ \text { ECCD } & - & \text { Early Childhood Care and Development } \\ \text { ECF } & - & \text { Extended Credit Facility } \\ \text { EFTA } & - & \text { European Free Trade Agreement } \\ \text { EIA } & - & \text { Environmental Impact Assessment } \\ \text { EPA } & - & \text { Economic Partnership Agreement } \\ \text { EU } & - & \text { European Union } \\ \text { FDI } & - & \text { Foreign Direct Investment } \\ \text { FIU } & - & \text { Financial Investigation Unit } \\ \text { FTCS } & - & \text { Farmers' Training Centres } \\ \text { FY } & - & \text { Financial Year } \\ \text { GDP } & - & \text { Gross Domestic Product } \\ \text { GNDI } & - & \text { Gross National Disposable Income } \\ \text { GNI } & - & \text { Gross National Income } \\ \text { GoL } & - & \text { Government of Lesotho } \\ \text { HDI } & - & \text { Human Development Index } \\ \text { HDR } & - & \text { Human Development Report } \\ \text { HIV } & - & \text { Human Immunodeficiency Virus } \\ \text { HMIS } & - & \text { Health Management Information Systems } \\ \text { ICT } & - & \text { Information and Communication Technology } \\ \text { IFAD } & - & \text { International Fund for Agricultural Development }\end{array}$




$\begin{array}{lll}\text { IFMIS } & - & \text { Integrated Financial Management Information System } \\ \text { IMF } & - & \text { International Monetary Fund } \\ \text { IMR } & - & \text { Infant Mortality Rate } \\ \text { INDF } & - & \text { Interim National Development Framework } \\ \text { IPRS } & - & \text { Intellectual Property Rights } \\ \text { JBCC } & - & \text { Joint Bilateral Commission of Cooperation } \\ \text { LDC } & - & \text { Least Developed Countries } \\ \text { LDHS } & - & \text { Lesotho Demographic and Health Survey } \\ \text { LEC } & - & \text { Lesotho Electricity Corporation } \\ \text { LHLDC } & - & \text { Lesotho Housing and Land Development Corporation } \\ \text { LHWP } & - & \text { Lesotho Highlands Water Project } \\ \text { LIPAM } & - & \text { Lesotho Institute of Public Administration and Management } \\ \text { LNDC } & - & \text { Lesotho National Development Corporation } \\ \text { LPMS } & - & \text { Lesotho Produce Marketing Services } \\ \text { LSPP } & - & \text { Land Survey and Physical Planning } \\ \text { LTDC } & - & \text { Lesotho Tourism Development Corporation } \\ \text { M\&E } & - & \text { Monitoring and Evaluation } \\ \text { MAFS } & - & \text { Ministry of Agriculture and Food Security } \\ \text { MCC } & - & \text { Maseru City Council } \\ \text { MDGs } & - & \text { Millennium Development Goals } \\ \text { MDWSP } & - & \text { Metolong Dam and Water Supply Programme } \\ \text { MOET } & - & \text { Ministry of Education and Training } \\ \text { MOPWT } & - & \text { Ministry of Public Works and Transport } \\ \text { MHAPS } & - & \text { Ministry of Home Affairs and Public Safety } \\ \text { MSMEs } & - & \text { Micro, Small and Medium Enterprises } \\ \text { MTEF } & - & \text { Medium-Term Expenditure Framework } \\ \text { MTFF } & - & \text { Medium-Term Fiscal Framework } \\ \text { MTICM } & - & \text { Ministry of Trade and Industry, Cooperatives and Marketing } \\ \text { NGOs } & - & \text { Non-Governmental Organisations } \\ \text { NIR } & - & \text { Net International Reserves } \\ \text { NSDP } & - & \text { National Strategic Development Plan } \\ \text { OBFC } & - & \text { One-Stop Business Facilitation Centre } \\ \text { ODA } & - & \text { Official Development Assistance } \\ \text { OVCs } & - & \text { Orphaned and Vulnerable Children } \\ \text { PERs } & - & \text { Public Expenditure Reviews } \\ \text { PFM } & - & \text { Public Financial Management } \\ \text { PFMAA } & - & \text { Public Financial Management and Accountability Act } 2011 \\ \text { PRS } & - & \text { Poverty Reduction Strategy } \\ \text { PMTCT } & - & \text { Prevention of Mother-to-Child Transmission } \\ \text { PWD } & - & \text { People living With Disability } \\ & & \end{array}$




$\begin{array}{lll}\text { R\&D } & - & \text { Research and Development } \\ \text { RIA } & - & \text { Regulatory Impact Assessment } \\ \text { RMAs } & - & \text { Range Management Areas } \\ \text { RSA } & - & \text { Republic of South Africa } \\ \text { SAA } & - & \text { Selected Agricultural Area } \\ \text { SACU } & - & \text { Southern African Customs Union } \\ \text { SADC } & - & \text { Southern African Development Community } \\ \text { SDAs } & - & \text { Special Development Areas } \\ \text { SPS } & - & \text { Sanitary and Phyto-Sanitary } \\ \text { SQUAM } & - & \text { Standards Quality Accreditation and Metrology } \\ \text { SSA } & - & \text { Sub-Saharan Africa } \\ \text { SWAPs } & - & \text { Sector Wide Approaches } \\ \text { TB } & - & \text { Tuberculosis } \\ \text { TVET } & - & \text { Technical and Vocational Education and Training } \\ \text { UN } & - & \text { United Nations } \\ \text { UNAIDS } & - & \text { United Nations Programme on HIV and AIDS } \\ \text { USA } & - & \text { United States of America } \\ \text { VAT } & - & \text { Value Added Tax } \\ \text { VIP } & - & \text { Ventilated Improved Pit Latrine } \\ \text { WASCO } & - & \text { Water Authority and Sewerage Company } \\ \text { WHO } & - & \text { World Health Organisation } \\ \text { WiMAX } & - & \text { Worldwide Interoperability for Microwave } \\ \text { WLAN } & - & \text { Wireless Local Area Network } \\ \text { WTO } & - & \text { World Trade Organisation }\end{array}$





\section{Executive Summary}

This National Strategic Development Plan (NSDP) recognises, as a point of departure, the need and urgency for Lesotho to radically transform its economy. We need to define a future that is characterized by the capacity to produce goods and services for regional, African and global markets. This can be achieved by addressing the most binding constraints to growth and by exploiting our comparative advantages. These advantages include our central location within South Africa, which provides access to its markets and advanced infrastructure that creates links with the rest of the world, trade preferences and our relatively large, young, competitive and literate human resource base. The natural landscape and resource endowments offer great prospects for a greener economy. These windows of opportunity will pass if Basotho do not act quickly and decisively.

Strong economic performance will enhance our capacity to address the challenges we face. The key ones include poverty, inequality, unemployment, poor health and high mortality. Poverty and inequality are mostly attributable to low employment and productivity. Basotho also suffer low life expectancy primarily associated with high but declining HIV and AIDS prevalence. Coupled with high food insecurity this has led to high mortality rates, especially maternal and child mortality. Moderate economic growth has not resulted in significant job creation and poverty reduction. Furthermore, our small open economy remains vulnerable to negative external and natural shocks. The Government will also need to manage increasing urbanisation, especially by 
creating job opportunities in rural areas to curb out-migration and enhancing basic infrastructure in urban areas.

Strategic Goals: For the period $2012 / 13$ to $2016 / 17$, this Plan will serve as an implementation strategy for the National Vision 2020. It builds on the foundation set by the earlier planning documents including the Poverty Reduction Strategy and the Interim National Development Framework. The Vision is that: "By the year 2020 Lesotho shall be a stable democracy, a united and prosperous nation at peace with itself and its neighbours. It shall have a healthy and well-developed human resource base. Its economy will be strong, its environment well managed and its technology well established."

To achieve the National Vision goals and to reduce poverty and achieve sustainable development, the NSDP strategic goals will be to: (I) Pursue high, shared and employment creating economic growth; (II) Develop key infrastructure; (III) Enhance the skills base, technology adoption and foundation for innovation; (IV) Improve health, combat HIV and AIDS and reduce vulnerability; (V) Reverse environmental degradation and adapt to climate change; and (VI) Promote peace, democratic governance and build effective institutions.

Macroeconomic Framework and Fiscal Sustainability: Even though the world economy is recovering more slowly than had been anticipated, the Lesotho economy is expected to grow by about 5 per cent a year on average, over the Plan period. The implementation of this Plan is expected to result in a change in the structure of the economy and the transition to a more sustainable growth path. Significant benefits from the proposed reforms will also be achieved beyond this Plan period, as the growth rate will remain higher through to 2020/21. In addition, formal employment will continue to grow, 
creating an additional 47,000 jobs, at an annual average rate of $3.0 \%$. From a fiscal perspective, Government will be able to expand current expenses in real terms and to finance several years of exceptional allocations to capital projects while still achieving small fiscal surpluses and satisfying all critical debt sustainability indicators. In order to realize the target growth rates and attain macroeconomic stability, the fiscal strategy and monetary policy must achieve the following objectives: (i) Improving resource allocation and cost efficiency to support growth that will result in increased revenue thereby opening up additional fiscal space; (ii) Promoting fiscal consolidation by reducing deficits and adhering to debt sustainability targets (lower deficits/GDP and debt/GDP); (iii) Ensuring fiscal discipline, including adherence to hard budget ceilings and elimination of arrears; (iv) Improving tax/revenue administration, broadening the tax net and exploring ways of raising non-tax revenues as well as enhancing the capacity for mobilisation of finance for development; (v)Increasing absorptive capacity of Ministries to spend budget allocations efficiently; (vi)Sustaining the real value of capital expenditure and maintaining a stable ratio of capital to total spending; (viii) Containing the wage bill and increase public sector efficiency and (ix) Maintaining the Loti: Rand convertibility and/or building adequate international reserves

\section{I: Pursue High, Shared and Employment Creating Economic Growth}

The most effective way out of poverty is the creation of opportunities for employment. The Plan therefore seeks to establish the pre-conditions for high, sustainable and private sector led economic growth coupled with faster job creation up to 2016/17 and beyond. This Plan targets the attainment of 50,000 private sector jobs and long-term GDP growth of 5\% per annum, which will double the size of our economy every 16 years. The key strategies for 
creating high and shared growth are: (i) Mobilisation of domestic and foreign savings and improving the investment climate; (ii) Promoting economic diversification; (iii) Improving quality and competitiveness of the labour force; (iv) Facilitating technology transfer and partnerships for research; (v) Building minimum infrastructure platform, especially to link production centres and markets and to facilitate external trade and (vi) Promoting global integration and trade; and (vii) Development of the private sector.

Sources of Growth: Growth will be driven by major investments in two key growth accelerators: expansion of diamond mining and major water projects (Metolong Dam and the Lesotho Highlands Water Project Phase II). The mining investment of more than M 5 billion will lead to increased diamond exports, higher GDP and faster growth in tax revenues. These two projects will have significant impact on the growth of construction activities during the implementation phase. However, these large impacts on growth will not be sustained in the long-term. Only a few jobs will be maintained postconstruction phases and mining is highly capital intensive and will not yield many jobs. Therefore, in order to sustain growth and employment creation, four sustainable growth generators have been identified. These are Agriculture, Manufacturing, Tourism and deeper investment climate reforms. Deeper reforms, effective institutional support and investments are required to unlock the potential in these sectors. Growth in these leading sectors will stimulate demand in the 'followers' sectors which include transport, telecoms, construction and business services.

Investment Climate: Lesotho is ranked only 143 out of 183 countries in terms of competitiveness of doing business, far below regional competitors. In order to reverse our relative decline and remain an attractive investment 
destination, we must reform our investment climate faster than other countries. Improvements are needed to create incentives to convert domestic and foreign savings into viable investments in Lesotho. These investments are also required to diversify the production base and create the capacity to tap various export market opportunities, including SACU, SADC, US, Canada, EU, China and India. Lesotho needs to maintain political and macroeconomic stability, develop a sound and consistent policy framework, including investment, industrial, trade and sectoral policies and improving the business environment by reducing cost and time spent by investors in complying with Government regulations, rules and procedures. The business climate reform agenda, based on World Bank Doing Business Indicators, comprises ten key areas. For Lesotho, the priority areas for reform, which can deliver quick impacts, are: starting a business, registering property, dealing with construction permits and getting credit. Improvements will also be made in the other six areas, which are getting electricity, enforcing contracts, protecting investors, paying taxes, trading across borders and closing a business.

The process for obtaining work and residence permits needs to be improved to avoid delaying entry of the necessary foreign expertise. New laws and regulations will go through a process of Regulatory Impact Assessment (RIA) to ensure that reforms result in the expected results and that private sector needs are addressed. Further improvements of the land policy and regulatory framework, increasing capacity to deal with industrial disputes and fighting crime and corruption will also be focal areas in improving the investment climate.

Financial Services: The financial sector is relatively small and underdeveloped. More savings need to be generated and converted into productive investment 
in order to accelerate growth. On the other hand, the banking sector is highly liquid, but credit extension is relatively low. Therefore, the priority is to facilitate access to credit by removing key constraints and increasing access to financial services and alternatives for mobilising financial resources. The key measures include the development of money and capital markets as well as research and development of appropriate financial innovations. It is also necessary to enhance financial stability and soundness by improving the institutional framework and enhancing efficiency in the sector. It is vital to increase public financial literacy and bridge the skills gaps in the sector.

Global Integration and Trade: Lesotho's limited effective demand (in regional terms, we have a small population and low levels of per capita incomes) means that a growth strategy based exclusively on domestic demand would quickly exhaust its potential. Therefore, the objective of this Growth Strategy is to exploit regional and international markets, predominantly in labour-intensive export industries. This will be complemented by identifying niche opportunities in the domestic market and by building linkages between foreign and local firms, in order to maximise domestic content of production as well as linking to global industrial and marketing chains. The key strategic objectives are to: (i) Enhance productive capacity and increase exports; (ii) Diversify export markets by taking better advantage of regional and other unexploited international market opportunities and negotiating better market access; (iii) Improve investment and trade promotion; (iv) Develop the minimum infrastructure platform for trade; (v) Enhance consumer protection; (vi) Increase trade in services; and (vii) Consolidate policies and strengthen institutional support and coordination. 
Micro, Small and Medium Enterprises (MSMEs): MSMEs offer substantial opportunity for job creation and must therefore be liberated from burdensome regulation and have access to finance and effective business support services. MSMEs will be developed by actions to: (i) Improve access to finance; (ii) Develop entrepreneurship, business management capacity and technical efficiency to increase their competitiveness; (iii) Develop MSME infrastructure; and (iv) Facilitate integration between small and large industries and between local and international corporations.

Agriculture and the Rural Economy: The agricultural sector is one of the main sources of employment, especially in rural areas. A three pronged strategy will be pursued in developing the sector by: firstly, sustainable commercialisation and diversification and the development of integrated value chains; secondly, building effective agricultural support institutions; and thirdly, improving risk management in the sector and reducing stock theft. The strategies intended to boost growth and employment in the sector are to: (i) Improve access to finance; (ii) Promote the production of high value crops and livestock products; (iii) Improve quality livestock breeding, seed production capacity and access to farm machinery as well as facilitating the development of viable distribution and marketing systems; (iv) Develop water harvesting infrastructure and increase irrigation capacity; (v) Promote investment in agro-industry and development of agri-business to increase value-addition and market integration; (vi) Transform agricultural institutions and enhance capacity of farmers through effective training, transformation of extension services and focused agricultural research that is aligned with training and advisory services; and (viii) Promote household food security programmes, encourage the use of appropriate market mechanisms to manage market risk, reduce 
stock theft, protect animal and plant health and climate change proof the sector to reduce vulnerability and minimise risks.

Agricultural development and growth of the rural economy will be achieved if basic infrastructure is developed to reduce isolation, facilitate real time communication which will reduce time and costs for services. Strong linkages between rural and urban markets need to be established as well as integrated planning. It is also critical to support the preservation of important traditional systems.

Manufacturing: The private sector has considerable potential to create jobs through export-led growth in labour-intensive manufacturing. The core industrial development strategies are to: (i) Reinvigorate Lesotho as a textile hub and increase textile and clothing exports; (ii) Expand industrial infrastructure; (iii) Build on recent high growth in non-textile manufacturing industries by developing other industrial hubs to diversify the production base; and (iv) Increase forward and backward integration and between foreign and locally owned industrial concerns.

Tourism: To make better use of our natural beauty and existing infrastructure, Lesotho needs to attract more tourists. The focus in the next five years will be to: (i) Develop tourism products and some circuits to their full potential; (ii) Increase the visibility and marketability of Lesotho as a destination of choice; (iii) Improve quality and standard of services in the sector; (iv) Protect, conserve and promote viable use of tourism and cultural heritage; and resources and (v) Improve the institutional support services.

Mining: Private sector investments in excess of M 5 billion over the Plan period will boost GDP and tax revenue significantly. To ensure that Lesotho makes the 
most of its finite resource endowments, the Government will: (i) Develop a consolidated mining policy and review legal frameworks to adhere to best practices; (ii) Facilitate access of mining companies to the electricity grid and improve the main roads that lead to mining areas; (iii) Enhance investment promotion capacity and indigenous participation in the sector; (iv) Promote the development of down-stream industries; and ( $v$ ) Generate comprehensive information to augment mineral resource wealth intelligence and inform potential investors.

\section{II: Develop Key Infrastructure}

Lesotho needs to identify and develop the minimum infrastructure platform that is necessary to propel growth. This has several components:

Water: The primary focus will be on developing water harvesting capacity and distribution networks to industry, households, other institutions and the region. Creation of water reserves for national water security will also be taken into consideration. Access to good sanitation is still low and innovative financing solutions are required to augment infrastructure. It is also urgent that pre-treatment and water recycling facilities are developed for industry and other purposes.

Transport: The objective is to develop integrated transport systems. Priority lies with the improvement of national roads and access roads to production sites for agriculture, manufacturing, tourism, mining and other areas. The creation of seamless borders is critical for trade facilitation. Therefore, key investments include establishment of a dry port, access roads to border posts and modern one-stop border facilities. Engagement with RSA to improve the handling of transit cargo in RSA ports is also critical. Rural and urban roads as 
well as other modes of transport need to be developed to improve access and reduce time to markets and services. Options for developing more efficient public transport systems and financing of the sector need to be explored.

Energy: The electricity distribution network needs to be revamped to improve safety and reliability and to expand connections to households and potential growth areas, including institutions such as mines that are currently off-grid. Investment will be mobilised to tap the established potential of more than $1000 \mathrm{MW}$ that can be generated through a combination of hydropower and pump storage, wind and solar. Efforts will be stepped up to promote energy conservation and safe use of commonly used bio-fuels and other types to reduce health risks. A medium - long term strategy for improving national energy security will also be developed to manage risks.

Information and Communication Technology: Lesotho has experienced a decade of high growth in the sector, driven by mobile phone technology. The main goal is to build on this success and continue to improve the operating environment and backbone infrastructure. The Government will facilitate access to high-speed broadband and to basic ICT services throughout the country, widen ICT literacy, review and implement the e-Government strategy and facilitate smooth migration from analogue to digital. Promotion of eservices and development of niche ICT sub-industries through FDI and research and development as well as enhancing surveillance capacity to deal with cyber security will also be pursued.

Shelter and Property Development: In order to develop well-planned towns and human settlements the Government will: (i) Strengthen land administration and physical planning; (ii) Facilitate provision of basic infrastructure to improve quality of shelter; (iii) Improve the quality and safety 
standards and their enforcement; (iv) Encourage local production of construction inputs; (v) Promote densification, regularise the housing and commercial property rental markets to improve safety and achieve the desired physical lay out; (vi) Develop housing finance and land markets as well as property development capacity; and (vii) Identify appropriate housing solutions, especially for low income households and industrial workers.

Growth poles and Industrial hubs: Increasing urbanisation and area specific comparative advantages offer opportunities for the development of growth poles in urban centres, including industrial and service sector nodes and hubs. A two-pronged approach targeting urban growth poles and linking them with the rural economy is needed to attain optimum balance. The development of growth poles including tourism circuits linked to agriculture, mining and manufacturing will require substantial investments for infrastructure. This will be guided by the growth pole and industrial hub development strategy that is to be developed.

Sports: The Government will develop sports infrastructure, within a phased multi-year programme and through promoting private sector participation in sports infrastructure development that have high commercial viability. Sports development will also be enhanced by developing the capacity of supporting institutions, building international competitiveness in a few areas of high potential and promoting cultural and sports tourism activities.

\section{III: Enhance the skills base, Technology adoption and foundation for Innovation}

If Lesotho is to exploit the 'demographic bonus' of its large young labour force, then skills must be raised. The Government focus will be on:(i) Improving relevance and applicability of skills; (ii) Expansion and upgrading of TVET 
institutions to support growth sectors; (iii) Transformation of tertiary institutions in the education sector to become world class in selected fields; (iv) Improving performance and promoting enrolment in science and maths at all levels through increased quality of teaching and improvement of infrastructure; (v) Enhancing the foundation for skills development by improving access, instituting appropriate curriculum and best practices in teaching from early childhood to high school; (vi) Strengthening the national library system; (vii) Developing the infrastructure and capacity for distance learning at different levels; (viii) Mainstreaming special education at all levels; (ix)Transforming institutions for business and entrepreneurship development and improving coverage and quality of training programmes for the public sector and $(\mathrm{x})$ Reviewing the institutional framework to enhance coordination, cost-efficiency and effectiveness in the sector.

Technology and Innovation: Entrepreneurship development and competitiveness depend on use of appropriate technology. Lesotho needs to create an ecosystem that facilitates technology diffusion and adoption and to build good foundation for innovation in selected areas of science and other disciplines, such as law, economics and finance, to develop business technology. It is critical that capacity is developed to source and funnel technology, acquire licenses to produce technology and provide industrial engineering support, especially to MSMEs. The Government will develop strategies to attract and develop core skills and infrastructure. The involvement of the private sector and collaboration with regional and international research institutions will be essential. 


\section{IV: Improve Health, Combat HIV and AIDS and Reduce Vulnerability}

Efforts will be made to improve the health of the nation and special focus will be given to programmes that are aimed at improving infant and child nutrition and both under-5 and maternal mortality. The key strategic objectives for the sector are to: (i) Improve the coverage of health facilities, their management and quality of services; (ii) Improve planning, health information and public financial management system; (iii) Improve quality and coverage of health prevention and education programmes, including use of ICT solutions; (iv) Improve procurement and dispensing systems for pharmaceuticals and essential supplies; (v) Promote blood donation and improve health laboratory system; (vi) Establish institutions for development of high-end skills and improve capacity and quality of education of existing institutions (vii) Strengthen public-private partnerships and complementarity of services and promote research, including traditional medicine.

Lesotho has one of the highest prevalence rates for HIV and AIDS, though it is stabilising. Therefore focus will be on increasing HIV and AIDS competency of the society with the resultant change in behaviour and reduction of infections as well as adherence to drugs. The key strategies will be to (i) Step up HIV and AIDS prevention; (ii) Increase Anti-retroviral Treatment (ART) coverage and education to increase adherence; (iii) Improve efficiency and sustainability of mitigation measures; and (iv) Enhance institutional efficiency, effectiveness and coordination.

In reducing social vulnerability, the focus will be on (i) Consolidating social protection programmes and improving their efficiency and coverage; (ii) Providing support to vulnerable able-bodied persons to adopt sustainable livelihood strategies and reviewing and implementing the strategy for social 
security scheme development; (iii) Promoting work safety and easing job search; and (iv) Strengthening capacity for disaster risk management.

\section{V: Reverse Environmental Degradation and Adapt to Climate Change}

Sound environmental policies and land use planning can make a significant contribution to long-term sustainable economic growth. To achieve this, there is need to: (i) Reverse land degradation and protect water sources through integrated land and water resource management; (ii) Improve national resilience to climate change; (iii) Promote biodiversity conservation; (iv) Increase clean energy production capacity and environment friendly production methods and explore opportunities for carbon trading; (v) Improve land use and physical planning as well as increasing densification and ringfencing towns to avoid human encroachment on agricultural land and other fragile ecosystems; (vi) Improve the delivery of environmental services, including waste and sanitation and environmental health promotion; and (vii) Improve coordination, enforcement of laws, information and data for environmental planning and increase public knowledge and protection of the environment.

\section{VI: Promote Peace, Democratic Governance and Build Effective Institutions}

Lesotho is a relatively young and stable democracy. The Government will focus on consolidating past achievements by continuing efforts to improve public sector effectiveness and efficiency in service delivery, improving public financial management, deepening decentralization and maintaining the rule of law and the independence of the judiciary. It is important to institutionalise wide participation in policy-making and planning and create mechanisms to improve implementation of plans, strengthen public accountability and 
transparency and create the space for a well-functioning media. Lesotho is also a member of a number of regional and international blocs and should position herself to tap opportunities and influence policy-making internationally. These can only be realised if we have effective, efficient and adaptable institutions.

Cross-Cutting Issues: The Government will promote gender equality and protect the interests of children and youth, people with disabilities and the elderly. General challenges that will be addressed for all cross-cutting thematic areas include the generation of disaggregated data for analysis and monitoring and evaluation and improving coordination and mainstreaming into policies, programmes and budgets. Interventions for these themes will be implemented by the various Ministries and should therefore be integrated in relevant chapters.

Implementation Strategy: The plan objectives will be achieved if the expected investments take place, Government maintains stability, implements the key reforms, improves allocative efficiency and absorptive capacity and there is effective leadership and management that yield results. The Government has to take into account the main risks that can affect the implementation of the NSDP. These include sluggish global economic recovery, international security, regional revenue sharing arrangements, food and oil price variability and climate change impacts. The Government must also address administrative and management capacity constraints and weakness of the domestic private sector. Implementation excellence will also be built through ensuring local ownership of the Plan by all stakeholders, effective mobilisation of resources and development of timely and robust monitoring and evaluation systems. 


\section{Growth and Development Strategic Framework}

\section{"Towards an accelerated and sustainable economic and social transformation"}

\section{Introduction}

\section{$1.1 \quad$ Background}

After 45 years of independence, Lesotho has made much progress towards development but we have not yet fully escaped poverty. We are still a Least Developed Country (LDC) with per capita income of approximately $\$ 1000$. Though located in the centre of the largest and most sophisticated economy on the African continent, Lesotho has not taken full advantage of its opportunities. Instead, it served as a labour reservoir for South African mines and industries. It experienced low economic growth, poor agricultural productivity, low wages, limited industrial skills, poor physical infrastructure and high costs for cross border logistics. These led to an unhealthy dependence on its neighbour and external assistance for employment, incomes, high-level institutions for scientific education and research. The situation has been steadily improving, especially in the post-apartheid era.

This Strategic Development Plan recognises, as a point of departure, the need and urgency for Lesotho to radically transform its economy, intellectual and skills profiles by taking advantage of our location and defining a future that is characterized by the capacity to produce goods and services for the large 
Southern African markets, the African continent and global markets. This requires political and social stability, a favourable investment climate, a labour force with the necessary technical skills and institutions that are capable of: meeting the challenges of global competitiveness, responding quickly to changing circumstances and dealing with the challenges that are brought about by economic transformation. Together, these factors will help to ensure that Lesotho achieves broad-based and sustainable economic growth and employment generation resulting in long-term reductions in poverty.

This Plan will be the key policy tool for the implementation of the National Vision 2020 that was launched in 2003. The Vision articulated is:

"By the year 2020 Lesotho shall be a stable democracy, a united and prosperous nation at peace with itself and its neighbours. It shall have a healthy and well-developed human resource base. Its economy will be strong, its environment well managed and its technology well established."

While still facing a number of challenges, Lesotho has made considerable progress in many areas, including progress towards universal primary education, literacy, water and sanitation, gender equality, and various health indicators. Unfortunately, the spread of HIV and AIDS has caused deterioration in several indicators and some Millennium Development Goals are unlikely to be attained by 2015 .

The challenge for Lesotho is to look deeply into its history, culture and institutions to find the impetus and levers and drivers of economic transformation. This requires strong leadership and a national consensus supporting determined efforts to turn the challenges of being a small, landlocked country into opportunities to access global markets through increased 
trade. Opportunities occur notwithstanding economic crises but they tend to pass quickly. Lesotho will not be able to exploit them unless it is prepared to move rapidly, with a determination to succeed.

\subsection{Progress Review}

Vision 2020 is the core policy document that this Plan is committed to implement. In addition, Lesotho is signatory to a number of international agreements, notably the Millennium Development Goals (MDGs).

\section{Progress towards Vision 2020}

A comprehensive country review was conducted in 2010 as part of the African Peer Review Mechanism. It concluded that Lesotho has made considerable progress in many areas, including: governance; peace and political stability; gender equality; dealing with social vulnerability; expansion of new productive sectors such as manufacturing and mining and significant increase in trade/exports; development of infrastructure; dispensation of justice especially through alternative dispute resolution mechanisms; high literacy rates and human resource development; and increasing coverage of health services. Key challenges that need to be addressed include public service delivery and accountability, conflict resolution, , environmental degradation, HIV and AIDS, technological progress and achieving high, sustained and shared economic growth that results in poverty reduction.

The Vision 2020 has a comprehensive list of targets. Some critical achievements are as follows:

- the 2010 target of US\$ 600 for Gross National Income (GNI) per capita has been exceeded and Lesotho is now classified as a lower-middle income country, though poverty and unemployment are still high 
- real GDP growth rates averaged 3.8\% per annum from 2000/01 to 2010/11, somewhat higher than the target of 3.5\% for 2010, but below the $5 \%$ required to reduce poverty on a sustainable basis ${ }^{1}$

- in terms of income inequality, there are no recent data to confirm the current level of the Gini coefficient, although it improved from 0.57 in $1994 / 95$ to 0.53 in 2002/03 and is believed to be moving in the desired direction

- the unemployment rate of $24 \%$ derived from the Labour Force Survey 2008 is significantly below the target of $29.5 \%$ for 2010

- adult literacy is on target at $85 \%$

- trends in access to water and sanitation are moving in the right direction with $77 \%$ of households having access to improved water sources and $25 \%$ having improved sanitation facilities

More work needs to be done to achieve some other Vision targets:

- the Human Development Index (HDI) of 0.43 in 2010 is substantially below the target of 0.58 Per capita income and expected years of schooling are improving. Life expectancy is close to the target of 0.40 for 2010 but it seems unlikely that it could recover to meet the target of 0.60 by 2016 . The prospects for meeting the target of 0.58 , which Lesotho experienced in the 1990s, seem not to be feasible

- both the savings and investment targets are far below the targets. In $2009 / 10$, the savings ratio was only $21 \%$ against the target of $35 \%$ while investment was $16 \%$ and far below the target of $39 \%$.

\footnotetext{
The Vision set a GDP growth rate of 7\% for 2016 and 2020. However, this target was set at a time when Lesotho was experiencing population growth of approximately $2 \%$ per annum. Now that population is remaining stable, a real economic growth rate of at least $5 \%$ would deliver a similar impact on per capita incomes and poverty reduction.
} 


\section{Progress towards the Millennium Development Goals}

A global partnership of 189 countries set out eight interrelated Millennium Development Goals (MDGs) in 2000, The focus was on eradicating extreme poverty, achieving universal primary education and gender equality, addressing critical health challenges, including HIV and AIDS, maternal health and child mortality, environmental sustainability and promoting global partnership for development.

An update of current progress was prepared in September 2011 (see Table $\left.1.1^{2}\right)$. Lesotho is on course to meet the goals of promoting gender equality and achieving universal primary education. The HIV prevalence rate has stabilised at around 23\% which represents considerable progress even though the 2015 target is unlikely to be met unless there are effective measures for prevention (which explains the assessment of "slow progress" in the Table. The spread of HIV and AIDS has caused the deterioration in other indicators, especially child and maternal mortality and, therefore, in life expectancy.

\footnotetext{
Data sources may differ in coverage, definitions, frequency and sampling errors. The data used in the MDG Update are not necessarily those referred to elsewhere in this Plan.
} 
Table 1.1: Progress towards the Millennium Development Goals (2000 - 2009)

\begin{tabular}{|c|c|c|c|c|c|}
\hline Goals & Indicators & Progress & $\begin{array}{c}2000 \\
\text { (earliest) }\end{array}$ & $\begin{array}{c}2009 \\
\text { (latest) }\end{array}$ & $\begin{array}{c}2015 \\
\text { (target) }\end{array}$ \\
\hline \multirow{4}{*}{$\begin{array}{l}\text { Goal 1: Combat } \\
\text { HIV and AIDS }\end{array}$} & 15- 49 HIV Prevalence & Slow progress & 23.8 & 23.6 & 17.0 \\
\hline & Condom Use rate & Off track & \multicolumn{2}{|c|}{$14.5(2004)$} & $\mathrm{n} / \mathrm{a}$ \\
\hline & Women $15-49$ using condoms & Slow progress & \multicolumn{2}{|c|}{$12.5(2002)$} & 30 \\
\hline & Life expectancy at birth & Off track & 48.9 & $46.3(2008)$ & 63 \\
\hline \multirow{4}{*}{$\begin{array}{l}\text { Goal 2: Eradicate } \\
\text { extreme poverty } \\
\text { and hunger }\end{array}$} & Portion of people living below the poverty line & Off track & \multicolumn{2}{|c|}{$56.6(2003)$} & 29 \\
\hline & Unemployment rate & Slow progress & $28.7(2003)$ & $29.4(2009)$ & 15 \\
\hline & Prevalence of Underweight children under $5 \mathrm{yrs}$. & Slow progress & 18.0 & 13.2 & 8 \\
\hline & $\begin{array}{l}\text { Proportion of undernourished people in total } \\
\text { population }\end{array}$ & Off track & 26 & $25(2005)$ & 14 \\
\hline \multirow{7}{*}{$\begin{array}{l}\text { Goal 3: } \\
\text { Achieve universal } \\
\text { primary education }\end{array}$} & Net enrolment rate & Slow progress & 82.0 & 80.9 & 100 \\
\hline & Proportion of pupils in Std. 1 who reach Std. 5 & Slow progress & 89.7 & 73.1 & 100 \\
\hline & Adult literacy rate & Slow progress & 80.0 & $82.0(2005)$ & 100 \\
\hline & Pupil: teacher ratio & On track & 48 & 34 & 40 \\
\hline & Pupil: classroom ratio & Off track & 65.1 & 55 & 40 \\
\hline & Dropout rate & Off track & 7.3 & $6.0(2006)$ & 0 \\
\hline & Primary School completion rate & Slow progress & $87.5(2001)$ & $83.1(2007)$ & 100 \\
\hline \multirow{5}{*}{$\begin{array}{l}\text { Goal 4: Promote } \\
\text { gender equality } \\
\text { and empower } \\
\text { women }\end{array}$} & Net enrolment rate & Slow progress & 82.0 & 80.9 & 100 \\
\hline & Primary education (girls/100 boys) & On track & 121 & $97(2008)$ & 100 \\
\hline & Secondary education (girls/100 boys) & Slow progress & 131 & $121(2007)$ & 100 \\
\hline & Tertiary education (girls/100 boys) & Slow progress & 85 & $107(2007)$ & 100 \\
\hline & $\begin{array}{l}\text { Proportion of seat held by women in the National } \\
\text { Assembly }\end{array}$ & Slow progress & $15(2003)$ & $25(2007)$ & 30 \\
\hline \multirow{3}{*}{$\begin{array}{l}\text { Goal 5: } \\
\text { Reduce } \\
\text { child } \\
\text { mortality }\end{array}$} & Under-five mortality rate (per 1,000 live births) & Off track & 111 & 119 & 37 \\
\hline & Infant mortality rate (per 1,000 survivors to 1 year) & Off track & 79 & 91 & 24 \\
\hline & Proportion of 1 year olds immunized against measles & Slow progress & 72.2 & 80.3 & 100 \\
\hline
\end{tabular}




\begin{tabular}{|c|c|c|c|c|c|}
\hline Goals & Indicators & Progress & $\begin{array}{c}2000 \\
\text { (earliest) }\end{array}$ & $\begin{array}{c}2009 \\
\text { (latest) }\end{array}$ & $\begin{array}{c}2015 \\
\text { (target) }\end{array}$ \\
\hline \multirow{3}{*}{$\begin{array}{l}\text { Goal 6: } \\
\text { Improve maternal } \\
\text { health }\end{array}$} & Maternal mortality rate (per 100,000 live births) & Off track & 419 & 970 & 70 \\
\hline & $\begin{array}{l}\text { Proportion of births attended by skilled health } \\
\text { personnel }\end{array}$ & Slow progress & 60 & 62 & 80 \\
\hline & Contraceptive prevalence rate among married women & Off track & 12.6 & 45.6 & 80 \\
\hline \multirow{3}{*}{$\begin{array}{l}\text { Goal 7: Ensure } \\
\text { environmental } \\
\text { sustainability }\end{array}$} & Proportion of protected areas \& sustainable use areas & Off track & 6.9 & $\mathrm{n} / \mathrm{a}$ & 12.6 \\
\hline & Prop. of people without access to safe water & Slow progress & 21.1 & $26.1(2006)$ & 19 \\
\hline & Prop. of people without access to basic sanitation & On track & $57.7(2001)$ & $25.7(2006)$ & 33 \\
\hline $\begin{array}{l}\text { Goal 8: Develop a } \\
\text { global partnership } \\
\text { for development }\end{array}$ & Foreign financing $\%$ of GDP & On track & $\mathrm{n} / \mathrm{a}$ & $\mathrm{n} / \mathrm{a}$ & $\mathrm{n} / \mathrm{a}$ \\
\hline
\end{tabular}

Source: United Nations Development Programme, Lesotho Office (September 2011) 


\subsection{Plan Objectives}

The preparation of Lesotho's National Strategic Development Plan provides an opportunity to identify key levers for getting us on a sustainable development path. By addressing the challenges and exploiting the opportunities that have been identified (see Section 4), the Government will ensure that sustained progress is made towards achieving the national goals set out in the National Vision 2020, which this Plan serves to operationalise.

In order to reduce poverty and achieve sustainable development the following strategic goals will be pursued over the Plan period:

I. Pursue high, shared and employment creating economic growth

II. Develop key infrastructure (Minimum Infrastructure Platform)

III. Enhance the skills base, technology adoption and foundation for innovation

IV. Improve health, combat HIV and AIDS and reduce vulnerability

V. Reverse environmental degradation and adapt to climate change

VI. Promote peace, democratic governance and build effective institutions

This Plan emphasizes the necessity of achieving sustained and broad based economic growth as the most effective route for poverty reduction. It sets out the intended growth and development strategy and provides strategic direction to all agencies on the resource allocations and budgeting decisions that will be integrated into the Government's annual Medium-Term Expenditure Framework (MTEF) and NSDP Part II - Public Sector Investment and Development Programme.

Economic growth is not an end in itself but it is the only reliable mechanism for achieving sustained reductions in the number of people living below the 
poverty line. The benefits of growth are influenced by the pattern of income distribution. A highly unequal distribution (indicated by a Gini coefficient above 0.5) reduces the impact of economic growth on the incidence of poverty whereas an effective pro-poor growth strategy will improve income distribution by ensuring that the benefits are broadly shared.

This can be achieved if economic growth translates into sustained employment opportunities. For most Basotho, formal wage jobs are the main avenue out of poverty. The Plan's main indicator for success will therefore be the number of jobs added to the economy, since that represents the best way of achieving national objectives in terms of growth, poverty and equality. The Government intends to encourage the private sector to add 50,000 sustainable jobs to the economy by the end of the Plan period, approximately 10,000 jobs each year. This level of employment growth would allow us to achieve the National Vision interim unemployment target of $18 \%$ for $2016 / 17$ and put us on track to reduce it to $15 \%$ by 2020 .

The minimum long-term economic growth needed to achieve the Plan's objectives and to sustain poverty reduction is $5 \%$. At this growth rate, our economy will double approximately every 16 years. There is no single magic "growth bullet" that will deliver this transformation. Instead, the Plan provides a framework and strategy that will serve as the foundation for long-term growth and development.

This Plan identifies key strategic areas that shall provide the basis for shared and sustainable growth. Our growth target will require a substantial increase in the rate of investment. Recognising the importance of the private sector to Lesotho's growth and prosperity, the Plan defines how the government proposes to create an environment that is conducive to investment and private 
sector-led economic growth and the ways in which the efficiency and effectiveness of the government will be improved. Lesotho needs to implement a wide range of reform activities to improve its comparative and competitive advantages, and difficult decisions need to be made regarding trade-offs and priorities. 


\section{Context, Challenges and Opportunities}

\section{$2.1 \quad$ Context}

\subsubsection{Population}

Lesotho is a small country with a small population of 1.88 million (Census 2006). This represents an annual increase of $1.7 \%$ from the population of 970,000 at Independence in 1966 . Over $60 \%$ of the population live in the four districts that comprise the western corridor where the bulk of arable land is located and which has the best access to physical infrastructure, utilities and service delivery facilities. By ecological zone, $56.7 \%$ of Basotho live in the Lowlands, $12.8 \%$ in the Foothills and $30.5 \%$ in the Mountains and Senqu River Valley. Around $25 \%$ of this population live in urban areas. The national average population density is quite low at only 61 per square kilometre, ranging from 24 in Mokhotlong to 112 in Berea. However, expressed in terms of arable land, population density rises to 658 people per square kilometre, with a low of 485 in Thaba-Tseka and a high of 902 in Maseru.

Lesotho is undergoing a rapid demographic transition (see figure 2.1). Whereas the population grew rapidly in the first thirty years of Independence, the population remained virtually the same from 1996 to 2006 and it is projected to grow by only $0.13 \%$ each year up to $2020^{3}$. The steady increase in the country's population was driven by previous high fertility rates and rapid

This forecast total of 1,972,791 in 2020 (derived from the 2006 Census) is considered more accurate than the estimate in the UN Human Development Report that the 2010 population is 2.1 million and that the growth rate will be $0.8 \%$ from 2010-2015. 
mortality decline. The recent slowing in population growth has been driven by two main factors: Declining total fertility rate of 5.4 children per woman in 1976 to 3.5 children per woman in 2006 . The latest estimate from $2009^{4}$ suggests that the total fertility rate has further reduced to 3.3 children per woman and is projected to decline further to 2.8 children per woman by 2025. ${ }^{5}$ Secondly, the Crude Death Rate has doubled from 12.8 per 1000 people in 1996 to 26.5 deaths in 2006.

Figure 2.1: Lesotho Population Pyramid, 2006

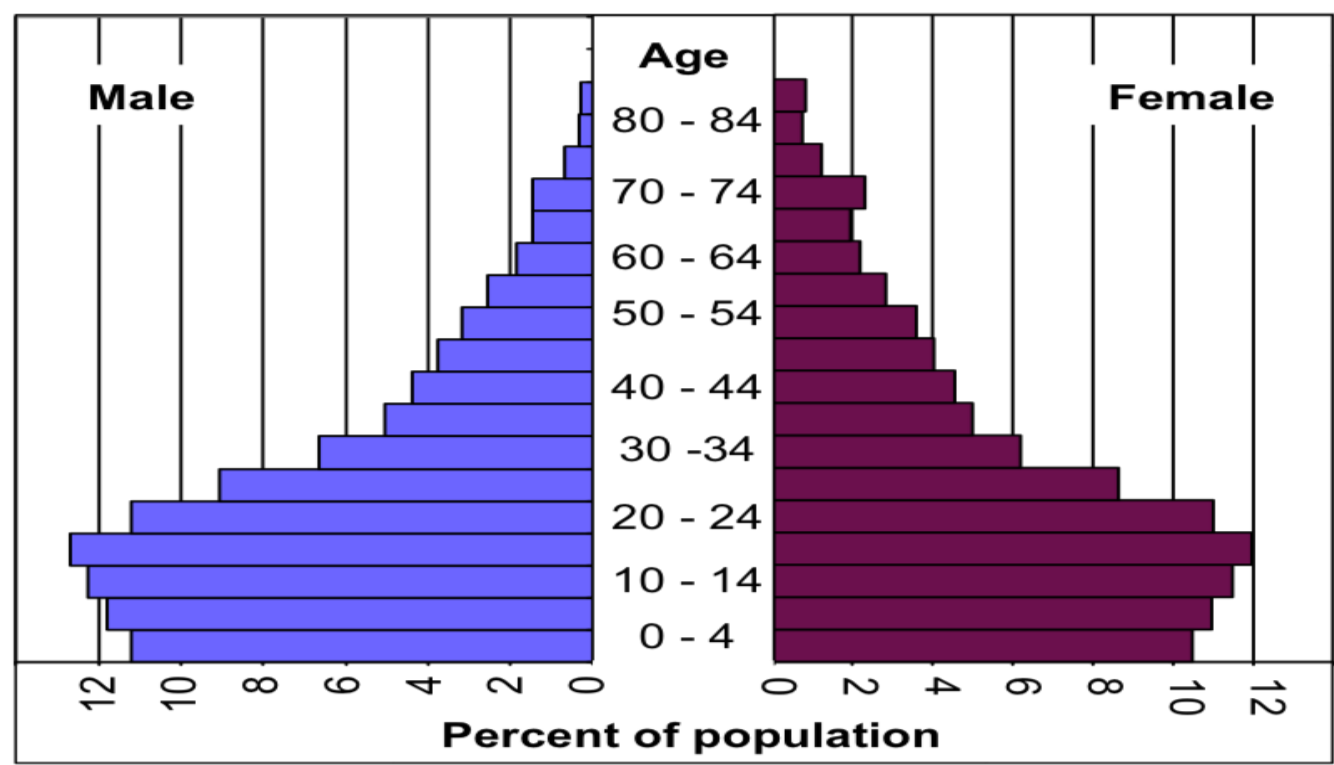

These trends have resulted in a significant decline in life expectancy at birth, from 51.0 years in 1976 to 59.0 in 1996 but fell to only 41.2 in 2006. The elderly population is increasing, $7.8 \%$ of the population is 60 and above, which shows an increasing need for social services and safety nets.

This demographic profile gives Lesotho a large labour force that is an opportunity for development (see Section 2.3.1).

Lesotho Demographic and Health Survey.

Bureau of Statistics, 2010. 


\subsubsection{Geography}

Most of Lesotho's 30,355 square kilometres are mountainous. Over $80 \%$ of the land is above 1,800 metres altitude and only $9 \%$ of the total area is suitable for arable cultivation. The Census indicated that the arable area had fallen by nearly $10 \%$ from $3,134 \mathrm{~km}^{2}$ in 1996 to only $2,833 \mathrm{~km}^{2}$ in 2006 , mostly as a result of soil erosion. Lesotho has few natural resource endowments, but has an abundance of water and natural beauty, whose economic potential has not been fully tapped. In addition, there are concentrations of diamonds and the mining sector will attract substantial investment over the Plan period. Lesotho's mountains offer great potential for wind power and hydropower generation.

However, the country is highly vulnerable to extreme weather conditions, including floods, drought and early and late frosts. Even in normal years, frost means that it has a limited growing season. Heavy rainfall contributes to rapid soil erosion and deteriorating conditions of range and arable land. Climate change is likely to make adverse events more frequent and more severe.

\subsubsection{The Economy}

Lesotho's economic development is framed by its central location in Southern Africa. Lesotho is a member of the Southern African Customs Union (SACU), the Common Monetary Area (CMA) and the Southern African Development Community (SADC). SACU and CMA are key influences on the trade, exchange rate and monetary policies of all member countries. South Africa remains Lesotho's main trading partner, supplying about $80 \%$ of imported goods and many services, as well as buying approximately one-quarter of Lesotho's exports. The main national resource is the abundant, literate and regionally competitive labour force. 
Gross Domestic Product $(\mathrm{GDP})^{6}$ has grown at a real annual average rate of $4.0 \%$ between $1982 / 83$ and $2010 / 11$. Unfortunately, this has not resulted in a decrease in poverty because many of the gains in GDP have been offset by falling remittances. The fall in the number of mineworkers from approximately 120,000 in the 1980 s to less than 50,000 today has resulted in a much smaller proportion of households receiving income from abroad. Consequently, the real annual growth rate of Gross National Income (GNI) from 1982/83 to $2010 / 11$ is only $0.9 \%$ per annum while Gross National Disposable Income (GNDI), which includes net transfers from the SACU revenue pool, has grown by $1.2 \%$ per annum over this period. Trends in all three indicators are shown in Figure 2.2. Since the average annual population growth between 1982 and 2006 was 1.1\%, this implies that there has been no real gain in national disposable income on a per capita basis.

Income is increasingly generated domestically. Whereas in 1982/83, the majority of domestic consumption was derived from productive activity abroad, Lesotho is now much more independent. The share of GDP as a proportion of total income has more than doubled from $30 \%$ to $64 \%$.

Figure 2.3 shows the annual growth rates in real GDP and GNI. Although GDP has been positive in every year since 1982/83, periods of acceleration have been followed by years of slow growth ( $2 \%$ or less). GNI has been much more volatile, with several years of negative growth.

\section{Figure 2.2: GDP, GNI \& GNDI 1982/83-2009/10 (Mm, constant 2004 prices)}

\footnotetext{
$6 \quad$ Gross Domestic Product (GDP) shows the value added by the domestic economy. Net primary income from abroad is added to GDP to measure Gross National Income (GNI) and net transfers are added to GNI to measure Gross National Disposable Income (GNDI). Lesotho is unusual because Lesotho receives substantial inflows of net factor income from abroad, principally remittances from Basotho mine-workers. Therefore GNI is a more appropriate measure of Lesotho's economic well-being than GDP, while GNDI determines the resources available for savings and consumption.
} 


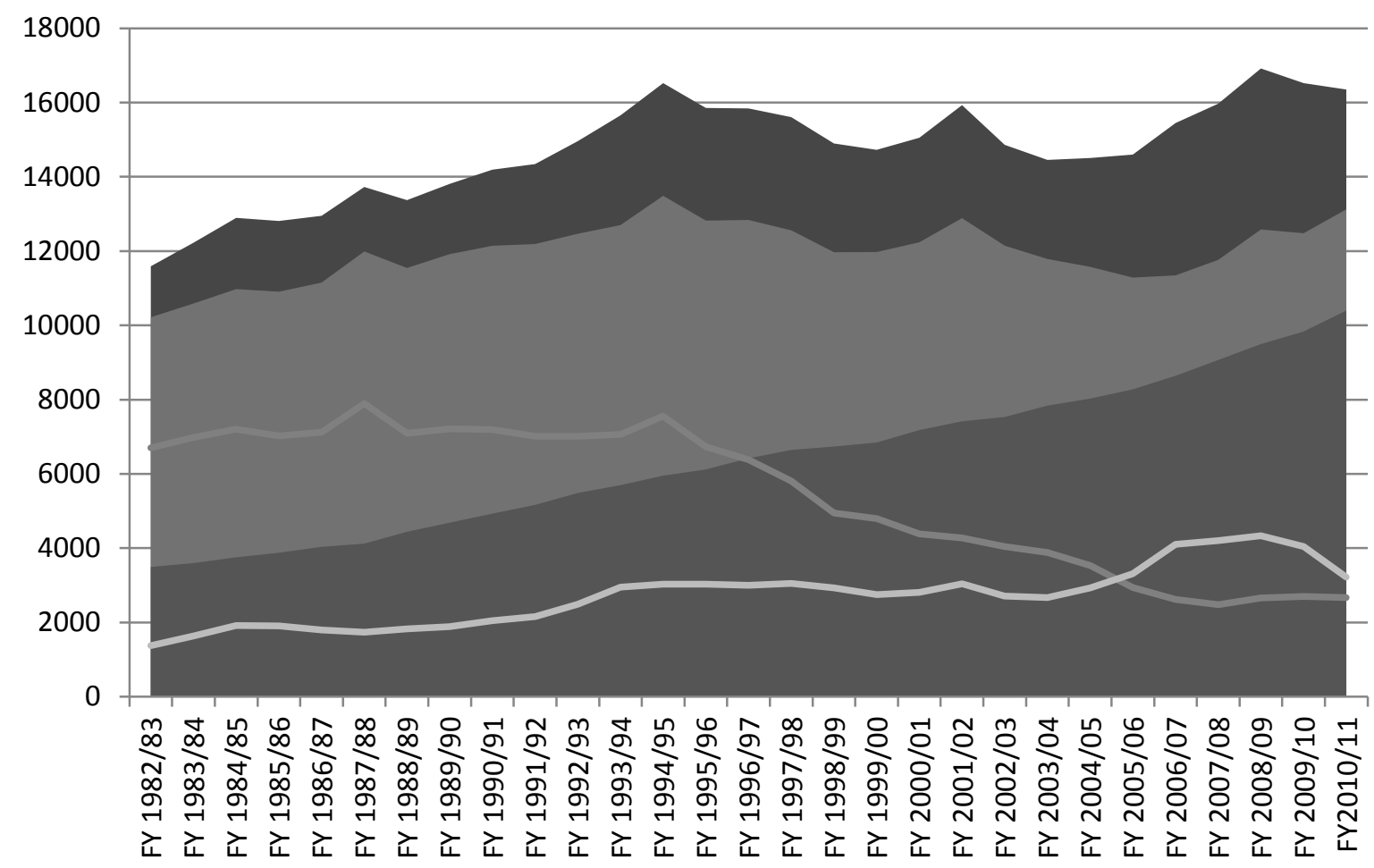

Real GNDI Real GNI Real GDP $\quad$ Primary incomes $\quad$ Current transfers

Figure 2.3: Annual Growth Rates of Real GDP and GNI 1982/83 - 2010/11

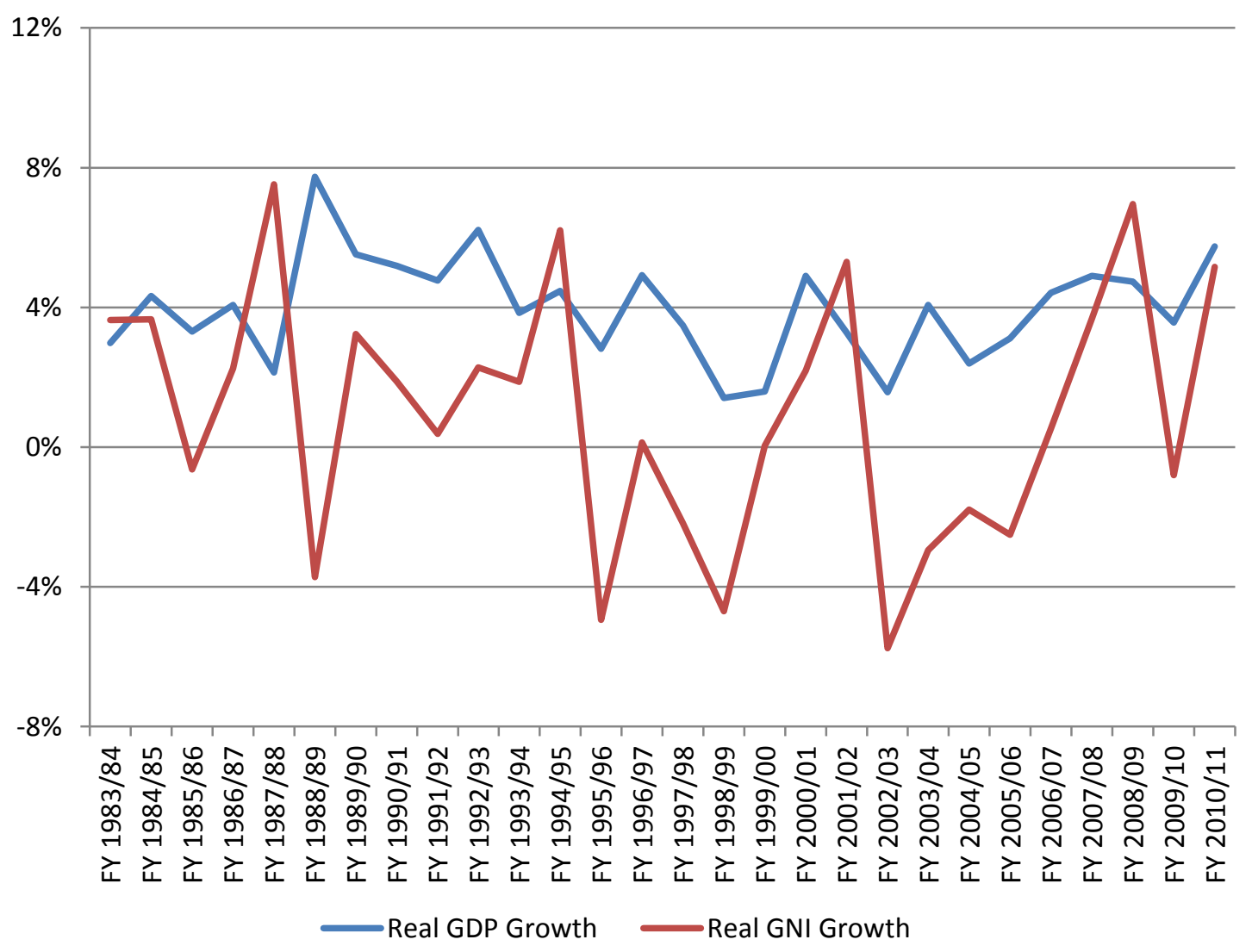


The strongest driver of GDP growth has been the secondary sector, of which the majority is manufacturing (see Figure 2.4). Between 1982/83 and 2010/11, the primary sector has increased by $1.8 \%$, the secondary sector by $7.8 \%$ and the tertiary sector by $3.8 \%$.

Agriculture remains important to most households, with over half having some agricultural land and keeping some livestock, and one-third of rural females and two-thirds of rural males engaging in some agricultural work. However, Agriculture's contribution to GDP has been declining. In 1982/83, the primary sector, at that time almost exclusively agriculture, contributed $24.5 \%$ of GDP. This has declined to $13.1 \%$ of GDP by $2010 / 11$, despite a substantial increase in the contribution of mining. Agricultural growth over the period averaged only $0.4 \%$ per annum. Most crop output is not marketed because grain and cereals are mostly produced for home consumption. Agricultural work does not generate much income: two-thirds of all labour do not receive any wages as they are self-employed or work for a family member.

Figure 2.4: Sector Shares of GDP, 1982/83 - 2010/11

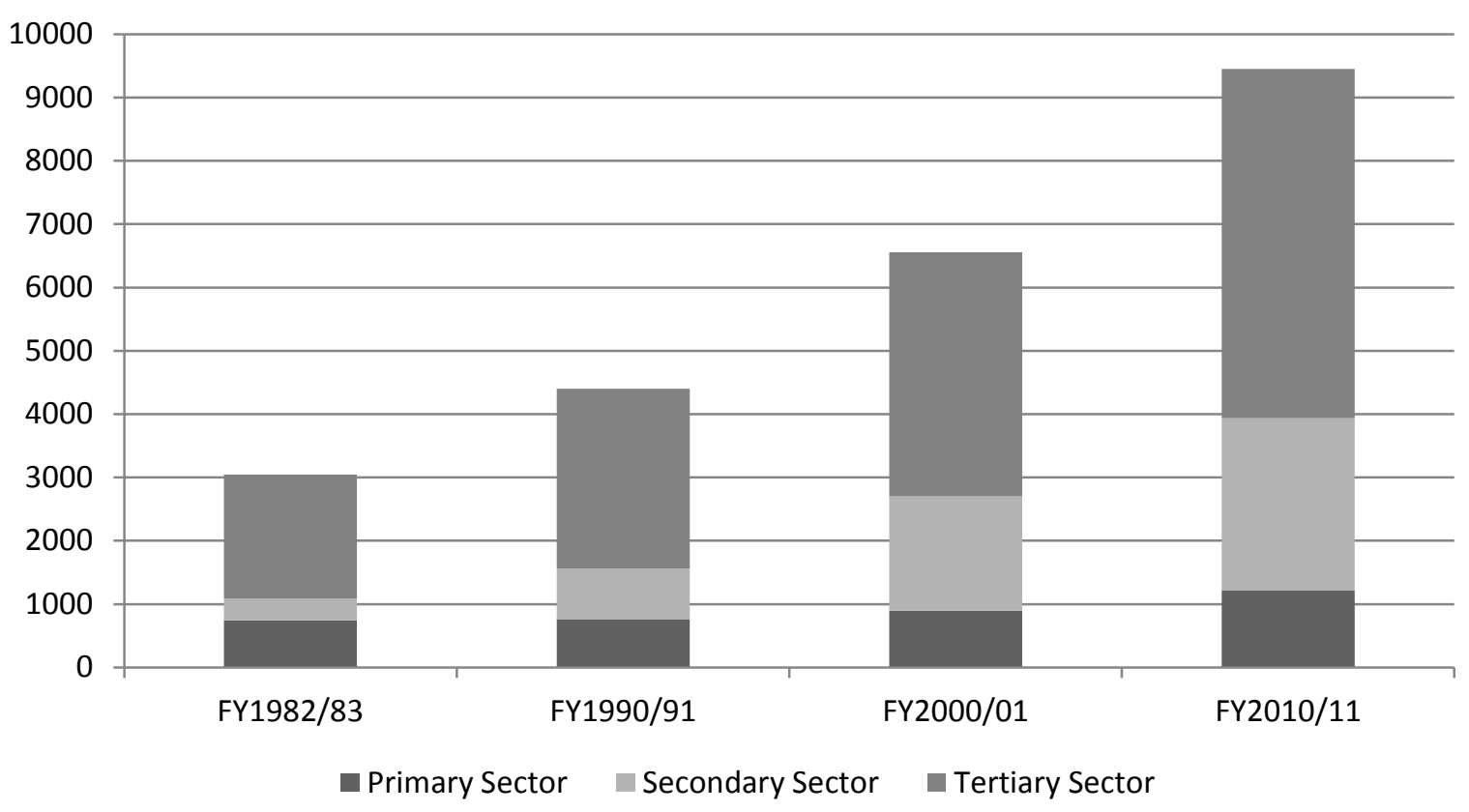


Manufacturing has increased more than six-fold. Textiles have been the main growth driver over the last thirty years, but other manufacturing has remained high even during the recent global economic crisis. Growth in manufacturing has also been the main engine of job creation. In the past few years, decreases in exports to the United States have been partially offset by increases in exports to South Africa.

Growth in the tertiary sector has been in line with overall GDP growth. Public administration has grown by $3.6 \%$. High rates of growth have been generated by some sub-sectors, notably Posts and Telecommunications (11.5\%), especially since the take-off of the boom in mobile phones, and Financial Intermediation (10.9\%). Hotels and restaurants generated only $1.7 \%$.

Figure 2.5 shows trends in public and private consumption. The decline in remittances has meant that private consumption has only grown in line with population growth since $1982 / 83$. Indeed, up to 2002/03 per capita consumption had declined but there have been increases over the past decade. On the other hand, higher SACU revenues have allowed public consumption to expand rapidly from its low base in 1982/83.

Over the last thirty years, the main drivers of investment have been major infrastructure projects, foreign direct investment and public sector projects. Overall, investment (part of which is required to deal with depreciation of existing assets) remained very low throughout the 1980 s (less than $40 \%$ of GDP and less than $10 \%$ of $\mathrm{GNDI}$ ). It rose to around $25 \%$ of GNDI with the implementation of the Lesotho Highlands Water Project in the 1990s but it has subsequently fallen back to around $15 \%$. 
Figure 2.5: Consumption 1982/83 - 2010/11 (Mm, constant prices)

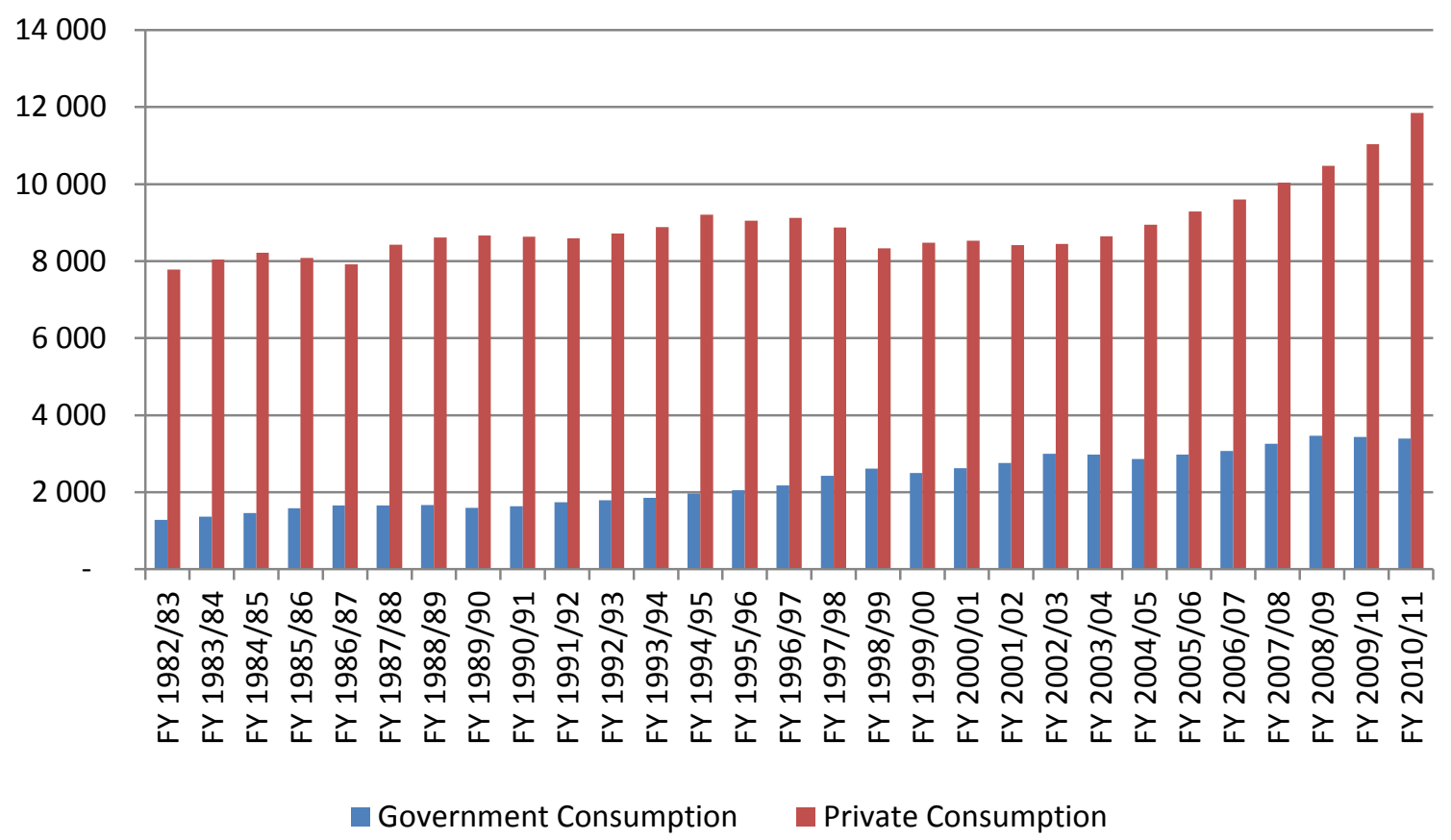

Savings have declined from M 2,521.1 million in $1982 / 83$ to only M 1,105.1 million in 2010/11 (in constant 2004 prices). Throughout the 1980s, much of mineworker income was saved through the deferred pay scheme so high remittances translated into high savings (equal to around $80 \%$ of GDP and over $20 \%$ of GNDI). However, the savings ratio has been on a declining trend since the mid-1990s and has fallen to only $13 \%$ of GDP and $8 \%$ of GNDI in $2010 / 11$.

Figure 2.6 shows the ratios of savings and investment as a percentage of GNDI since $1982 / 83$. Over the period up to the mid-1990s, there was a substantial surplus of savings over investment. Subsequently, the gap has narrowed and both followed a declining trend. With the reduction in LHWP investment, savings has exceeded investment. However, investment has picked up in recent years and now exceeds savings, which have continued to decline. Overall, these trends have resulted in the accumulation of financial assets by the Central Bank of Lesotho and the commercial banks, much of which is held overseas. This is unusual in developing countries, which generally face a 
shortfall of capital and therefore find it hard to make productive use of their labour. In Lesotho's case, there appear to be too few bankable projects proposed by creditworthy private investors.

Figure 2.6: Savings and Investment as \% of GNDI, 1982/83 - 2010/11

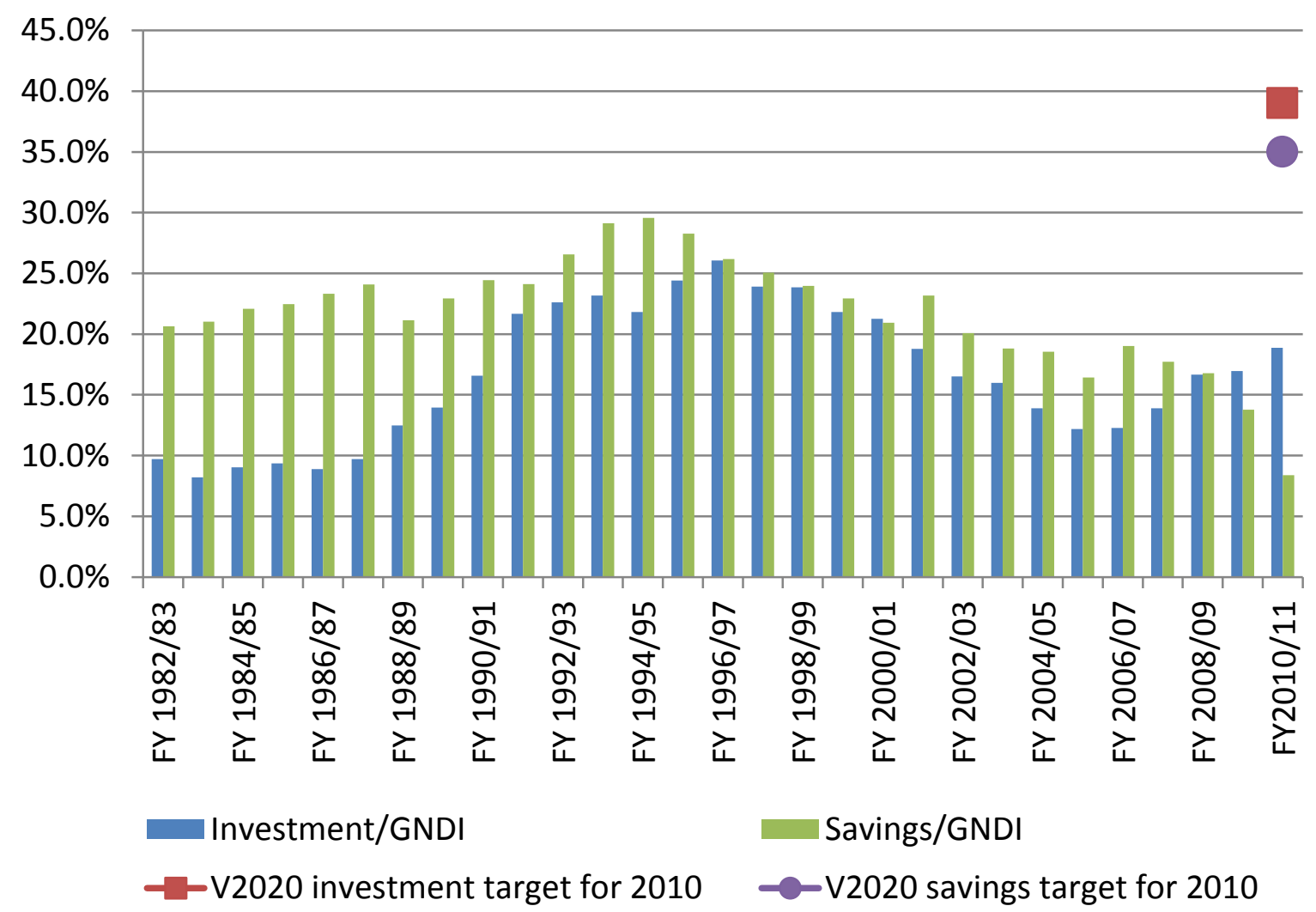

In $2010 / 11$, the savings ratio was only $8.4 \%$ against the Vision target of $35 \%$ while investment was $18.9 \%$, whereas the Vision target was $39 \%$. It is clear that these historically low savings and investment ratios have curtailed development and they are currently far below what is considered necessary for economic transformation.

Attaining higher savings and investment ratios is critical to achieving the economic targets of this Plan. The challenge for Lesotho is therefore twofold: to encourage higher savings and to increase the supply of high quality investment opportunities to ensure that those savings are invested domestically. 


\subsubsection{International Economic Outlook ${ }^{7}$}

Lesotho has a small open economy and consequently our economic prospects are highly interlinked with output, growth and prices elsewhere in the world. The projections in this Plan, in terms of critical indicators such as job creation, output and exports are therefore influenced by the global and regional forecasts.

Global and Regional GDP Forecasts: Lesotho is expected to benefit from a world economy that is recovering from crisis, but which remains vulnerable to downside risks. The International Monetary Fund (IMF) expects the world economy to grow at about $4.3 \%$ in 2011 and $4.5 \%$ in 2012. However, there are vast regional differences.

Growth in advanced economies is forecast at only 2.2\% in 2011 and $2.6 \%$ in 2012. The most recent forecasts have been revised down from previous estimates as a result of greater-than-anticipated weaknesses in the United States and Euro-periphery economies.

Emerging and developing economies will grow at a much higher $6.5 \%$ over the next two years. Notably, Sub-Saharan Africa has recovered well from the global financial crisis and is now second only to developing Asia in its rate of expansion (5.5\% in 2011 and 6.0\% in 2012).

South Africa: Lesotho must pay close attention to the economy of South Africa, with which it is most intimately connected. Unfortunately, South African economic growth is lagging behind that of other emerging markets.

\footnotetext{
$7 \quad$ This Section is based on a number of forecasts made by the International Monetary Fund (IMF) in the 'World Economic Outlook' (April 2011), the 'Regional Economic Outlook - Sub-Saharan Africa - Recovery and New Risks' (April 2011) and the 'World Economic Outlook UPDATE' (June 17, 2011) and by South Africa's Treasury in the 'Medium Term Budget Policy Statements' (2011).
} 
South Africa was hard hit by the global financial crisis and the economy lost more than a million jobs between 2008 and 2010 (8.0\% of total jobs). This has resulted in an output gap ${ }^{8}$ of approximately $3 \%$ of GDP which is not expected to close until 2013 at the earliest.

There are several causes for this. Private consumption is expected to remain depressed as a result of high unemployment, high household indebtedness and fragile consumer confidence. Private investment has declined by about $2 \%$ of GDP since 2008 and has only been partly offset by increases in public investment. High levels of capital inflows are pushing up the exchange rate and undermining the competitiveness of the Rand.

Consequently, South African GDP growth is forecast to be modest at 3.5\% in 2011 but stronger at $4.1 \%$ in 2012 and at $4.4 \%$ in $2013^{9}$. Other indicators look good. Fiscal expansion during the crisis resulted in a budget deficit of $6.7 \%$ of GDP which is expected to revert back to $3.5 \%$ by FY 2013/14 as the economy recovers. Inflation in South Africa declined to $4.3 \%$ in 2010 and is expected to stay below $6 \%$ over the next three years.

Commodity Prices: Over the next few years, world commodity prices are expected to remain high as a result of demand from developing countries and, in some cases, uncertainty about supply. Expectations of high prices for minerals are driving substantial investments, including diamond mining in Lesotho. However, high prices of food and fuel, which Lesotho imports, are expected to have adverse effects.

\footnotetext{
$8 \quad$ The Output Gap is an economic concept that measures the difference between actual GDP growth and its potential growth rate. For South Africa, the gap is currently estimated at approximately 3\% of GDP (IMF: Regional Economic Outlook - Sub-Saharan Africa - Recovery and New Risks, April 2011).

$9 \quad$ South Africa Treasury 'Medium Term Budget Policy Statements' (2011).
} 
The net impact of these commodity price movements is expected to have a significant negative impact on our trade accounts and terms of trade. The IMF predicts that our trade balance will deteriorate by more than $3 \%$ of GDP in 2011. The urban poor will be worst affected as they rely on transport to get to work and do not have access to subsistence farming to complement their income.

\subsection{Challenges}

\subsubsection{Poverty, Unemployment and Inequality}

The HDI is an internationally comparable assessment of development status. The Index is compiled by combining data on health, education and income. In 2010, Lesotho ranked 141 out of 169 countries based on Human Development Index (HDI) value of $0.427^{10}$. The Index for Lesotho was 0.397 in 1980 but it rose to 0.451 in 1990 and stayed at 0.452 in 1995 . It subsequently declined to 0.423 in 2000 and fell further to 0.404 in 2005 before recovering to 0.423 in 2009.

Poverty: Although Lesotho has a per capita income of around $\$ 1,000$, the national poverty line recorded an average national poverty head count of $54 \%$ (58\% in rural areas, 40\% in urban areas) in the 2002/03 Household Income Survey. The World Bank international $\$ 1$ a day poverty line figure produced a significantly lower average national head count of $37 \%$ (41\% in rural areas, $25 \%$ in urban areas) $)^{11}$. It is estimated that $27.5 \%$ of the population and $21.4 \%$ of households $(117,309$ out of 548,032$)$ are at risk of multi-dimensional

\footnotetext{
10 The Human Development Index score is derived from life expectancy at birth of 45.9, 5.8 mean years of schooling, 10.3 expected years of schooling and GNI per capita of $\$ 2,021$ (calculated at purchasing power parity).

$11 \quad$ World Bank, Poverty Assessment, 2010, page 24.
} 
poverty. Larger households with many children, headed by older and less educated people, were worse off, while households headed by migrating males are better off. Households receiving remittance income from abroad have amongst the highest incomes and best outcomes in the rural economy. Unusually, the poorest households grow less of their own food than do higherincome households. The Government old-age pension, introduced in 2005 for all citizens aged 70 and above, has had a significant impact on poverty.

The most recent information (LDHS 2009) suggests that $76.7 \%$ of the population have access to improved water sources (although that includes $7.6 \%$ who rely on protected wells or springs) and that $72.2 \%$ are less than 30 minutes from water; in the area of sanitation, $25.1 \%$ have improved, nonshared facilities, $38.8 \%$ have non-improved, shared facilities and $36.0 \%$ have no facilities. In the case of energy, $16.1 \%$ of the population $(17.0 \%$ of households) have electricity, although for cooking, $49.4 \%$ use wood, $20.5 \%$ use LPG and just $6.1 \%$ use electricity.

The 2006 Census indicates that there are 221,000 single or double orphans (representing $28.5 \%$ of all children aged 0-17 years), equally split between males and females. These cases are mostly attributed to HIV and AIDS related mortality. Increasing orphan hood calls for new, more effective social protection measures. Efforts to provide social grants and bursaries have made important contribution to livelihoods and to school enrolment, with approximately 180,000 orphans now attending primary and secondary school.

Unemployment: The 2008 Labour Force Survey indicated that Lesotho had a working-age population of $1,237,000$ of whom 608,000 people were employed and 192,000 were unemployed, giving an unemployment rate of $24 \%$. Only about 230,000 are believed to have formal wage employment, while a 
substantial majority of the employed (71.7\%) appear to be engaged informally, principally as family labour in household activities such as subsistence agriculture (often only in seasonal jobs) or as informal employees in formal enterprises. Many informal workers do not receive wages but are paid in kind. This high level of underemployment (low labour productivity) suggests ample flexibility in the labour market.

Employment growth has lagged behind GDP growth. Much of the economic growth in recent years has come from capital-intensive activities. Growth drivers such as Lesotho Highlands Water Project Phase I and diamond mining have had limited linkages to the rest of the economy and create very few permanent jobs. At the same time, opportunities for well-paid work on the South African mines have been declining. This suggests that the rate of formal employment creation has lagged behind the growth in the labour force plus returning ex-mineworkers. Although the unemployment rate had decreased to 2008 , it is likely that the global economic crisis has made the situation worse subsequently.

Inequality: Household Income and Expenditure Surveys indicate that the national Gini coefficient has fallen from 0.57 in 1994/95 to 0.53 in 2002/03 and that there has been a significant reduction in headcount poverty from $66.6 \%$ to $56.6 \%$. This still suggests significant inequality, and income distribution is heavily skewed with the richest $20 \%$ securing $60 \%$ of income while the poorest $20 \%$ receive only $2.8 \%{ }^{12}$. Inequality is high in both urban and rural areas, having been a structural feature of Lesotho for decades. Even though the top wealth quintile resides predominantly in the lowland areas with half of the 
poorest quintile living in the Mountains, the rural-urban divide can explain only $4 \%$ of overall inequality, with the remaining $96 \%$ being attributable to intraurban and intra-rural inequality ${ }^{13}$. Lesotho similarly has a higher level of consumption inequality than most countries in the region. With a Gini coefficient of approximately 0.5 , Lesotho can only expect to reduce the poverty head count by $1 \%$ in response to each $1 \%$ increase in the growth rate.

Gender Equality: According to the Gender Inequality Index (HDR 2010, using 2008 data), Lesotho performs relatively well with an index score of 0.685 and a rank of $102^{14}$. However, women have long been disadvantaged by cultural traditions, even though they play a vital role in the economy (the LDHS 2009 indicates that $35 \%$ of households are female-headed). The Legal Capacity of Married Persons Act 2006 repealed many discriminatory provisions in the formal legal system and represents a crucial improvement in women's legal position. Once the Act's provisions are fully implemented, women will be able to access credit, improve their land (assuming they own it), invest their money, engage in entrepreneurial activities and be the sole guardians of their children. Whereas Lesotho is on the right path, the challenge is to continue implementation of the gender policy framework which is expected to reduce women's social subordination and empower them to contribute more fully to development and poverty reduction.

\footnotetext{
$13 \quad$ World Bank, Poverty Assessment, 2010, page 26.

14 The Gender Index score is derived from a Maternal Mortality Rate of 960, adolescent fertility rate of 73.5, female MPs at $25.8 \%$, female secondary education of $24.3 \%$, female labour participation rate of $71.9 \%$, married women contraceptive prevalence rate of $37.3 \%$, at least one antenatal visit at $90 \%$ and $55 \%$ of deliveries with trained birth attendants.
} 


\subsubsection{Economic Resilience}

As a small open economy, Lesotho's growth and prosperity is both driven by and vulnerable to international trends. The recent economic and financial crises have been challenging for Lesotho and the country currently finds itself in a difficult economic environment. The global economic and financial crises have affected Lesotho in several ways: the SACU revenue pool, which provides 50 - $60 \%$ of Government revenue, declined, necessitating expenditure reductions; world FDI has decreased as a result of global uncertainty; and the private sector has been forced to reduce output and employment in response to decreased demand for its exports.

In addition to our vulnerability to external trends in commodity prices (discussed in Section 4.1.4), Lesotho is also affected by movements in the exchange rate. The currency link between the Loti and the Rand provides a fixed exchange rate with our main trading partner and greater stability against other currencies. However, our producers for international markets (notably textile firms selling to the American market) face potentially volatile movements in the exchange rate. This can have a significant impact on profitability and hence on production levels. The challenge is to encourage greater diversity in markets and products to reduce exposure to risk.

\subsubsection{Vulnerability to natural disasters and climate change}

Our country is vulnerable to a range of natural disasters and climate change. Early in 2011, Lesotho experienced the heaviest rains in decades, resulting not only in loss of agricultural output but also damage to infrastructure: power grids have been destroyed, roads have been swept away and bridges have collapsed. In recent years, droughts, hailstorms and other natural disasters have similarly caused periods of loss of output. 
Rural communities depending on subsistence agriculture are the most vulnerable. Although agriculture, at $8 \%$ of GDP, is only a small component of national output, it is an essential source of income for many Basotho. Making provision for such vulnerabilities is therefore an essential aspect of the NSDP.

\subsubsection{Health, HIV and AIDS}

Maternal health: The Census data suggests that the Maternal Mortality Rate (MMR) is about 939 per 100,000 live births ${ }^{15}$. Although this rate is substantially higher than previous estimates, maternal mortality accounts for only $1.1 \%$ of all deaths. The LDHS 2009 states 92\% of pregnant women made at least one visit to a professional ante-natal care provider (and $70.4 \%$ made $4+$ visits) and that $58.7 \%$ gave birth in a health facility (this proportion rises with wealth but declines with number of previous births).

Child health: The Infant Mortality Rate (IMR) had declined from 103 per 1000 live births in 1976 to 74 in 1996 but the 2006 Census data produced an IMR of 94.0 (102.5 for males, 83.9 for females). The Child Mortality Rate is 23.7 (26.5 for males, 21.1 for females). The LDHS 2009 states that $61.7 \%$ of all children aged 12-23 months have received all basic vaccinations (and coverage for individual vaccines ranges from 74.9\% to 95.7\%). On nutrition, LDHS 2009 states that $39.2 \%$ of children are stunted (short relative to their age) while $14.8 \%$ are severely stunted. However, only $3.8 \%$ are wasted (inadequate weight relative to height) and $13.2 \%$ are underweight (low weight for age).

HIV and AIDS: LDHS 2009 states that $26.7 \%$ of the female population aged $15-$ 49 and $18.0 \%$ of the male population aged $15-59$ were HIV positive, equivalent

\footnotetext{
15 The LDHS 2009 estimates the MMR as 1,155 per 100,000 live births but acknowledges that this calculation has wide confidence intervals.
} 
to a national rate of $23.0 \%$. Lesotho has the third-highest HIV prevalence rate in the world. The percentage of HIV-positive women is greater than the percentage of infected men in almost all age groups except men 40 years and older, and prevalence is considerably higher among young women than among young men.

\subsubsection{Productivity and Skills}

People are our most valuable resource, but unless Basotho attain the necessary skills, they remain underemployed and their potential is wasted. Lesotho's investments in education and skills development are not reflected in improved productivity across the entire economy.

The challenge is to increase productivity and reduce wastage in manufacturing, reform TVET and tertiary institutions so they can produce an adequate supply of relevant and competitive skills. At present, the skills that are supplied are often not those that are demanded by the economy and many recent graduates struggle to find productive work locally. This contributes to the brain drain to other countries and increasing youth unemployment.

In laying the foundation for better skills development and utilization, the education and training system needs to implement reforms to address the challenges of quality, access and relevance.

Other problems include the low level of entrepreneurship, an inadequate range of relevant business skills and inappropriate choices of technology.

\subsubsection{Urbanisation}

Rapid urbanisation is a common form of structural transformation as lowincome countries make the transition to middle-income status. Urbanisation will bring more Basotho closer to centres of employment as well as to critical 
services such as schools, clinics and utilities. Provision of such infrastructure is more cost effective in urban areas than in rural areas as a result of geography and economies of scale. This will allow the government to do more with less.

Based on demographic trends alone, the Bureau of Statistics predicts that the population living in urban areas will grow by $20 \%$ over the next 10 years, whilst the population in rural areas will remain approximately constant. Even faster urbanisation is predicted beyond 2020 and the employment growth stimulated by this Plan is likely to accelerate the trend towards urbanisation, as the majority of job opportunities will be in urban areas.

Business activity tends to cluster in core production and transport hubs. The informal sector is able to develop linkages alongside large firms by offering goods and services that firms and workers need. The result is to raise household incomes by creating better-paying, more secure employment in the urban private sector.

However, urbanisation, unless properly managed, carries risks. Urban poverty could become a threat. The urban poor who cannot find work are arguably worse off than rural poor because they don't have access to subsistence farming and don't have support from strong rural social networks. There is a risk of urban sprawl and increasing human encroachment on fertile agricultural land. New arrivals living on the periphery of urban areas are particularly vulnerable as they have less access to infrastructure and higher transportation costs that could lead to economic exclusion.

In order to address this challenge, the Government will implement efficient planning policies and institutions in order to ensure that the benefits of urbanisation are properly utilised and the risks are mitigated. 


\subsubsection{Infrastructure}

The national infrastructure is relatively poor as compared to other countries in the region. Major improvements are required in transport, power, water and sanitation and border and customs services.

Transport: The transport sector is important both for trade facilitation and to reduce costs and time to markets. The recent heavy rains have had negative impact on the already not so developed national road network. The quality and safety of roads linking major towns and the border posts, as well as roads between Lesotho and major towns in RSA needs to improve. This will enable faster and easier movement of people and goods and, as a result, improvement in trade and tourism.

Water and Sanitation: Though Lesotho has water in relative abundance, collection and distribution for industrial and household consumption is still limited. Industrial effluent treatment and disposal capacity also needs to be augmented.

Energy: The power distribution network is old and requires rehabilitation and maintenance to prevent power cuts resulting from network failure and to minimize environmental hazards associated with the poorly maintained network. Already, the potential for $6,000 \mathrm{MW}$ of wind power and 4,000 MW of pumped storage hydropower plus $80 \mathrm{MW}$ of conventional hydropower generation has been established. The government needs to mobilise investment and negotiate with potential investors to optimise returns for Basotho. This will ensure consistent, reliable and affordable power supply to industries and large customers and enable Lesotho to exploit the potential for export. 
Customs and Trade Facilitation: Related to the investment climate, the weakest areas in trade facilitation are: poor quality of roads between border posts and nearest towns on both sides; poor customs infrastructure including double customs clearing points on the Lesotho and RSA side; limited automation and roll out of customs clearing technology; limited storage capacity; dilapidated rail link and poor container handling facilities; and long lead times for cargo processing in RSA ports.

\subsection{Opportunities}

Our most likely sources of growth come from the opportunities that determine our comparative and competitive advantages. These arise from the combination of three dimensions: our people, our location, and our access to international markets. Moreover, our small carbon-footprint gives us the opportunity to develop in a green and sustainable way. The growth generators that will ensure that Lesotho achieves the aspirations set out in this Plan have been identified through a diagnostic growth analysis that is based on exploiting these opportunities.

\subsubsection{Labour Force}

The Basotho themselves are Lesotho's greatest comparative advantage. Our abundant and literate labour force, if properly employed, will be the motor for our development. Especially within the region, our labour is highly productive relative to their wage cost.

The impact of the rapid demographic change (described in Section 2.1.1) is that Lesotho will experience a "demographic bonus" which presents a "window of opportunity" for development. For several years to come, Lesotho will have an unusually large labour force, which is now approximately $60 \%$ of 
the total population. This has the potential to increase our income. Another impact of this transition is that the population aged less than 15 has declined from $41.5 \%$ of the total in 1986 to $38.6 \%$ in 1996 and further to $34.1 \%$ in 2006, with a corresponding fall in the dependency ratio. In East Asian countries that have recently escaped poverty, this demographic bonus is estimated to have accounted for about one-third of the region's unprecedented economic growth from 1965 to 1990.

Addressing current skills shortages is a prerequisite for taking advantage of this opportunity. Our education system and skills development strategy therefore needs to be more responsive to emerging economic demands.

Economic gains can only be realized if the economy generates jobs and increases productivity, savings and investment. Our competitiveness must therefore not be eroded by excessive domestic price increases. It is natural that there will be pressure on labour unions to demand higher wages for their members. However, wage growth, both in the private and public sectors, must remain in line with gains in labour productivity. Government intends to manage this trade-off between the welfare of those already employed and the welfare of the labour force as a whole by building on the constructive labour relations that have characterised the country to date.

\subsubsection{Location}

Lesotho is located at the centre of South Africa and has great opportunities of integrating into the main economic centres of the Republic of South Africa. For example, in supplying the huge Gauteng market, Lesotho has better labour cost competitiveness than Mpumalanga and better road access than the Eastern Cape. Moreover, access to South Africa's infrastructure means that it is 
easier for Lesotho than for many other African countries to access world markets.

Over the Plan period, Lesotho could significantly increase her exports of goods and services in the region, thus decreasing Lesotho's trade deficit with South Africa. In the 1980s, Lesotho was essentially a consumption-based economy financed by income from abroad: two-thirds of national income (GNI) was generated by remittances from South Africa while only one-third was the result of productive activity within our borders. By 2010, GDP generates over $70 \%$ of national income and it is expected to increase further over the Plan period.

Traditional migration patterns from Lesotho's rural areas to South African mines and kitchens will be gradually replaced by migration within Lesotho's borders. Domestic employment opportunities have the positive social impact that migrant labour can increasingly afford to work closer to home.

\subsubsection{Trade Preferences}

Lesotho is unusual in Africa in that a high proportion of our national output is derived from trade in manufactured products. Export-led growth, particularly in labour-intensive manufacturing, offers opportunities for substantial job creation.

Over the last ten years, Lesotho has already taken full advantage of the US Africa Growth and Opportunity Act (AGOA) and Lesotho is the largest African textile exporter to the US market. Notwithstanding the importance of the American market, Lesotho will seek to leverage other trade preferences in order to diversify our export markets. A policy of diversification is pursued not only because it offers potential for growth but also to ensure that our country is less vulnerable to particular economic shocks. 
The greatest source of potential for diversification and growth comes from South Africa and other regional markets. Our membership of bodies such as SACU and SADC provide access to the most advanced and prosperous markets in Africa. These opportunities are especially attractive because of Lesotho's favourable geographic location and access to South African infrastructure.

Lesotho has also recently negotiated an Economic Partnership Agreement (EPA) with the European Union that offers trade preferences to the world's largest single market. As many developed countries are still struggling to recover from the global economic and financial crises, Lesotho will also seek to explore the opportunities of increasing South-South trade. Bilateral relations with countries such as China will be strengthened. To take advantage of these export opportunities, Lesotho must attract and sustain foreign investment, especially from new sources such as South Africa.

\subsubsection{Clean Energy and Green Technologies}

Lesotho has a small carbon footprint but must nevertheless play its part in mitigating the threats from climate change. We have the opportunity to ensure that our economic development will be greener and sustainable. Our electricity supply is already amongst the greenest in the world, with almost all demand being satisfied by hydropower. Increasing demand for energy means that Lesotho will need to invest in expanding hydroelectric supply. Other renewable energy sources, including water and wind, have potential to be particularly important in supplying rural areas that are not connected to the electricity grid.

Lesotho will promote public and private investments that reduce carbon emissions and pollution, while preventing the loss of biodiversity and ecosystems. Investment in green technology will help to reverse trends of 
deforestation and soil erosion and enable Basotho to heat their houses and cook their food more efficiently.

Our development path will maintain, enhance and, where necessary, rebuild natural capital as a critical economic asset and source of public benefits, especially for poor people whose livelihoods and security depend strongly on nature. 


\section{The Growth Strategy}

\subsection{Growth Diagnostics}

Employment creation represents the best way of achieving progress towards Vision 2020 goals. Therefore, the Plan's main indicator for success will be the number of jobs added to the economy. The Government has set the objective of adding at least 50,000 sustainable jobs to the economy by the end of the Plan period, approximately 10,000 jobs each year. This will be an indicator of success in terms of growth, poverty and equality. The Government intends to increase private sector participation in achieving this target by significantly reducing barriers to private investment and private sector development.

The most binding constraints to growth in Lesotho are:

(i) Uncompetitive business environment, which includes difficult access to finance/credit, high regulatory burden to open and close a business, registering property and dealing with construction permits. There is poor enforcement of contracts due to delays in dealing with court cases, limited protection of investors and taking long for products to reach export markets (trading across borders) leading to long design-to-store timelines and relatively burdensome tax administration. Capacity to deal effectively with industrial disputes, corruption and crime is also limited, though performing better than many comparator countries. These challenges results in low investment and Lesotho fails to achieve economic and market diversification.

(ii) Limited industrial infrastructure, especially industrial estates and effluent treatment, inhibits expansion and new investments. Relatively poor trade facilitation infrastructure such as national roads and access 
roads to production sites and border posts as well as maintaining parallel customs and border services on the Lesotho and South Africa sides results in long lead times to markets. This is exacerbated by poor cargo handling facilities in Lesotho, high costs of road haulage since the rail link stopped operations due to dilapidated infrastructure and high traffic in the main ports of RSA that causes delays in cargo handling.

(iii) Low productivity as a result of limited quality technical skills, poor health mainly linked to high HIV and AIDS prevalence and low entrepreneurship capacity and quality management due to limited use of appropriate (hard and soft) technology.

(iv) Limited institutional capacity and coordination for regulatory and policy reforms, investment and trade promotion coupled with weak private sector organisations/associations.

In order to achieve high, sustained and job-creating growth, Lesotho needs to transform its economy by undertaking structural reforms to address the above mentioned binding constraints.

\subsection{Growth Strategy}

In Lesotho, poverty reduction through high, shared, job-creating and sustainable economic growth with resilience, essentially requires macroeconomic and political stability, higher savings and investment, economic diversification, skilled and competitive labour force, access to technology and/or capacity for innovation, development of (hard and soft) key infrastructure or Minimum Infrastructure Platform (MIP), entrepreneurship and private sector development and international market integration and trade. 
Political and macroeconomic stability: Predictable political environment, rule of law, low corruption, strong institutions and a conducive business environment are prerequisites for growth. Lesotho needs to accelerate and deepen institutional reforms and stay on track, most importantly on fiscal consolidation, despite tough economic conditions brought about by the economic crisis so that it can significantly improve its investment competitiveness.

Savings: Historically, levels of savings and investment have been too low to achieve sustained growth. One element of the strategy will therefore address improvements in the savings culture and financial intermediation. Creative mobilisation of domestic savings and blending with foreign sources will further increase resources that can be channelled into investment.

Investment: Higher levels of investment will enhance productive capacity, economic diversification and export opportunities. A crucial determinant of Lesotho's ability to increase investment and the productive base depends on improvements in the general investment climate and sector specific business environment. Strategies are required to convert savings into viable private domestic investment, while attracting and retaining foreign investment from diversified sources. Government also needs to increase capacity to mobilise ODA, domestic financing, concessional loans and smart Public Private Partnerships (PPPs).

Economic Diversification: There are great commercial opportunities in agriculture, manufacturing, mining and tourism sectors to be tapped. Together with improvements to the investment climate, these four sources of growth will enable Lesotho to achieve the Plan objectives. Growth of these leading sectors will drive demand for business services, transport, telecommunications 
and others. This growth will be more resilient if Lesotho is successful in diversifying the economy, making it less dependent on a small number of commodities and less vulnerable to world trade cycles.

Competitive, flexible and skilled labour force: In order to increase productivity and compete in domestic and international markets, effective skills development strategies are required. This needs to be complemented by the removal of unnecessary constraints to the import of skills that are not available in the country. FDI is already an important avenue for bridging skills and sophisticated management skills gaps.

Technology and Innovation: Creating a competitive economy requires growthminded entrepreneurs which are not only risk-taking, but also have innovative ideas and capacity for mobilization of available local and international knowledge, skills and technology. Strategies for improving technology diffusion and creating innovation culture in science and other fields are also essential.

Minimum Infrastructure Platform: Lesotho needs to identify and develop minimum infrastructure developments that are necessary to propel growth. In the water sector, the primary focus will be on developing water harvesting capacity and distribution networks to industry, households and other institutions. It is also urgent to ensure construction of pre-treatment and water recycling facilities and instituting appropriate incentives and/or amending the tariff structure for industrial waste disposal to mitigate current effluent discharge.

In terms of transport, investment needs to be mobilised to improve national roads and access roads to production sites for agriculture, manufacturing, tourism, mining and other areas. The creation of seamless boarders is critical for trade facilitation, including the establishment of a modern dry port, access 
roads to border posts and nee stop border facilities. Engagement with RSA to improve the handling of transit cargo in RSA ports is also critical. The electricity distribution network also needs to be revamped to ensure safety and reliability and to expand connections to potential growth areas and mines that are currently off-grid.

Increasing urbanisation and area specific comparative advantages offer opportunities for the development of growth poles in cities, including industrial and service sector nodes and hubs. However a two pronged approach targeting urban growth poles and linking them with the rural economies is needed to attain optimum balance. Agricultural markets and agribusiness need to be developed to serve as the primary links between the rural economy and the urban and export economies. The development of industrial and services sector nodes and hubs, including tourism circuits linked to agriculture, mining and manufacturing will require vast investments for the development of infrastructure. This will be guided by the growth pole development strategy that will be crafted.

Supporting institutions also have to be strengthened to develop appropriate policies and regulatory frameworks. Institutions that deal with corruption, crime, industrial and political disputes need special attention. Improved organisation and support of the private sector is also necessary to implement this growth agenda.

Private Sector Development: The private sector is expected to be the engine of growth. The main role of Government is to intervene in ways that crowds-in private investment, thus encouraging growth that exploits the full potential of our productive capacity. The key business of government is to provide necessary infrastructure platform and set regulatory frameworks that directs 
private efforts and investment in areas that will benefit the widest section of society. Lesotho must overcome the numerous constraints to development by creating an attractive macroeconomic and microeconomic environment and by implementing structural and institutional reforms that enhance its competitiveness and make us an attractive investment destination. The focus of sectoral programmes should be providing the right policy environment and enhancing the private sector capacity to exploit the potential and opportunities that exist.

The need to extent the investment climate reforms to areas where the poor are in terms of geography and vocation, including farms and informal sector and for the MSMEs to grow and thrive is recognised. Private initiatives do not only propel productivity growth but also provide complementary basic services such as health and education. Therefore, appropriate regulatory frameworks and support is required to make such services affordable/accessible, especially where options, other than private provision, are limited. Removing entry barriers, divestiture and/or contracting out to private sector and NGOs provide avenues for better service delivery.

Global Integration and Trade: Lesotho's limited effective demand (it has a small population and low levels of per capita incomes) means that a growth strategy based exclusively on domestic demand would quickly exhaust its potential. Therefore, the objective of this Growth Strategy is to exploit regional and international markets, predominantly in labour-intensive export industries. This will be complemented by exploiting niche opportunities in the domestic market and by building linkages between foreign and local firms, in order to maximise domestic content of production as well as linking to global industrial and marketing chains 
In summary, the impact of the growth strategy should be improved output, regional and global competitiveness, increasing total factor productivity, labour participation, foreign and domestic investment and greater utilisation efficiency of natural resources. The Government should ensure that the benefits of growth are shared, with a consequential reduction in income inequality, promote intergenerational equity through sound macroeconomic management and sustainable exploitation of non-renewable natural resources.

Although Government faces human and institutional capacity constraints, implementation of agreed interventions must be timely and efficient. Investment projects will be selected on the basis of their potential impact in breaking the binding constraints that currently hold back growth but which are affordable (within financial and human resource constraints) and sustainable in the long-term.

\subsection{Growth Scenarios}

The starting position is unfavourable: Lesotho has been adversely affected by regional and international developments since the global economic shock in 2008. Reductions in US demand for textiles and in global demand for diamonds forced some domestic textile producers to close down and some mines to suspend operations. At the same time, reductions in the size of the SACU Customs Pool resulted in lower payments under the revenue-sharing arrangements (exacerbated by the requirement to repay excess payments made in previous years). Despite some fiscal adjustment, which has had adverse effects on industries that are major suppliers to Government, there have been substantial fiscal deficits in 2009/10 and 2010/11 that have largely been financed by drawing down Government balances with the Central Bank of Lesotho (CBL). The consequence has been a dramatic drop in aggregate Net 
Foreign Assets, reducing the extent of import cover to undesirable levels (less than 3 months in 2011/12). Three potential growth scenarios are explored.

\subsubsection{Low Growth Scenario}

The current difficult circumstances clearly demonstrate Lesotho's vulnerability to exogenous events. The "low growth forecast" extrapolates the outcome if economic performance and fiscal outcomes continue along their present unsatisfactory path. However, the forecast assumes that SACU revenues recover from the recent low levels and that major investments, such as the Metolong Dam construction, supported by the Millennium Challenge Corporation, and other major public capital projects are completed since resources have already been committed and implementation is expected to be successful. Other key assumptions are that, after the ongoing fiscal adjustment, public expenditure resumes a long-term trend rate of $2 \%$ growth in real terms, and that an increase in total factor productivity of $0.5 \%$ per annum can be achieved in some sectors to reflect the impact of the recent investment climate reforms such as land tenure reforms inscribed in the Land Act 2010 and those related to tax administration, starting a business and getting credit.

As a result, the scenario shows slow growth in real GDP (an annual average of only $1.9 \%$ from the base year of $2010 / 11$ to $2016 / 17$ ) and in formal employment (1.0\% a year). Even sub-sectors that have achieved high and sustained historical growth (such as telecommunications and financial services) are expected to slow to around $2 \%$ per annum in real terms. Without any additional drivers of economic growth, the "low growth forecast" indicates that, while employment might recover from its low base in 2010/11, it will average less than 220,000 formal sector jobs throughout the Plan period. 
Table 3.1: Key Indicators for the Low Growth Forecast, 2010/11 - 2016/17

\begin{tabular}{|l|r|r|r|r|r|r|r|}
\hline Indicator & $2010 / 11$ & $2011 / 12$ & $2012 / 13$ & $2013 / 14$ & $2014 / 15$ & $2015 / 16$ & $2016 / 17$ \\
\hline Real GDP (Mm) & 15,399 & 15,960 & 16,519 & 16,363 & 16,450 & 16,787 & 17,197 \\
\hline $\begin{array}{l}\text { Real GDP (\% } \\
\text { annual change) }\end{array}$ & & $3.6 \%$ & $3.5 \%$ & $-0.9 \%$ & $0.5 \%$ & $2.0 \%$ & $2.4 \%$ \\
\hline Real GNI (Mm) & 20,781 & 21,263 & 21,873 & 21,809 & 21,868 & 22,138 & 22,780 \\
\hline $\begin{array}{l}\text { Real GNI (\% } \\
\text { annual change) }\end{array}$ & & $2.3 \%$ & $2.9 \%$ & $-0.3 \%$ & $0.3 \%$ & $1.2 \%$ & $2.9 \%$ \\
\hline $\begin{array}{l}\text { GDP (Mm, } \\
\text { current prices) }\end{array}$ & 15,399 & 16,557 & 18,257 & 18,851 & 19,653 & 20,902 & 22,343 \\
\hline $\begin{array}{l}\text { GNI (Mm, } \\
\text { current prices) }\end{array}$ & 20,834 & 22,128 & 24,071 & 25,019 & 26,050 & 27,488 & 29,526 \\
\hline $\begin{array}{l}\text { Formal Employ- } \\
\text { ment (000) }\end{array}$ & 211.7 & 213.3 & 221.1 & 216.0 & 215.5 & 219.2 & 224.5 \\
\hline $\begin{array}{l}\text { Investment } \\
\text { (Mm) }\end{array}$ & 4,994 & 5,752 & 6,758 & 6,846 & 6,754 & 7,111 & 7,685 \\
\hline $\begin{array}{l}\text { Fiscal Balance } \\
\text { (Mm) }\end{array}$ & $-1,634$ & $-1,935$ & -99 & -848 & $-1,155$ & $-1,658$ & $-1,865$ \\
\hline $\begin{array}{l}\text { Import cover } \\
\text { (months) }\end{array}$ & 3.4 & 2.5 & 2.9 & 2.8 & 2.1 & 1.4 & 0.6 \\
\hline
\end{tabular}

Macroeconomic stability would be undermined by persistent fiscal deficits (averaging M 1,300 million each year from 2010/11 to 2016/17), while balance of payments deficits would have to be financed by drawing down the Central Bank's net foreign assets. As a result, import cover would fall from 3.4 months in $2010 / 11$ to only 0.6 months by $2016 / 17$, threatening the convertibility of the Loti and our continued membership of the CMA. These outcomes are so damaging that they cannot be allowed to occur. Government would be forced to take severe and sustained adjustment measures by cutting real expenditures and raising domestic revenue. Even if such emergency measures preserved the currency peg, the adjustments would have highly negative impacts on the prospects for sustained economic growth and employment creation. 


\subsubsection{Moderate Growth Scenario and Growth Accelerators}

The moderate growth scenario incorporates the plausible investment plans by major economic agents. In particular, several mining firms have made substantial commitments to invest in expansion of their current operations and preparations are underway for the commencement of the Lesotho Highlands Water Project Phase II during this Plan period.

\subsubsection{Mining}

The diamond mining industry has experienced strong growth over the last decade, its share of GDP increasing from $0.2 \%$ in 2000 to $7.0 \%$ in 2010 . The sector contributes significantly towards tax revenues and export earnings. All of Lesotho's mining companies are planning substantial expansions of their operations, leading to further growth, throughout the Plan period. The expected investment outlay will be around M 5.8 billion, most of which will be spent between 2012/13 and 2015/16. These investments are expected to increase diamond exports from M 1.7 billion in 2010/11 to an estimated M 9.0 billion in 2016/17. GDP will increase by M 4.2 billion in real terms. Tax revenues are expected to go up by M 1.7 billion (in current prices), even after making provision for tax deductions in respect of mining investment

\subsubsection{Water Projects}

A major source of growth over the Plan period will be investment in water projects. Construction of Metolong Dam will already be underway by 2012/13. Construction of Lesotho Highlands Phase II will see investment in 2010 prices of around M 3.2 billion up to 2016/17 and a further M 3.9 billion subsequently. However, the impact on the economy is expected to be much smaller than that of LHWP Phase I because the overall size of the economy is much larger now 
than twenty years ago. Nevertheless, the construction activities should add over M 500 million to GDP in 2016/17. Approximately 11,000 jobs will be created annually during the main construction period from 2015/16 to 2019/20. Approximately half of these jobs will be in construction and the rest in indirect activities in sectors such as agriculture, transport and services. However, the majority of these jobs will only be temporary during the investment phase and the challenge will be to sustain this employment once major civil works are completed.

\subsubsection{Moderate Growth Forecast}

The net impact of the mining investments should result in a trebling of GDP generated by the industry from M 1.2 billion in 2010/11 to M 4.3 billion by 2016/17 (in constant 2010/11 prices). Mining's contribution to GDP is expected to increase from $7 \%$ to $20 \%$ over this period. The forecast assumes that the $\mathrm{M}$ 7.0 billion investment in LHWP Phase II will take place, with preparatory infrastructure investments commencing in $2013 / 14^{16}$. This will have a significant impact on the construction industry and will have multiplier effects in ancillary activities such as transportation, trade and business services.

This scenario ${ }^{17}$ indicates that GDP will grow from M 15,572 million in 2010/11 to $M 21,890$ million in $2016 / 17$, equal to an annual growth rate of $5.8 \%$ (in constant prices). Mining companies will make substantial payments of investment income to their overseas shareholders and these outflows will

\footnotetext{
16 The forecast only includes investment related to the transfer tunnel. It does NOT include investment connected with possible hydroelectric generation as plans for that are not yet finalised.

17 This Forecast represents the current "best estimate" of the probable evolution of the economy up to 2016/17. However, there will inevitably be movements around the trend. Some of the core investments may be delayed; other activities, not captured in this forecast, may occur as investors respond to emerging commercial opportunities.
} 
mean that GNI and GNDI will grow more slowly than GDP $(4.2 \%$ and $4.6 \%$ per annum respectively). There will be significant growth in exports ( $16.4 \%$ a year) while employment grows by 39,000 (only $2.9 \%$ a year) to around 252,000 . These forecasts reflect the capital-intensive nature of the mining industry (i.e. it requires low labour utilisation relative to the scale of investment) which is expected to generate only 2,700 additional mining jobs in 2016/17. Construction is more labour-intensive and the LHWP II investment should create approximately 11,000 jobs during peak years of activity.

Table 3.2: Key Indicators for the Moderate Growth Scenario, 2010/11- 2016/17

\begin{tabular}{|l|r|r|r|r|r|r|r|}
\hline Indicator & $2010 / 11$ & $2011 / 12$ & $2012 / 13$ & $2013 / 14$ & $2014 / 15$ & $2015 / 16$ & $2016 / 17$ \\
\hline Real GDP (Mm) & 15,572 & 16,534 & 17,771 & 18,006 & 19,169 & 21,132 & 21,890 \\
\hline $\begin{array}{l}\text { Real GDP (\% } \\
\text { annual change) }\end{array}$ & 20,925 & 21,717 & 22,907 & 23,227 & 24,152 & 25,813 & 26,843 \\
\hline Real GNI (Mm) & & $3.8 \%$ & $5.5 \%$ & $1.4 \%$ & $4.0 \%$ & $6.9 \%$ & $4.0 \%$ \\
\hline $\begin{array}{l}\text { Real GNI (\% } \\
\text { annual change) }\end{array}$ & 15,572 & 17,175 & 19,800 & 21,071 & 23,390 & 27,117 & 29,375 \\
\hline $\begin{array}{l}\text { GDP (Mm, } \\
\text { current prices) }\end{array}$ & 20,982 & 22,628 & 25,377 & 26,990 & 29,215 & 32,740 & 35,577 \\
\hline $\begin{array}{l}\text { GNI (Mm, } \\
\text { current prices) }\end{array}$ & 213.0 & 215.6 & 230.6 & 233.7 & 231.7 & 243.0 & 252.2 \\
\hline $\begin{array}{l}\text { Formal Employ- } \\
\text { ment (000) }\end{array}$ & 5,207 & 5,950 & 8,237 & 10,126 & 8,979 & 9,712 & 10,926 \\
\hline $\begin{array}{l}\text { Investment } \\
\text { (Mm) }\end{array}$ & $-1,585$ & $-1,727$ & 380 & -201 & 104 & 487 & 564 \\
\hline $\begin{array}{l}\text { Fiscal Balance } \\
\text { (Mm) }\end{array}$ & 3.4 & 2.5 & 3.0 & 3.3 & 3.2 & 3.4 & 3.7 \\
\hline $\begin{array}{l}\text { Import cover } \\
\text { (months) }\end{array}$ & & & & & & & \\
\hline
\end{tabular}

The probable timing of diamond investment and the resultant increase in production, hence in GDP, means that strong growth will be achieved throughout the Plan period. The fiscal year 2013/14 is an exception, with GDP growth of only $1.3 \%$, which reflects relatively limited mining investment and a decline in Government's capital expenditure. While these aggregate measures of macroeconomic performance seem acceptable over the Plan period, the 
pattern of growth is a major concern. The annual rate of growth remains strong until 2015/16, when it is expected to reach $10.2 \%$. After that, GDP growth will slow to only $3.6 \%$ in $2016 / 17$ and to $1.6 \%$ in $2017 / 18$ because the contribution of both drivers of economic growth will tail off. The additional mining capacity will be fully on-stream by $2015 / 16$ and output will stabilise at the new higher level unless further commercial mineral opportunities are identified and exploited. Furthermore, the contribution of investment in LHWP II to GDP, mainly through construction, will grow in 2014/15 and 2015/16 but, thereafter, the construction industry performance will stabilise.

After the substantial fiscal deficits in $2010 / 11$ and $2011 / 12$, the fiscal position shows a substantial improvement, and is expected to record small surpluses averaging around M 300 million per annum over the Plan period. However, it should be noted that the fiscal outcome deteriorates after 2016/17 as expenditure is assumed to keep increasing while the mineral-led increase in domestic revenue slows down. The overall balance of payments position improves substantially, allowing the Central Bank to rebuild net foreign assets as the growth in exports results in a smaller current account deficit, despite higher imports and increased dividend payments to foreign investors. The overall outcome is that net foreign assets remain positive and import cover stays above three months throughout the Plan period.

\subsubsection{Plan Scenario and Growth Generators}

The moderate growth forecast reflects a generally positive outcome but even the major investments in the two key growth accelerators will not fully achieve this Plan's objectives for sustained employment creation. More significantly, the prospects for growth after $2016 / 17$ are poor, as a result of the dependence on two growth accelerators rather than on long-term drivers of economic 
growth. The results therefore highlight the need to do better and this forecast provides the basis for determining how Government interventions can be structured to improve macroeconomic outcomes.

Doing better requires Government to improve the enabling environment for economic activity. Four potential growth generators have been identified and their potential impact on key economic aggregates was determined. The growth generators are agriculture, manufacturing, tourism and deeper investment climate reforms. The Plan scenario consolidates the assumptions underpinning each growth generator. In preparing this scenario, the 2012/13 budget allocations are used as the base. Even though Plan initiatives will start to be implemented in 2012/13, the impacts of the planned reforms that would unlock the potential in the identified growth generators, will effectively start from 2013/14 onwards and will gradually build up over next three financial years. The overall differences between the Plan scenario and the moderate growth scenario are quite small because this is relatively short period to show the effects of systemic reforms. Our analysis indicates that the measures described in Section 5 in respect of the investment climate, agriculture, manufacturing and tourism are expected to create 11,700 jobs by $2016 / 17$ above and beyond the 39,200 already projected in the moderate growth forecast. Once these reforms are embedded in the productive system, they will continue to generate approximately 8,000 jobs annually from 2017/18 onwards.

Section 4.3 summarises the macroeconomic forecast which shows the potential impact of these strategic growth drivers on economic activity during this Plan period (and Section 4.5 presents the significant results out to 2020/21) if the underlying actions are implemented and if the expected responses occur. Reforms affecting the growth drivers are mutually 
reinforcing. For example, the impacts of investment climate reform will facilitate the potential gains from manufacturing. Similarly, it is easier to achieve increased production in agriculture where financial markets have been strengthened to give farmers better opportunities to purchase inputs. Increases in income produced by one industry feed through the economy and, by creating new demands, provide additional commercial opportunities. These multiplier effects do not have much impact by $2016 / 17$ but they will create a much more favourable environment for the post-Plan period.

Several necessary conditions must be met in order to achieve these potential outcomes: relevant institutions will need to resolve long-standing binding constraints so that the necessary pre-conditions for economic growth can be established within this Plan period; problems in planning and sequencing the physical infrastructure interventions which will be competing for scarce resources must be overcome and reform must be implemented on a broad front. For instance, delays in improving the investment climate could have a wider negative impact because those reforms are intended to improve productivity, thereby providing incentives for more investment in agriculture and manufacturing and other sectors.

\subsubsection{Investment Climate}

Having a good investment climate is a precondition for sustained growth in all sectors. The World Bank has estimated that a good environment for doing business can add $1.4 \%$ to annual GDP growth. The aim of the Government's investment climate reform package is to remove a range of bottlenecks in order to make Lesotho a destination of choice for both domestic and foreign investors. Our analysis assumes that investment climate reforms will make firms more competitive through an annual productivity gain of $1 \%$ a year. 
Reductions in the financial and human costs of doing business should promote a faster pace of innovation, the rate at which new ideas for improved products and processes lead to more efficient and competitive business practices. Between 2013/14 and 2016/17, these reforms are expected to increase real GDP by approximately $1.7 \%$. An improvement in productivity does not necessarily lead to a direct increase in employment. This is because, by enabling existing workers to work more efficiently, it means that the same quantity can be produced with fewer employees. However, the main benefit from these reforms will occur indirectly, since higher productivity will generate gains in competitiveness which will enable companies to sell larger quantities in domestic and foreign markets and will therefore establish the pre-conditions for additional investment. This investment is expected to create more job opportunities in industries including agriculture, manufacturing and services.

\subsubsection{Agriculture}

The aim is to increase the contribution of agriculture to GDP by raising productivity. An increase in maize yields and/or a switch of 10,000 households from maize to higher value products and increasing livestock output and productivity would increase real agricultural GDP by M 70 million. However, the net impact on total GDP is less (because some resources are diverted from other activities) so the overall gain would be only around $0.2 \%$ by $2016 / 17$. On the other hand, the labour intensity of the sector means that employment would grow by about 2,400 jobs, an increase in total employment of $1 \%$. 


\subsubsection{Manufacturing}

The improvement in the investment climate will contribute to improved performance of the manufacturing sector, by providing necessary infrastructure in the form of serviced industrial sites and new factory shells in existing and new industrial sites, improving trade facilitation through enhanced boarder operations and cargo handling, provision of trade finance and taking advantage of opportunities in greening the economy. The Government will also promote investment to facilitate the development of a textiles hub and promote industrial clusters in niche industries. Training of Lesotho's labour force to increase productivity and reduce wastage is critical to compete effectively with countries, such as China and Bangladesh, which have major textile industries.

The impact of growth in manufacturing is estimated to drive an increase in exports of M 1.25 billion by 2016/17. The impact on both GDP and employment will be substantial: in real terms GDP would grow by M 392 million, $(+1.8 \%)$; and there would be 8,400 additional jobs $(+3.3 \%)$. Average household income would increase by M 398 per year. Achieving this growth will require investment of approximately M 865 million, which would mostly come from foreign investors.

\subsubsection{Tourism}

Lesotho has outstanding natural beauty and a unique cultural identity, factors which could drive growth in tourism. However, the potential has not yet been fully exploited. The sector employs about 3,100 people and its contribution to GDP has remained constant over the past five years at less than $2 \%$. The annual growth rate of $1.4 \%$ has been slower than that of the economy as a whole. 
The target is to increase demand by $50 \%$. This will bring the number of tourists to approximately 500,000 in $2016 / 17$. Although the impact on GDP is limited (up by $0.2 \%, \mathrm{M} 54$ million in real terms), it should increase employment in the sector by approximately $25 \%$, or 800 jobs. Many of these jobs will be created in rural areas where the highest levels of underemployment occur. The priority issues that need to be addressed are marketing, product development, and quality of customer services, regulatory environment and strengthening institutional support. 
Table 3.3: Key impacts of the Growth Accelerators and Generators

\begin{tabular}{|c|c|c|c|c|c|c|}
\hline & $\begin{array}{c}\text { GDP } \\
\text { (Mm constant } \\
\text { prices }) \\
\end{array}$ & $\begin{array}{c}\text { GNDI } \\
\begin{array}{c}\text { (Mm constant } \\
\text { prices })\end{array} \\
\end{array}$ & Employment & $\begin{array}{c}\text { Exports } \\
\text { (Mm current } \\
\text { prices) }\end{array}$ & $\begin{array}{c}\text { Tax Revenues } \\
\text { (Mm current } \\
\text { prices) }\end{array}$ & $\begin{array}{l}\text { Household Income } \\
\text { (M current prices) }\end{array}$ \\
\hline Lesotho FY 2010/11 & 15,572 & 25,113 & 213,009 & 6,743 & 3,416 & 45,976 \\
\hline $\begin{array}{l}\text { Low Growth Scenario } \\
\text { FY 2016/17 }\end{array}$ & 17,197 & 28,920 & 224,538 & 10,161 & 4,491 & 46,400 \\
\hline \multicolumn{7}{|c|}{ Lesotho FY 2016/17 showing impact of growth drivers by levels and percentages against the low growth projection } \\
\hline $\begin{array}{l}\text { Growth Accelerator 1: } \\
\text { Diamond Mining }\end{array}$ & \begin{tabular}{|r|}
4,167 \\
$24.2 \%$ \\
\end{tabular} & \begin{tabular}{|r|}
3,507 \\
$12.1 \%$ \\
\end{tabular} & $\begin{array}{r}16,539 \\
7.4 \% \\
\end{array}$ & $\begin{array}{r}6,638 \\
65.3 \% \\
\end{array}$ & \begin{tabular}{|r|}
1,686 \\
$37.5 \%$ \\
\end{tabular} & $\begin{array}{r}1,572 \\
3.4 \% \\
\end{array}$ \\
\hline $\begin{array}{l}\text { Growth Accelerator 2: } \\
\text { LHWP II Construction }\end{array}$ & $\begin{array}{r}527 \\
3.1 \%\end{array}$ & $\begin{array}{r}478 \\
1.7 \%\end{array}$ & $\begin{array}{r}11,078 \\
4.9 \%\end{array}$ & $\begin{array}{r}44 \\
0.4 \%\end{array}$ & $\begin{array}{r}207 \\
4.6 \% \\
\end{array}$ & $\begin{array}{r}1,006 \\
2.2 \% \\
\end{array}$ \\
\hline $\begin{array}{l}\text { Moderate Growth } \\
\text { Scenario FY 2016/17 }\end{array}$ & $\begin{array}{r}21,890 \\
27.3 \% \\
\end{array}$ & $\begin{array}{r}32,895 \\
14.1 \% \\
\end{array}$ & $\begin{array}{r}252,168 \\
12.3 \% \\
\end{array}$ & $\begin{array}{r}16,775 \\
65.1 \% \\
\end{array}$ & $\begin{array}{r}6,388 \\
42.2 \% \\
\end{array}$ & $\begin{array}{r}52,931 \\
14.1 \% \\
\end{array}$ \\
\hline $\begin{array}{l}\text { Growth Generator 1: } \\
\text { Agriculture }\end{array}$ & $\begin{array}{r}40 \\
0.2 \% \\
\end{array}$ & $\begin{array}{r}-54 \\
-0.2 \% \\
\end{array}$ & $\begin{array}{r}2,434 \\
1.0 \% \\
\end{array}$ & $\begin{array}{r}-11 \\
-0.1 \% \\
\end{array}$ & $\begin{array}{r}24 \\
0.4 \% \\
\end{array}$ & $\begin{array}{r}-159 \\
-0.3 \% \\
\end{array}$ \\
\hline $\begin{array}{l}\text { Growth Generator 2: } \\
\text { Manufacturing }\end{array}$ & $\begin{array}{r}392 \\
1.8 \% \\
\end{array}$ & $\begin{array}{r}289 \\
0.9 \% \\
\end{array}$ & $\begin{array}{r}8,392 \\
3.3 \% \\
\end{array}$ & $\begin{array}{r}1,251 \\
7.5 \% \\
\end{array}$ & $\begin{array}{r}144 \\
2.3 \% \\
\end{array}$ & $\begin{array}{r}398 \\
0.8 \% \\
\end{array}$ \\
\hline $\begin{array}{l}\text { Growth Generator 3: } \\
\text { Tourism }\end{array}$ & $\begin{array}{r}54 \\
0.2 \% \\
\end{array}$ & $\begin{array}{r}52 \\
0.2 \% \\
\end{array}$ & $\begin{array}{r}760 \\
0.3 \% \\
\end{array}$ & $\begin{array}{r}122 \\
0.7 \% \\
\end{array}$ & $\begin{array}{r}23 \\
0.4 \% \\
\end{array}$ & $\begin{array}{r}88 \\
0.2 \% \\
\end{array}$ \\
\hline $\begin{array}{l}\text { Growth Generator 4: } \\
\text { Investment Climate Reform }\end{array}$ & $\begin{array}{r}372 \\
1.7 \% \\
\end{array}$ & $\begin{array}{r}391 \\
1.2 \% \\
\end{array}$ & $\begin{array}{r}156 \\
0.1 \% \\
\end{array}$ & $\begin{array}{r}429 \\
2.6 \% \\
\end{array}$ & $\begin{array}{r}17 \\
0.3 \% \\
\end{array}$ & $\begin{array}{r}71 \\
0.1 \% \\
\end{array}$ \\
\hline $\begin{array}{l}\text { Plan Scenario } \\
\text { FY 2016/17 }\end{array}$ & $\begin{array}{r}22,770 \\
37.9 \% \\
\end{array}$ & $\begin{array}{r}33,590 \\
16.1 \% \\
\end{array}$ & $\begin{array}{r}263,910 \\
17.5 \% \\
\end{array}$ & $\begin{array}{r}18,621 \\
83.3 \% \\
\end{array}$ & $\begin{array}{r}6,599 \\
46.9 \% \\
\end{array}$ & $\begin{array}{r}53,300 \\
14.9 \% \\
\end{array}$ \\
\hline
\end{tabular}




\section{Macroeconomic Framework}

\section{$4.1 \quad$ Overview}

\subsubsection{Recent Economic Performance}

Long-term macroeconomic trends were presented in Section 2.1.3. When preparing the economic projection for the Plan period it was also necessary to have a clear understanding of the factors that determined macroeconomic performance at the start of the forecasting period in 2010/11.

There has been rapid growth in GDP, which (in current prices) has nearly doubled between 2000/01 and 2010/11 (+195\%). Both GNI and GNDI have grown more slowly (+130\%). This means that domestic product is now equal to $80 \%$ of national income and $65 \%$ of disposable income. Since the total population is estimated to have increased by only $4 \%$ over this period, GNI per capita in current prices (which is the most suitable measure of national welfare) has increased from $M 4,684$ in $2000 / 01$ to $M$ 10,393 in $2010 / 11$ $(+122 \%)$.

In real terms, the annual average GDP growth rate has been $3.8 \%$ over the decade and the annual rate has exceeded $3 \%$ in all six years since 2005/06, making this Lesotho's longest sustained period of growth since the boom inspired by LHWP Phase I. This has been driven by the revival of the mining industry, strong export-led growth of manufacturing and by double-digit growth in some service industries, such as telecommunications and financial intermediation. After slowing to $3.6 \%$ in response to the global crisis in 2009/10, GDP growth reached a high of $5.7 \%$ in 2010/11 with exceptional performance in crops. Over the decade, GNI in constant prices has achieved an 
annual average growth rate of only $0.7 \%$. It has been much more volatile than GDP with negative rates in several years.

Investment has doubled in current prices since 2000/01. The main driver in recent years has been public sector investment, mostly in connection with Metolong Dam, the Millennium Challenge Account and major roads projects. However, savings have actually declined over the decade, notably in 2010/11, when the reduction in SACU transfers meant that Government ran a large fiscal deficit. As a proportion of GDP, the savings and investment rates (at 13\% and $19 \%$ respectively in $2010 / 11$ ) remain far below the levels considered necessary to generate sustained growth.

Over the decade, private consumption has grown by $29 \%$ in real terms while Government consumption has increased by $39 \%$. Since the population is estimated to have grown by only $4 \%$ over this period, these figures imply that there has been an increase in household welfare, both through direct consumption and through the provision of public services.

\subsubsection{Recent Fiscal Trends}

The main instrument of macroeconomic management is fiscal policy. The Plan Projection is therefore based on an analysis of recent fiscal trends and key lessons are incorporated into the fiscal policy and reflected in the fiscal framework for the Plan period (Sections 4.2.2 and 4.4). Compared with other developing countries, Lesotho has an unusually high level of public expenditure (an average of $52 \%$ of GDP over the last decade and over $60 \%$ in some years). Up to 2009/10, high growth in expenditure was financed by steadily increasing domestic revenue and rapid growth in SACU transfers. However, the global financial crisis caused a dramatic decrease in SACU revenues, and public 
expenditure had to be cut in 2010/11 to keep the deficit under control. Trends in Revenue and Expenditure are shown in Figure 4.1.

Figure 4.1: Total Revenue and Total Expenditure 2001/02 - 2010/11 (Mm)

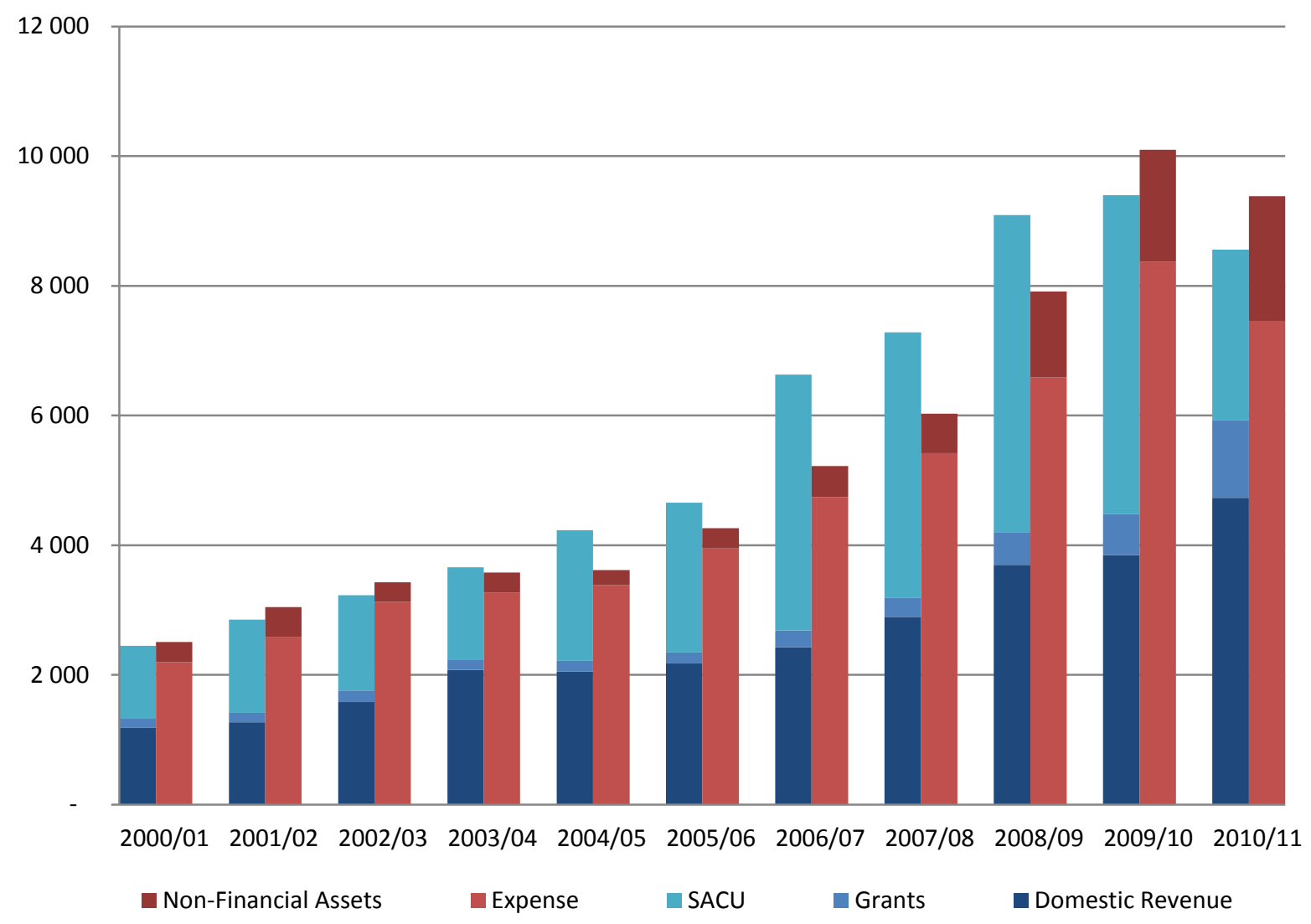

Total revenue has grown by $249 \%$ from M 2,451 million in 2000/01 to M 8,559 million in 2010/11. Domestic revenue (i.e. excluding grants and SACU) has grown by $300 \%$. Increases in tax revenue have been achieved through improved collections following the creation of the Lesotho Revenue Authority and the introduction of Value Added Tax at a standard rate of $14 \%$ in 2003. Tax revenue has grown significantly faster than GDP. This shows tax buoyancy, even though a number of reforms have reduced the effective rates of company and income tax in recent years. In particular, it appears that cutting the standard rate of company income tax from $35 \%$ to $25 \%$ (with even lower rates for exporters) in 2008 did not adversely affect collections and may have contributed to improved compliance. 
Grants have increased from M 138 million in 2000/01 to M 1,200 million in 2010/11 but this includes exceptional receipts of general budget support from several development partners and substantial drawdowns under the Millennium Challenge Account.

SACU revenues of M 1,129 million contributed $46 \%$ to total Government revenue in 2000/01. A new SACU Agreement was ratified in 2002 and the amended revenue sharing formula came into operation in 2005/06. Rapid growth in the Customs Pool generated a big increase in SACU receipts in 2006/07 (up from M 2,306 million to M 3,945 million, $60 \%$ of total revenue). However, as a result of the global economic downturn, SACU revenues fell by $47 \%$ in $2010 / 11$ to only M 2,628 million (31\% of total revenue).

This sustained period of rapid revenue growth created fiscal space which allowed the Government to increase total expenditure by $284 \%$ (despite the cuts imposed in 2010/11). All categories of expense have grown: Compensation of employees (up $222 \%$, partly driven by the introduction of the contributory public service pension scheme in 2008/09); Use of Goods and Services (up by $178 \%$, despite a cut of $26 \%$ in 2010/11); and Transfers to households and state-owned enterprises (which grew by 535\%, partly explained by introduction of the national old-age pension in 2004/05 and by increases in student bursaries).

Despite some annual variations, resources used for acquisition of non-financial assets remained fairly constant between 2000/01 and 2006/07 (averaging M 320 million annually). However, expenditure has subsequently grown very rapidly (more than doubling in 2008/09), with expansion of both Government and development partner-funded infrastructure projects. This category was not affected by cuts in $2010 / 11$, instead increasing by $11 \%$ to $M 1,923$ million. 
There were deficits of around 3\% of GDP in 2001/02 and 2002/03 but strong revenue performance enabled surpluses averaging 7\% of GDP to be achieved from $2003 / 04$ to $2008 / 09$. In $2009 / 10$ total expenditure went up by $22 \%$ whereas revenue grew by only $3 \%$, resulting in a deficit equal to $6.4 \%$ of GDP. Aggregate expenditure was cut in response to the global financial crisis in 2010/11. However, the dramatic fall in SACU receipts meant that the deficit increased to $6.6 \%$ of GDP.

There are several key lessons from this recent fiscal experience: the rapid growth in most categories of public expenditure appears unsustainable and Lesotho should apply fiscal rules to ensure that spending is aligned with longterm sustainable revenues; fiscal adjustments have been necessary to reduce emerging deficits by cutting expenditure and hard budget ceilings should be adhered to in future; since Lesotho remains overly dependent on revenues from SACU, efforts should be made to increase domestic revenues by accelerating structural reforms to boost productivity and competitiveness; the recent volatility in total revenue has demonstrated the need to build and maintain adequate reserves both for fiscal prudence and in support of monetary policy; and Lesotho needs to build fiscal resilience to deal with negative shocks (measures to manage downside risk are discussed in Section 4.6).

\subsection{Macroeconomic Policy}

The Plan Projection is based on the key assumption that we set an appropriate macroeconomic policy framework and deliver sound macroeconomic management. The objectives of macroeconomic policy are to: provide an attractive environment for foreign and domestic investment; encourage 
domestic savings and foreign capital inflows; ensure sustainable levels of fiscal deficit and public debt; ensure low and stable inflation rates (price stability is not only key to our competitiveness but also to our efforts to reduce poverty, since inflation acts as a tax on the poor); maintain sound external balances; and set tax and expenditure policies which have a beneficial impact on the distribution of incomes and wealth.

\subsubsection{Fiscal Policy}

The Government actively manages both aggregate revenues and expenditure in order to achieve fiscal balances which are consistent with long-term sustainability of public debt. As described in the preceding section, current economic conditions mean that there is need for fiscal discipline and little immediate headroom for fiscal expansion. The Government's expenditure strategy for the Plan period is based on the current medium-term expenditure framework up to $2014 / 15$, which implies that strategic expenditure goals and objectives must be pursued through cost efficiencies and a better allocation of existing resources. From 2015/16 onwards, fiscal policy can allow expense on Goods and Services to grow at approximately $2 \%$ a year in real terms while adhering to the fiscal policy objectives of debt sustainability and external balances.

Government relies heavily on receipts from the SACU revenue pool. The revenue-sharing formula under the current SACU Agreement usually provides over $50 \%$ of total revenue. Rapid growth in these transfers has permitted Government to adopt an expansionary public sector budget in which both revenue and expenditure account for over half of GDP, which is exceptionally high by African and developing country standards. 
Domestic revenue policy must ensure that sustainable levels of tax are collected through an effective and efficient system. In order to ensure that all taxpayers are treated fairly, the tax system is designed to achieve: horizontal equity (i.e. the same tax burden should fall on different members of the same income group); vertical equity (i.e. the tax burden should be shared equivalently among people that have different abilities to pay); economic efficiency with tax neutrality between the interests of both consumers and producers; administrative simplicity with a tax regime that can be easily understood and has low compliance costs; symmetry, meaning that, if gains are taxable, then losses should be deductible; and inclusiveness (i.e. tax rules apply to all sources of income).

Expenditure policy must address two potentially conflicting objectives: to provide goods and services that improve national welfare, while ensuring that Government does not hinder private-sector-led growth by absorbing an excessive share of resources and crowding out private sector demand. These goals can both be achieved if growth in public expenditure is kept below forecast economic growth, as this will reduce the size of Government relative to the size of the economy in the long-term. Thus, fiscal policy will support the Plan objective of enabling key private sector-led growth generators, whilst ensuring sufficient fiscal space to implement reforms and provide necessary public goods and social services.

\subsubsection{Monetary Policy and External Sustainability}

Lesotho is a member of the Common Monetary Area, with Namibia, South Africa and Swaziland. The fixed exchange rate regime pegs Lesotho's currency, the Loti, at par with the South African Rand. Although monetary policy is less important as a tool of macroeconomic management, Lesotho will maintain the 
current arrangements over the Plan period as they are an essential part of Government's strategy to encourage cross-border trade and operate as a liberal open economy.

Since the Reserve Bank of South Africa manages monetary policy on behalf of the entire CMA, Lesotho does not pursue an independent monetary policy. Nonetheless, these arrangements have been highly beneficial to Lesotho. Firstly, the dual currency system allows unrestricted movement of capital between CMA member states. Secondly, domestic inflation is anchored to regional inflation, ensuring that goods produced in Lesotho for export remain competitively priced relative to those produced by South Africa. Lastly, goods and services can move freely across borders without incurring the transaction costs and risks experienced when moving to a different currency regime. Although the strong Rand is currently an obstacle to export-led growth, exporters will benefit from South Africa's policy commitment to maintain a competitive exchange rate. ${ }^{18}$

Inflation is driven primarily by price developments in South Africa, which supplies about $80 \%$ of Lesotho's imports for final consumption. The Reserve Bank of South Africa has set an inflation target of 3-6\%. This has been achieved other than during periods of exceptional regional food price inflation and spikes in international prices (notably 2002/03 and 2008/09). The integrated money and capital market system prevents members from excessive money creation to finance fiscal deficits and requires Lesotho to underwrite the fixed exchange rate peg by maintaining an adequate level of net international reserves (NIR). The Monetary Policy Committee sets targets for NIR (US\$ 776 
million as at February 2012), which are adequate to ensure that Lesotho honours its foreign financial obligations (e.g. financing imports of goods and services, making debt repayments, meeting the foreign exchange demands of travellers). An associated indicator is that reserves should be equal to the value of 3-6 months of imports of goods and services. After reaching 6.3 months of cover in 2008/09, this indicator had reverted to a more usual 3.8 months in 2010/11.

Lesotho's external debt portfolio was approximately M 4,955 million in 2010/11, equal to less than one-third of GDP. However, changes in Loti / US dollar exchange rates cause significant fluctuations in the total value of outstanding external debt. About $90 \%$ is provided through concessional project financing, mainly from multilateral organisations. Domestic debt is equal to less than $10 \%$ of GDP. A comprehensive debt sustainability analysis was conducted in 2010. It concluded that non-concessional borrowing for Metolong Dam might increase key ratios temporarily but that debt service ratios would remain well below the critical thresholds due to the highly concessional nature of existing debt.

As part of its actions to secure external sustainability, Lesotho entered into a three-year Extended Credit Facility (ECF) with the International Monetary Fund (IMF) in June 2010. The objective of the ECF is to support Lesotho to achieve significant economic growth, pursue fiscal consolidation and increase exports over the next few years. As a result, there should be an improvement in the current account balance and strengthening of both net international reserves and import cover. The IMF will provide some additional foreign financing subject to the attainment of specific targets relating to these outcomes. Performance is monitored through six-monthly reviews. The third ECF Review 
(completed February 2012) is consistent with the main elements of the Plan Projection.

\subsection{Economic Projection for the Plan Period}

The Plan Projection is based on the structure of the economy as used in preparing the low growth scenario plus the mining and water investments anticipated in the moderate growth scenario together with the impact of the reforms describes in Section 3.3. The Projection shows that real GDP (in 2010 prices) could grow from $M 15,572$ million in $2010 / 11$ to $M 22,770$ million in $2016 / 17$, an average annual growth rate of $6.5 \%$, up from $5.8 \%$ in the moderate growth scenario. While this is not a substantial difference from the moderate growth scenario, however, the pattern of growth is much more satisfactory. The figures for $2012 / 13$ are the same in both the Plan Projection and the moderate growth scenario and both forecasts reflect the inevitable slowdown after the rapid pace of expansion in mining and construction. However, the reform measures proposed in this Plan show a small but positive impact in 2013/14 (growth is forecast at 1.9\%, against 1.3\%) and this increases to $0.9 \%$ in $2014 / 15$ (7.4\% against $6.5 \%)$ and further to $1.4 \%$ in both $2015 / 16$ and $2016 / 17$ (11.6\% and $5.0 \%$ against $10.2 \%$ and $3.6 \%$ respectively). As in the moderate scenario, both GNI and GNDI grow more slowly than GDP but in this Plan Projection, they increase at an annual average rate of $4.7 \%$ and $5.0 \%$ respectively, up from $4.2 \%$ and $4.6 \%$.

An extremely beneficial outcome is that employment could rise at an annual average of $3.6 \%$ from 213,000 in $2010 / 11$ to around 264,000 in $2016 / 17$. This confirms that it is possible to achieve the Plan objective to create 50,000 sustainable jobs in the private sector. In the low growth scenario, employment 
would be only 225,000 while it would reach 252,000 in the moderate growth scenario. Thus the Plan reforms add a further 12,000 jobs.

One factor in this improved performance is a higher level of investment (as measured by gross fixed capital formation) of approximately M 450 million annually from 2014/15 onwards. Although the Plan Projection does not make any growth assumptions beyond those described previously, it is quite plausible that successful performance by the growth generating industries will create a demonstration effect that will spur even stronger economic growth. For example, the expansion of the mining industry is likely to encourage further exploration based on the geological survey database, followed by investment above the projected levels.

Table 4.1: Key Indicators for the Plan Projection, 2010/11 - 2016/17

\begin{tabular}{|l|r|r|r|r|r|r|r|}
\hline Indicator & $2010 / 11$ & $2011 / 12$ & $2012 / 13$ & $2013 / 14$ & $2014 / 15$ & $2015 / 16$ & $2016 / 17$ \\
\hline Real GDP (Mm) & 15,572 & 16,534 & 17,771 & 18,101 & 19,436 & 21,688 & 22,770 \\
\hline $\begin{array}{l}\text { Real GDP (\% } \\
\text { annual change) }\end{array}$ & & $6.2 \%$ & $7.5 \%$ & $1.9 \%$ & $7.4 \%$ & $11.6 \%$ & $5.0 \%$ \\
\hline Real GNI (Mm.) & 20,925 & 21,717 & 22,907 & 23,323 & 24,393 & 26,297 & 27,611 \\
\hline $\begin{array}{l}\text { Real GNI (\% } \\
\text { annual change) }\end{array}$ & & $3.8 \%$ & $5.5 \%$ & $1.8 \%$ & $4.6 \%$ & $7.8 \%$ & $5.0 \%$ \\
\hline $\begin{array}{l}\text { GDP (Mm, } \\
\text { current prices) }\end{array}$ & 15,572 & 17,175 & 19,800 & 21,100 & 23,537 & 27,620 & 30,339 \\
\hline $\begin{array}{l}\text { GNI (Mm, } \\
\text { current prices) }\end{array}$ & 20,982 & 22,628 & 25,377 & 27,007 & 29,329 & 33,152 & 36,390 \\
\hline $\begin{array}{l}\text { Formal Employ- } \\
\text { ment (000) }\end{array}$ & 213.0 & 215.6 & 230.6 & 234.0 & 234.6 & 250.2 & 263.9 \\
\hline $\begin{array}{l}\text { Investment } \\
\text { (Mm.) }\end{array}$ & 5,207 & 5,950 & 8,237 & 10,250 & 9,451 & 10,189 & 11,491 \\
\hline $\begin{array}{l}\text { Fiscal Balance } \\
\text { (Mm) }\end{array}$ & $-1,585$ & $-1,727$ & 380 & -186 & 142 & 557 & 658 \\
\hline $\begin{array}{l}\text { Import cover } \\
\text { (months) }\end{array}$ & 3.4 & 2.5 & 3.0 & 3.2 & 3.1 & 3.3 & 3.5 \\
\hline
\end{tabular}

The balance of payments remains stable (an increase in the current account deficit is offset by the higher inflows of foreign direct investment on the financing account). The fiscal outcome improves by approximately M 50 
million per annum from 2013/14 onwards. Net Foreign Assets are similar in both the moderate growth and the Plan Projections and import cover remains consistently above three months.

Overall, the Plan Projection represents a better outcome than the moderate growth forecast. However, it must be recognised that achieving the positive results in the Plan Projection depends (i) on Government implementing a coordinated package of interventions that will improve the environment for doing business and (ii) on the positive responses to those reforms by economic agents. In part, that will be determined by what is happening in other countries (especially South Africa) as Lesotho will face severe competition, both for investment and for markets.

Table 4.2 provides a comparison of the low, moderate and Plan forecasts. It supports the analysis above.

Table 4.2: Comparing the Growth Forecasts

\begin{tabular}{|c|c|c|c|c|c|c|}
\hline & GDP & GNDI & \multirow[t]{2}{*}{ Employment } & Exports & $\begin{array}{c}\text { Tax } \\
\text { Revenue }\end{array}$ & \multirow{2}{*}{$\begin{array}{c}\text { Average } \\
\text { Household } \\
\text { Income (M) }\end{array}$} \\
\hline & \multicolumn{2}{|c|}{ (Mm, constant prices) } & & \multicolumn{2}{|c|}{ (Mm, current prices) } & \\
\hline $\begin{array}{l}\text { Lesotho FY } \\
2010 / 11\end{array}$ & 15,572 & 25,113 & 213,009 & 6,743 & 3,416 & 46,000 \\
\hline \multicolumn{7}{|c|}{ Lesotho FY 2016/17 totals (with annualised percentage growth rates) } \\
\hline $\begin{array}{l}\text { Low Growth } \\
\text { Forecast }\end{array}$ & $\begin{array}{l}17,197 \\
(1.9 \%)\end{array}$ & $\begin{array}{r}28,920 \\
(2.5 \%)\end{array}$ & $\begin{array}{r}224,538 \\
(1.0 \%)\end{array}$ & $\begin{array}{l}10,161 \\
(7.4 \%)\end{array}$ & $\begin{array}{r}4,491 \\
(4.9 \%)\end{array}$ & $\begin{array}{r}46,400 \\
(1.6 \%)\end{array}$ \\
\hline $\begin{array}{l}\text { Baseline } \\
\text { Forecast }\end{array}$ & $\begin{array}{r}21,890 \\
(5.8 \%)\end{array}$ & $\begin{array}{r}32,895 \\
(4.6 \%)\end{array}$ & $\begin{array}{r}252,168 \\
(2.9 \%)\end{array}$ & $\begin{array}{r}16,775 \\
(16.4 \%)\end{array}$ & $\begin{array}{r}6,388 \\
(11.0 \%)\end{array}$ & $\begin{array}{r}52,900 \\
(2.4 \%)\end{array}$ \\
\hline $\begin{array}{l}\text { Plan } \\
\text { Projection }\end{array}$ & $\begin{array}{r}22,770 \\
(6.5 \%)\end{array}$ & $\begin{array}{r}33,590 \\
(5.0 \%)\end{array}$ & $\begin{array}{r}263,910 \\
(3.6 \%)\end{array}$ & $\begin{array}{r}18,621 \\
(18.4 \%)\end{array}$ & $\begin{array}{r}6,599 \\
(11.6 \%)\end{array}$ & $\begin{array}{r}53,300 \\
(2.5 \%)\end{array}$ \\
\hline
\end{tabular}




\subsection{Fiscal Framework, 2011/12 - 2016/17}

The three core elements that need to be considered in setting the fiscal framework are the forecast resource envelope, the current level of expenditure and its projected rate of growth and the impact of the overall fiscal balance on debt sustainability. A summary of these indicators is given in Table 4.3.

In current prices, total revenue is expected to grow by an annual average rate of $10.1 \%$. A major part of this growth occurs in $2012 / 13$ as SACU receipts are expected to bounce back from the exceptionally low level in $2010 / 11^{19}$. Indeed, part of the 2012/13 distribution was in respect of a forecast basic distribution that was below the entitlement based on actual collections. From 2013/14 onwards, the Projections anticipate an average annual increase of just $3.1 \%$ in current prices. The Customs Pool is likely to decline as a result of lower average tariffs and free trade agreements between SACU and its trading partners.

Tax revenue is forecast to increase by an annual average of $10.6 \%$. Most of the growth occurs in 2015/16 and 2016/17 as a result of assumptions about the value of diamond production and on the effect of allowing capital expenditure against tax liabilities, which will reduce collections in the early years of higher production. For Lesotho, there is currently limited scope to modify tax rates. This is particularly significant as higher taxes would have an adverse impact on

\footnotetext{
19 The original forecast of the Customs Revenue Pool in 2008/09 was used to determine distributions to member states but the global financial and economic crisis meant that actual collections were substantially less than anticipated. Distributions in 2010/11 were far below average as the forecast was more conservative and members had to repay excess amounts from 2008/09.
} 
the investment climate and damage the attainment of the Plan growth objectives.

The uncertainties about long-term SACU revenues suggest that Government should take a cautious approach to setting the aggregate expenditure ceiling. Any windfall receipts, such as higher than anticipated Customs revenue in the short-term, should be used to rebuild reserves and to pay off some of the accrued liabilities. This will increase fiscal resilience and improve Government's ability to deal with any future downside risks that may occur.

Table 4.3: Plan Summary Fiscal Framework, 2011/12 - 2016/17 (Mm)

\begin{tabular}{|l|r|r|r|r|r|r|}
\hline Fiscal Account & \multicolumn{1}{|c|}{$2011 / 12$} & \multicolumn{1}{|c|}{$2012 / 13$} & \multicolumn{1}{|c|}{$2013 / 14$} & \multicolumn{1}{|c|}{$2014 / 15$} & \multicolumn{1}{|c|}{$2015 / 16$} & \multicolumn{1}{c|}{$2016 / 17$} \\
\hline Total Revenue & 9,190 & 13,337 & 12,424 & 12,339 & 13,510 & 14,844 \\
\hline Tax Revenue & 3,984 & 4,554 & 4,749 & 5,048 & 5,740 & 6,599 \\
\hline Grants & 1,558 & 1,846 & 1,186 & 684 & 698 & 712 \\
\hline Non-Tax Revenue & 3,649 & 6,937 & 6,489 & 6,607 & 7,072 & 7,533 \\
\hline Of which, SACU & 2,753 & 5,966 & 5,456 & 5,431 & 5,703 & 5,988 \\
\hline Expense & $-8,190$ & $-9,047$ & $-9,289$ & $-9,590$ & $-10,329$ & $-11,157$ \\
\hline Goods \& Services & $-5,605$ & $-6,429$ & $-6,589$ & $-6,806$ & $-7,282$ & $-7,797$ \\
\hline Property & -134 & -169 & -242 & -259 & -282 & -316 \\
\hline Transfers & $-2,450$ & $-2,449$ & $-2,458$ & $-2,525$ & $-2,765$ & $-3,044$ \\
\hline Capital Account & $-2,727$ & $-3,910$ & $-3,321$ & $-2,607$ & $-2,624$ & $-3,029$ \\
\hline Non-Financial Assets & $-2,727$ & $-3,910$ & $-3,321$ & $-2,607$ & $-2,624$ & $-3,029$ \\
\hline Fiscal Balance & 1,727 & 380 & -186 & 142 & 557 & 658 \\
\hline
\end{tabular}

The Government's expenditure strategy for the Plan period is based on the current medium-term expenditure framework up to 2014/15. There was a significant fiscal adjustment in 2010/11 in response to the decline in SACU revenues and strict ceilings were imposed on both Goods \& Services (including compensation of employees) and Transfers. The recovery in SACU revenues has allowed some additional fiscal discretion in 2012/13 but within a hard budget ceiling. From 2015/16 onwards, expense on Goods and Services is 
projected to grow at approximately $2 \%$ a year in real terms, while Transfers increase by $3-4 \%$ per annum.

Implicit in this forecast is the need to keep the public sector wage bill under control. This means that raising productivity of all levels and branches of the civil service will be necessary to implement the proposed Plan interventions. Additional fiscal space should become available by making efficiency savings through implementation of a number of public financial management reforms.

The capital budget has been exceptionally large in recent years, driven by funding for construction of Metolong Dam that is financed by the Millennium Challenge Account. Both these programmes will be winding down and the aggregate allocation for acquisition of non-financial assets will decline from $\mathrm{M}$ 3,910 million in $2012 / 13$ to $M$ 3,321 million in $2013 / 14$ and to $M$ 2,607 million in $2014 / 15$. However, the ceiling will increase slightly in 2015/16 (there will be additional fiscal space as the Metolong project should be completed in 2014/15 and will therefore drop out of the capital budget) and by about M 400 million to M 3.0 billion in $2016 / 17$. Although the increase in the aggregate capital ceiling is relatively small, resources will be released for Plan activities following the completion of ongoing projects.

Overall, matching the resource envelope and the expenditure ceilings shows that the fiscal balance will record a relatively small surplus over the Plan period (averaging about M 300 million per annum) and confirms that Lesotho will satisfy all critical debt sustainability indicators.

The Plan Projection of economic growth generates a fiscal framework that enables Government to expand current expenses in real terms. It also allows an exceptional allocation to acquisition of non-financial assets in 2012/13 of 
about M 3,910 million. Once the large ongoing projects are completed, there will be significant fiscal space for new Plan activities.

In current prices, the economy is expected to grow at $12.1 \%$ per annum whereas public expenditure is forecast to grow by $5.4 \%$ a year. As a result, the size of Government relative to the size of the private sector will reduce in line with the fiscal strategy. However, these favourable outcomes will only be achieved by strict aggregate expenditure control and by improving the quality of expenditure through allocative targeting and operational efficiency.

Therefore, in order to realize the target growth rates and attain macroeconomic stability, the fiscal strategy and monetary policy must achieve the following objectives:

- Improving resource allocation and cost efficiency to support growth that will result in increased revenue thereby opening up additional fiscal space

- Promoting fiscal consolidation by reducing fiscal deficits and adhering to debt sustainability (lower deficits/GDP and debt/GDP) and rebuild fiscal reserves

- Ensuring fiscal discipline, including adherence to hard budget ceilings and elimination of arrears

- Improve tax/revenue administration and mobilisation of finance for development by broadening the tax net and exploring ways of raising nontax revenues

- Increasing absorptive capacity of Ministries to spend budget allocations

- Containing the wage bill and increasing public sector efficiency

- Maintaining the Loti/Rand convertibility and/or building international reserves 
- Sustain the real value of capital expenditure and maintain a stable ratio of capital to total spending

\subsection{Economic Projection beyond the Plan period}

Together, the growth resulting from accelerators and generators will change the shape of the economy towards high sustainable growth by the end of the Plan period in $2016 / 17$. However, the main benefits of the proposed reforms will be achieved in the subsequent years up to 2020/21 and beyond.

Caution and prudence have guided the macroeconomic projection after $2016 / 17$. Thus, improvements in productivity are assumed to occur at a slower rate. The rate of increase in agricultural production will slow down (the prime opportunities to switch to commercial agriculture are likely to have been exploited by $2016 / 17$. The rate of tourism growth will slow down to $5 \%$ per annum although this will still be a significant increase, since the industry base will be larger than in 2012/13. Investment for LHWP Phase II will be virtually complete by $2020 / 21$, with a negative impact on construction activity. Employment in construction is expected to fall by 1,600 between 2019/20 and 2020/21, if no new investments are secured.

Taken together, these assumptions mean that the average rate of growth will slow. Nonetheless, GDP is projected to increase from $M 22,770$ million in $2016 / 17$ to $M 25,720$ million in $2020 / 21$, whereas it is projected to grow from M 21,890 to $M 23,637$ million in the moderate growth scenario. This means that reforms implemented during this Plan period will raise the annual average growth rate from $1.9 \%$ to $3.1 \%$. In addition, formal employment will continue to grow by an additional 47,000 jobs (at an annual average rate of $3.0 \%$ ). 
There is obviously considerable uncertainty about such a long-term forecast but the results suggest that Lesotho can shift to a faster growth path and take actions that support sustainable growth based on our comparative and competitive advantages that will generate benefits long after this Plan period.

\subsection{Managing downside risks}

Historically, there have been several occasions when internal events or international crises have threatened macroeconomic management. However, Government has demonstrated the willingness to deal with these challenges by taking appropriate actions to deal with emerging imbalances through: improved revenue collection (e.g. creation of the Lesotho Revenue Authority); expenditure control and rationalisation; public sector reform; financial sector reform; privatisation; and maintenance of external reserves at about 6 months of imports cover.

Over any five-year period there will be unexpected shocks that will threaten the smooth attainment of our economic objectives. These may be the result of natural disasters such as drought and floods or external shocks like another period of global recession or higher regional food prices. Although these shocks have not been incorporated into the three scenarios, prudent planning involves making provision not only for upside potential but also for downside risks. Therefore, Government fiscal strategy is designed to be sufficiently robust so that Lesotho can absorb the likely economic impact of such risks and to prepare responses that will improve Lesotho's resilience in the face of such shocks. In particular, the intention is to improve climate change resilience, rebuild reserves that have been eroded by recent deficits so that Government balances and net foreign assets regain acceptable precautionary levels. Debt sustainability indicators will also be closely monitored so that any early 
warning signs of stress can be addressed. A further risk is that Lesotho's share of SACU revenues may fall: this could occur because the pool gets smaller as a result of lower effective tariff rates, a change in trade arrangements (e.g. introduction of the SADC customs union) or because member states agree to renegotiate the revenue-sharing formula. A shock of this potential magnitude (without any offsetting compensation from partners) would force the Government to reduce its share of expenditure in the economy.

The analysis of the economic costs of the 2010/11 floods and the resource implications of the response provides a recent impact assessment of a natural disaster ${ }^{20}$. The initial losses (to agricultural production, disruption to delivery of goods and access to services, damage to physical assets) and the cost of action to mitigate those losses (feeding programmes, input supplies, rehabilitation of assets) can be quite substantial. However, evidence from previous events suggests that output can recover within 1 to 2 years and that the fiscal costs can be accommodated by temporary reallocation of resources within the fiscal envelope. This suggests that the impact would be manageable as long as economic performance returns to its sustainable path. The current initiative to establish a Disaster Management Fund will further strengthen domestic resilience to deal with natural shocks.

There is broad recognition that the performance of the world economy has deteriorated over the past years and recovery is sluggish. This could have serious implications for Lesotho's exports but indications are that planned investments will proceed since they have a long lead time and therefore will not target world markets for several years. Equally the reform programme set 
out in this Plan Projection is designed to improve the business environment under a range of market conditions.

One of the main external threats comes from the scheduled tightening of access to the US textile market under the provisions of AGOA. The timeframe currently proposes enforcement of double-transformation ${ }^{21}$ in 2012 and the termination of all benefits by 2015 . This would expose production for the US market to the full force of international competition and few firms would be able to maintain current production levels. Although some might survive by diverting capacity to serve other markets, such as SACU and Europe, many would simply close down. Overall, the industry would contract and there would be a substantial loss of direct and indirect employment. Consequently, the Government will be pro-active in using trade negotiations to protect industrial competitive advantages, while encouraging firms to raise productivity and to diversify both their products and their markets.

\footnotetext{
21 Producers based in Lesotho would be required to undertake at least two production processes in country or using materials sourced through other qualifying countries in order to remain eligible for quota and duty free access to the US textile market.
} 


\section{Strategic Framework}

This section outlines the strategic objectives and actions to be pursued in order to achieve our strategic goals over the Plan period. The strategic areas are: (i) Investment climate, including regulatory reforms to improve business environment, financial services and trade; (ii) Productive sectors, including agriculture and the rural economy, manufacturing, tourism, mining, and Micro, Small and Medium Enterprises (MSMEs); (iii) Infrastructure development, which covers transport, water and sanitation, energy, Information and Communication Technology (ICT), Shelter and property development, sports facilities and public asset management; (iv) Skills, Technology and innovation; (v) Health, HIV and AIDS and social vulnerability; (vi) Environment and climate change; and (vii) Governance and institutions.

\subsection{Create High, Shared, and Employment Generating Growth}

\subsubsection{Investment Climate}

Lesotho has made much progress improving the investment climate in recent years. Major improvements include the establishment of a One-Stop Business Facilitation Centre (OBFC), new Companies and Land legislation that have been enacted. However, the economy has not yet benefitted from these reforms. Despite these developments, in the last three years, Lesotho's overall ranking in Doing Business Indicators has slipped from 118 in 2008 to 143 in $2012^{22}$.

\footnotetext{
$22 \quad$ World Bank Doing Business Indicators: the DBI ranks more than 180 countries based on ten categories (starting a business, dealing with construction permits, registering a property, getting electricity, getting credit, protecting investors, paying taxes, trading across borders, enforcing contracts and closing a business).
} 
Lesotho scores poorly on other Global Competitiveness Indices ${ }^{23}$ and compares unfavourably with our regional and global competitors ${ }^{24}$. Our declining rank may not mean that our investment climate is getting worse, but rather that other countries have been improving their investment climates at a faster rate. High start-up and compliance costs discourage many domestic entrepreneurs from entering the formal sector. Setting up a legally registered company currently costs the equivalent of three months of the average Mosotho income. Procedures such as obtaining relevant licenses, obtaining land leases and paying taxes are both time-consuming and costly. Many procedures are so complex that most people do not understand them. The cost to the economy of this poor performance is evident. Businesses in border towns in the Eastern Free State such as Ladybrand, Ficksburg and Wepener are booming with business from Lesotho. Lesotho often loses out to competing destinations in the race to attract investment. Overcoming these constraints is a potential source of growth.

The current policy environment is also determined by a number of separate policies, some of which are informal. For example, MSME and Competition policies are still drafts and Trade policy is still being developed. Finalisation of these policies will ensure that investors are clear of the direction being taken by the Government.

The investment climate reform package will include a range of interventions designed to make our laws and regulations more business friendly. There is

\footnotetext{
23 Such as World Bank Business Enterprise Surveys and Global Competitiveness Reports.

$24 \quad$ According to the World Bank Doing Business Indicators (2012), Lesotho is the worst performer in SACU: South Africa ranks 35, Botswana 54, Namibia 78 and Swaziland 124. Other textile exporters in East Asia also score better.
} 
clear evidence from both developed and developing countries that regulatory reforms leading to sustained improvements in indicators of competitiveness can yield substantial and sustained improvements in productivity, generate higher investment and shift economies to a faster growth path. Therefore, Lesotho must focus on areas in which it currently ranks relatively poorly.

Export-led growth opportunities also depend on the ease of trading across borders. The process for obtaining work and residence permits needs to be improved to avoid delaying entry of the necessary foreign expertise. New laws and regulations will go through a process of Regulatory Impact Assessment (RIA) to ensure that reforms result in the expected results and that private sector needs are addressed. Further improvements of the land policy and regulatory framework, increasing capacity to deal with industrial disputes and fighting crime and corruption will also be focal areas in improving the investment climate.

A list of critical investment climate issues and proposed interventions is provided in Table 5.1. 
Table 5.1: Investment Climate Reform Agenda

\begin{tabular}{|c|c|}
\hline Critical issues & Strategic Actions \\
\hline \multicolumn{2}{|l|}{ Policy Framework } \\
\hline $\begin{array}{l}\text { 1. Lack of over- } \\
\text { arching policy } \\
\text { framework }\end{array}$ & $\begin{array}{l}\text { - Create one single overarching investment policy that gives both domestic and foreign investors clarity } \\
\text { about obligations and opportunities }\end{array}$ \\
\hline $\begin{array}{l}\text { 2. Institutionalisation } \\
\text { of Regulatory } \\
\text { Impact Assessment }\end{array}$ & $\begin{array}{l}\text { - Develop and disseminate Regulatory Impact Assessment (RIA) policy to } \\
\text { - ensure that it is mandatory to carryout RIA prior to policy and law making }\end{array}$ \\
\hline \multicolumn{2}{|l|}{ Business Regulation } \\
\hline \multirow[t]{3}{*}{$\begin{array}{l}\text { 3. Starting a business } \\
\text { (It takes many days } \\
\text { and procedures, } \\
\text { and it is costly) }\end{array}$} & $\begin{array}{l}\text { - Implement OBFC strategy: review the legal standing and structure of the OBFC to improve efficiency; } \\
\text { automate business registration procedure and develop related legal framework; develop a new Business } \\
\text { Registry Act and facilitate use of a single identification for businesses; improve inter-agency cooperation; } \\
\text { and strengthen management of OBFC. Join the Corporate Registries Forum which provides market } \\
\text { information and economic profiles. } \\
\text { - Rollout OBFC to the districts, starting with industrial centres }\end{array}$ \\
\hline & $\begin{array}{l}\text { Regularise Environmental Impact Assessment } \\
\text { - Review Environment Act and guidelines to ease application and test applicability for different sectors } \\
\text { - Introduce accreditation of ElA consultants- certification board and regulate fees }\end{array}$ \\
\hline & $\begin{array}{l}\text { Health Certificate } \\
\text { - Change health inspection from pre- to post-inspection (although, once the policy on risk has been } \\
\text { determined, high-risk businesses would be excluded) } \\
\text { - Review Public Health Act accordingly }\end{array}$ \\
\hline $\begin{array}{l}\text { 4. Dealing with } \\
\text { construction } \\
\text { permits (It takes } \\
\text { many days and } \\
\text { procedures and it is } \\
\text { costly) }\end{array}$ & $\begin{array}{l}\text { - Set time limits and service levels (e.g. enforce } 30 \text { day time limit to get a permit from MCC) } \\
\text { - Develop guidelines for applicants and automate the application process for construction permits } \\
\text { - Explore options for establishing one-stop centre for relevant agencies (MCC, LSPP, WASCO and LEC) to } \\
\text { enhance coordination and efficiency and network information registries in MCC, LTDC and MTICM and } \\
\text { others }\end{array}$ \\
\hline
\end{tabular}




\begin{tabular}{|c|c|}
\hline $\begin{array}{l}\text { 5. Getting electricity } \\
\text { (it takes too long } \\
\text { to get connected) }\end{array}$ & $\begin{array}{l}\text { - Improve responsiveness of LEC to business requests for electricity connections. Set time limits for } \\
\text { external connection works and meter installation and explore options for improving the efficiency for } \\
\text { equipment and materials procurement } \\
\text { - Set time limits and service standards for inspections and remove the security deposit fee }\end{array}$ \\
\hline $\begin{array}{l}\text { 6. Registering } \\
\text { property (It takes } \\
\text { many days and } \\
\text { costly procedures) }\end{array}$ & $\begin{array}{l}\text { - Fully implement the } 2010 \text { Land Act } \\
\text { - Computerize the Registry of Deeds to allow automated searches of titles } \\
\text { - Standardise transfer deeds documents and eliminate mandatory requirement for an attorney } \\
\text { - Administer the set time limits (one month as per } 2010 \text { Land Act) for issuance of tittles }\end{array}$ \\
\hline $\begin{array}{l}\text { 7. Enforcing contracts } \\
\text { (It takes many days } \\
\text { and procedures, } \\
\text { and it is costly to } \\
\text { enforce contracts) }\end{array}$ & $\begin{array}{l}\text { - Fully implement the Commercial Court operations } \\
\text { - Introduce the small claims procedure in the Magistrate Courts and integrate the Court Annexed } \\
\text { - Mediation programme in the High Court, Commercial Court and Magistrate Court } \\
\text { - Set time limit for execution of judgments } \\
\text { - Automate case management system (computerization) in the courts } \\
\text { - Capacity building for specialised skills of court personnel } \\
\text { - Restructure civil courts organizational structure } \\
\text { - Development and implementation of courts' strategic plan and performance evaluation system }\end{array}$ \\
\hline $\begin{array}{l}\text { 8. Protecting } \\
\text { Investors }\end{array}$ & - Implement new Companies Act \\
\hline $\begin{array}{l}\text { 9. Paying taxes (It } \\
\text { takes many } \\
\text { payments and } \\
\text { hours per year to } \\
\text { pay taxes) }\end{array}$ & $\begin{array}{l}\text { - Institutionalise operation of the tax policy committee and make the membership more inclusive } \\
\text { - Reduce compliance costs by establishing a small businesses tax regime } \\
\text { - Streamline business processes with respect to: frontline advice and assistance; registration; taxpayer } \\
\text { returns processing; audit; collection of revenue; debt management; clearance of goods; refunds; and } \\
\text { taxpayer records management }\end{array}$ \\
\hline $\begin{array}{l}\text { 10. Trading across } \\
\text { borders (It takes } \\
\text { many days and } \\
\text { procedures and } \\
\text { costly to } \\
\text { import/export) }\end{array}$ & $\begin{array}{l}\text { - Harmonize applicable laws and regulations (e.g. between SPS, OBFC and Customs); simplify } \\
\text { administrative and commercial formalities, procedures and documents } \\
\text { - Standardize and integrate information and requirements (make information on border requirement } \\
\text { easily available and accessible) } \\
\text { - Create a National Trade Facilitation Working Group to coordinate different agencies } \\
\text { - Review legislation such as the SACU Customs and Excise Act to facilitate automation of customs } \\
\text { processes etc. and the VAT agreement with RSA to enhance the existing border arrangement }\end{array}$ \\
\hline
\end{tabular}




\begin{tabular}{|c|c|}
\hline & $\begin{array}{l}\text { - Continue refurbishment of border posts, allow for use of technology and separation of trade traffic from } \\
\text { other traffic } \\
\text { - Create one stop border and develop programmes with South Africa to improve the complete border } \\
\text { - experience (including for business and tourism) } \\
\text { - Create a web based trade portal that allows provision of information on importers and exporters } \\
\text { - Enable online application of import and export permits and automated procedures } \\
\text { - Automate clearance of goods (e.g. use of scanners or sensors to confirm legitimate goods) }\end{array}$ \\
\hline $\begin{array}{l}\text { 11. Closing a } \\
\text { business (It takes } \\
\text { many days and } \\
\text { costly procedures) }\end{array}$ & $\begin{array}{l}\text { - Incorporate procedures for insolvency (currently under the } 1967 \text { Insolvency Act)in the new Companies } \\
\text { - Act and improve insolvency and debt enforcement procedures } \\
\text { - Capacitate Commercial Court Judges and legal practitioners on new insolvency procedures } \\
\text { - Establish a framework that allows out-of-court negotiations for the restructuring of outstanding debts }\end{array}$ \\
\hline \multicolumn{2}{|r|}{ ( } \\
\hline $\begin{array}{l}\text { 11. Modernization of } \\
\text { land policy and } \\
\text { administration }\end{array}$ & $\begin{array}{l}\text { - Development of related regulations and improvement of other complementary legislations to Land Act, } \\
\text { such as Land Survey Act (1980), Valuation and Rating Act (1980), Town and Country Planning Act (1980), } \\
\text { Local Administration (1997), etc. before the expiry of the Millennium Challenge Account in June } 2013\end{array}$ \\
\hline $\begin{array}{l}\text { 12. Systematic land } \\
\text { regularization and } \\
\text { registration }\end{array}$ & $\begin{array}{l}\text { - Fast-track Land Regularization and Registration programme (e.g. issue of leases to informal or unplanned } \\
\text { urban sites owners to enable them to 'transact' and invest on land as an economic asset) } \\
\text { - Strengthen public outreach and training }\end{array}$ \\
\hline \multicolumn{2}{|l|}{ Corruption and Crime } \\
\hline $\begin{array}{l}\text { 13. Reduce corruption } \\
\text { and crime }\end{array}$ & $\begin{array}{l}\text { - Strengthen capacity of Financial Investigation Unit(FIU) } \\
\text { - Implement recommendations of DCEO review study } \\
\text { - Enhance legal frameworks to fight corruption }\end{array}$ \\
\hline \multicolumn{2}{|c|}{ Labour Force and Relations } \\
\hline $\begin{array}{l}\text { 14. Industrial and } \\
\text { labour relations }\end{array}$ & $\begin{array}{l}\text { - Enhance capacity of institutions to enforce provisions of the labour laws and to prevent and resolve } \\
\text { labour disputes (DDPR, Ombudsman and the Labour Court, Labour department) } \\
\text { - Make legal provision for integrated work/ residence permits to be issued at the OBFC } \\
\text { - Train more arbitrators in Ministry of Labour and Employment }\end{array}$ \\
\hline
\end{tabular}


Reforms will be continually monitored to assess whether they are working and whether competitors have moved the goalposts by introducing even better systems. Thus, reform does not imply a static package of measures to be implemented once but, instead, involves a series of improvements that must be implemented and enhanced over time, learning from domestic experience and from successes and failures elsewhere and terminating policies that are not working.

\subsubsection{Financial Services}

Financial services play an important role in peoples' lives, such as reducing vulnerability by giving people a secure means of saving for investment as well as meeting unforeseen shocks. By regional standards, Lesotho has relatively high rates of access to finance even though the financial sector is relatively small and underdeveloped. It consists of four commercial banks, seven insurance companies, two asset management companies (responsible for six collective investment schemes including two money market funds), money lenders and credit-only institutions, and financial cooperatives. The sector's contribution to GDP in 2010 was about $6 \%$ while its assets accounted for $84.1 \%$ of Lesotho's GDP. Commercial banks account for about $51.3 \%$ of the assets of the financial sector. Three of the commercial banks are foreign owned ${ }^{25}$, and only one is local and state-owned. The insurance sector consists of seven insurance companies and a large number of insurance brokers. Assets of the insurance sector account for $29.5 \%$ of assets of the financial sector The sector has been fairly stable but this stability is threatened by out-dated regulatory laws, non-existence of legislation regulating non-bank financial institutions and

\footnotetext{
${ }^{25}$ These are subsidiaries of South African banks and their assets account for 90.3 per cent of the total assets of the banking sector in Lesotho
} 
conflicting legislation (e.g. FIA and Cooperatives Act, Deferred Pay Act, Societies Act). There are also no safety-nets to protect depositors and policyholders, who are likely to lose their savings if any of the financial institutions fail.

Financial intermediation is relatively low. The banking sector is highly liquid, but a small portion of deposits are on-lent to deficit sectors. The loans to deposit ratio of the banking system is at $35.4 \%$ as at 31 March 2011 compared to a range of $60 \%$ to $78 \%$ in emerging markets. Private sector credit as a percentage of GDP is $28.4 \%$ and is one of the lowest in Sub-Saharan Africa. This implies that access to credit is very limited in Lesotho.

According to initial findings of FinScope survey 2011, whose results are yet to be published, it is estimated that $62 \%$ of the population is unbanked. There are only 40 branches however only two banks have countrywide outreach with 29 branches. On average there are 10 branches per bank. However, because of the terrain of the country and lack of infrastructure, most of these branches are concentrated in the low lands and foothills, leaving a large part of the population in the rural areas unbanked and without access to financial services.

The Lesotho's money and capital markets are also underdeveloped. For example, the money market comprises only of Treasury bills and the interbank market. There have been developments in the primary market for Government securities but the secondary market does not exist, making it difficult to trade. Furthermore, the financial sector is highly concentrated so there is limited competition. There are few market instruments and limited product differentiation. These characteristics are reflected in very high fees charged by banks. 26 per cent of income of the banks is generated from fees as opposed 
to 35 per cent from interest. The wide spread between deposit and lending rates encourages consumers either to avoid using the financial sector at all or to seek banking services in South Africa since capital is freely mobile within the CMA.

The main challenges for Lesotho are to increase financial inclusion and access to credit, to develop a broad and deep secondary market for bonds and diversify the market to allow development and trading of different instruments. The Government will continue to build on successful policies to promote financial inclusion, deepen savings culture and enhance financial literacy. The legal and regulatory framework also has to be developed to accommodate the deepening and broadening of the market. Strengthening financial services sector regulation and supervision will improve trust in the financial system and decrease systemic risk. It will also allow for the development of financial risk management and insurance products that can help facilitate manufacturing and exports.

The operationalization of the established credit guarantee scheme (risk shared between banks, GoL and Borrower) and development of leasing policy and related law need to be accelerated. This will enhance credit extension/lending, especially to SMMEs, as the risk of non-repayment of loans is reduced. Other measures will be implemented, such as those targeted at improved functioning of courts and their ability to enforce contracts. Better enforcement of contracts is important in building linkages between foreign and Basotho businesses, as they are essential for outsourcing and other forms of cooperation. 


\section{Strategic objectives and actions}

- Improve financial stability and soundness

- Improve the regulatory and supervisory framework to deal with risk, especially external shocks, including adoption of macro-prudential approach

- Harmonise the regulatory frameworks with the SADC region

- Increase regulation coverage across the sector and eliminate overlaps between regulatory institutions

- Enhance consumer protection through, inter alia, enactment and/or improvement of deposit protection law and sections of the Cooperatives Societies Act dealing with cooperative banks

- Facilitate application of Basel Accords and adoption of best international practices to enhance surveillance in the sector

- Review and improve legal frameworks, including: pensions and insurance legislation; bankruptcy laws; credit reference and data protection laws; leasing law; and legislation for the development of money and capital markets

\section{- Improve access to financial services}

- Improve market information dissemination to enhance competition and consequently reduce the cost of financial services

- Operationalise the credit guarantee schemes

- Develop policy and incentives framework to encourage the development of low cost service channels

- Implement measures to ensure effective administration of new land laws and leasing laws so that the potential borrowers can provide land as collateral

- Enhance capacity and coverage for risk management services 
- Operationalise the national identity system and credit bureau to address information asymmetry

- Strengthen the legal framework and operations of the commercial court to improve contract enforcement

- Strengthen capacity and skills of micro-finance institutions

- Modernise the post-bank, including introduction of mobile banking

- Promote linkages between financial institutions, business development services institutions and MSMEs

- Increase alternatives for mobilising financial resources

- Undertake periodic research to develop appropriate financial instruments and institutions (enhance innovations) that facilitate better mobilisation of resources including long term finance

- Facilitate the development of secondary and capital markets

- Explore the establishment of diaspora bonds/investment vehicles to finance development

- Promote savings culture

- Promote the establishment of savings instruments with low operating costs and competitive and stable returns

- Promote long term contractual savings for retirement

- Improve efficiency of the financial sector

- Improve payment and settlement systems by establishing an automated clearing house with the necessary infrastructure

- Align national payment and settlement system to the regional payment and payment settlement systems

- Facilitate the linkage of micro-finance institutions to the clearing house 


\section{- Bridge the skills gaps in the financial sector and increase financial literacy}

- Improve the skills development capacity of local institutions to produce requisite high quality human resources

- Improve the linkages between financial sector institutions and institutions of higher learning in the country and internationally.

- Undertake education and information campaigns on savings and finance at community level

\subsubsection{Trade}

Lesotho has a very small domestic market and has to pursue an outward oriented strategy and utilise opportunities in regional and international markets, such as SACU, SADC, the US through AGOA, the EU through EPA and EFTA. In order to take advantage of the opportunities for trade, particularly exports, Lesotho has to increase productive capacity by removing the binding supply-side constraints for the main growth sectors, which are manufacturing, mining, agriculture and tourism. Securing and/or maintaining favourable trading arrangements will also be critical. In addition to trade in goods, Lesotho has the opportunity to strengthen trade in services in tourism and exporting services in mining, agriculture, education and other professional business services including call centres. Constraints to import and export of these services need to be addressed through the negotiation with other countries and review of our own immigration, labour and employment policies and laws.

Requisite infrastructure and related services such as freight, clearing services, certification plus trade finance services are also required to reduce time and cost to markets. Negotiating for the removal (or at least the reduction) of tariff and non-tariff barriers to trade in key/potential export markets is essential. The creation of SQUAM infrastructure and reduction of time and costs in dealing with import/export permits in the region and with other key and 
potential export markets remains critical. The other important ingredients include institutional strengthening of the private sector organisations, trade development and promotion, building a favourable business environment to unlock local entrepreneurial potential and attract FDI.

The improvement of internal trade efficiency through the development of requisite infrastructure, development of intermediaries to strengthen linkages between the city, towns and rural areas and the rest of the world is also necessary.

\section{Strategic objectives and actions}

- Enhance productive capacity and exports

- Implement programmes for expansion and diversification under manufacturing, mining, agriculture and tourism and other services

- Promote cooperatives and associations and improve their coordination and management capacity

- Develop commodity/industry specific production and export strategies

- Develop trade financing mechanisms and promote safe payment settlement systems

- Develop minimum infrastructure platform to facilitate internal and external trade

\section{- Diversify and improve market access}

- Negotiate and/or seek further market access agreements with more favourable conditions

- Adapt SADC standards to ease market access through harmonisation of standards 
- Improve the processing of import and export permits for trading with RSA and other markets, especially for fresh produce

- Develop national standards framework and establish a Bureau of Standards

\section{- Strengthen investment and trade promotion}

- Review and/or develop and implement trade promotion strategy

- Review, improve and implement investment promotion strategy, including use of e-solutions

\section{- Promote consumer protection}

- Review and develop appropriate legislative framework for consumer protection

- Establish appropriate institutional framework for dealing with consumer protection, complaints and education, including Small Claims court

\section{- Strengthen trade institutions capacity and efficiency}

- Develop policy frameworks, including a consolidated trade policy and a quality and standards policy and related laws

- Develop sustainable capacity building programmes for trade policy analysis and trade negotiations

- Restructure and/or improve capacity of the business development support institutions to enhance service delivery and institute mechanisms for improved coordination

- Establish industrial clusters to facilitate adoption of appropriate technology for industrialisation and improve quality of services 
- Strengthen private sector associations (e.g. chambers of commerce, private sector foundation, business council) to participate effectively in policy development and to provide advisory business and other services

- Put information on trademarks and Intellectual Property Rights in the public domain

\subsubsection{Agriculture and the Rural Economy}

Although the contribution of agriculture to GDP has declined over time, from around $20 \%$ thirty years ago to around $8 \%$ now, it still remains an important sector for increasing employment and rural incomes. The crops and livestock sector contribute $2.3 \%$ and $4.1 \%$ to GDP respectively.

The main crops produced are maize, sorghum and wheat which occupy about $60 \%, 20 \%$ and $10 \%$ of the agricultural land respectively. Around 25,000 ha of land is irrigable, but only a small percentage is used for irrigated crop production. More than $70 \%$ of grains are imported. The livestock sector is dominated by sheep and goats which are kept mainly for wool and mohair, which are also the main agricultural export products. Large stock constitutes cattle, horses and donkeys. Poultry, piggery and rabbitry are also important sources of income, especially for women. Lesotho is also among countries that produce the best trout but fisheries industry is very small. The high level of food imports suggests that Lesotho is facing a supply-side problem rather than a demand-side problem.

The farming community faces several constraints which inhibit output growth: limited access to finance, agricultural inputs, technology, quality extension services, marketing information; poor market organisation and integration due to poorly developed supply chains and limited capacity to deal with agricultural risks. Moreover high soil infertility contributes to low crop yields and large 
areas of unused and fallow land. High livestock theft has also affected the crop farming systems and rural wealth, which had already suffered due to declining number of households that receive remittances that were used to finance agriculture. The impact of HIV and AIDS on the sector has also been detrimental with loss of adult manpower that leaves orphans and/or widows that do not have the resources to sustain production. The land tenure system also does not create incentives to reduce inefficiency or underutilisation of land, though it is a limited asset. Furthermore, large parcels of agricultural land have already been unduly converted into human settlements.

Crop production is largely rain-fed and since Lesotho is increasingly susceptible to extreme weather variability, which results in prolonged drought, floods, early and late frosts, production is highly erratic. This also affects livestock productivity through the deterioration of the already fragile rangelands and diseases. Therefore, building resilience to climate change is necessary to ensure the long-term security of agricultural production.

The Government will pursue the following strategic objectives and associated interventions to realise sustainable agricultural growth that will contribute towards food security and poverty reduction:

\section{$\underline{\text { Strategic objectives and actions }}$}

\section{Promote sustainable Commercialisation and diversification in agriculture}

\section{- Improve access to finance}

- Provide support services to farmers to prepare bankable projects and to facilitate access to the Partial Credit Guarantee Scheme and matching grants facility supported by IFAD and other facilities

- Strengthen capacity of agricultural finance institutions (cooperatives and credit unions) 
- Improve quality livestock breeding capacity

- Develop a cadre of certified livestock breeders and use of livestock improvement centres and other facilities to increase the capacity to produce quality breeds for wool and mohair, poultry, piggery and other livestock industries

- Promote artificial insemination services in viable areas

- Improve access to farm machinery and quality inputs through the development of viable distribution and marketing systems

- Explore options for the development of a viable agricultural inputs distribution and marketing system

- Promote contract farming/out-grower schemes with integrated input and output markets

- Evaluate the programme of procurement and on-lending of tractor and irrigation equipment to eligible farmers and implement the recommendations

- Develop capacity for commercial seed production, export and promote investment in related infrastructure

- Establish an appropriate national seed bank

- Develop water harvesting infrastructure and increase irrigation capacity

- Identify land and declare as selected agricultural land (SAA) for irrigation development

- Develop dams and/or channels from large dams to make water accessible for irrigation in a cost-effective manner 
- Promote and facilitate the establishment of small gravity-fed irrigation schemes

- Develop viable irrigation schemes models

- Finalise irrigation policy, including the development of strategies to increase the efficient use of irrigable land

- Increase the production of high value crops and livestock products

- Identify niche markets, undertake comprehensive commodity systems analysis and develop production and marketing and/or export strategies and plans

- Strengthen production and marketing support units to identify and promote use of appropriate agricultural technologies for the development of high value-commodity systems and to promote private sector investment

- Promote block farming for commercial grain production, horticulture and other high-value crops

- Strengthen marketing information infrastructure and link to regional and international networks

- Strengthen capacity to undertake marketing research and to establish effective dissemination mechanisms

- Increase value-addition and market integration through investment in agro industry and development of agri-business

- Undertake comprehensive quantitative value chain analysis and promote investment across value chains 
- Increase the capacity of Lesotho Produce Marketing Services (LPMS) to provide technical marketing operations support and small agroprocessing industrial design and support

- Divest or outsource the management of the remaining commercial public agricultural enterprises

- Develop a programme targeted at small-medium scale agro-processing, distribution and marketing at community level

- Develop public marketing infrastructure and appropriate management arrangements, including access roads, market centres and slaughter houses

- Promote agri-business development to facilitate marketing of agricultural produce

\section{Strengthen capacity of farmers and institutions}

- Enhance agricultural institutions and capacity of farmers through effective training and transformation of extension services

- Review the land tenure system from the agricultural perspective and introduce measures to increase productive use and reduce the deterioration of agricultural and rangelands

- Review and transform the current extension system to facilitate commercialization and diversification

- Outsource extension and training services in some areas on a pilot basis

- Develop more effective and specialised curricula for farmers and extension staff to support commercial agriculture 
- Rehabilitate Farmers Training Centres and improve/outsource management

- Strengthen capacity of agricultural groups in production and agribusiness development as well as offering services that attract and maintain membership

\section{- Improve capacity and relevance of agricultural research and training}

- Improve agricultural research capacity (infrastructure, equipment etc.) to increase the identification and adaptation of new and effective technologies

- Develop an integrated land and water management policy and framework

- Review the agriculture research system with a view to improve coordination and alignment with the strategic priorities of the sector

- Review the agricultural education system and make it more responsive to national needs

- Strengthen linkages between Lesotho Agricultural College and Faculty of Agriculture and the sector

- Strengthen young farmers' programmes

- Review curriculum and explore the need to introduce 3-6 months intensive programmes targeted at potential lead and young famers

\section{Enhance capacity and systems for policy analysis and planning}

- Develop efficient systems for data generation and enhance capacity for monitoring and evaluation at different levels

- Review agricultural land use plans 
- Update and develop sub-sector policies and corresponding legislation (e.g. irrigation policy, livestock policy and phyto-sanitary frameworks)

- Undertake regular public expenditure reviews

- Establish inter-ministerial coordination mechanisms

\section{Reduce Vulnerability and Manage Risk}

- Improve household food security

- Promote conservation farming

- Promote community gardens

- Provide training for food preservation, storage, processing and preparation at community level

- Support and promote animal exchange programmes

- Promote orchard development and diversification

- Reduce stock theft and increase recovery

- Identify other strategies as options or to complement livestock registration and marking (microchip)

- Intensify cross-border collaboration

- Strengthen capacity of police services/stock theft unit, including access to helicopter services and links with community policing

\section{- Maintain animal and plant health}

- Rehabilitate dipping facilities and improve collection of levy

- Introduce and train para-veterinary staff

- Strengthen border inspection of imported animals and plants for safety of people and ensure that banned species do not enter/leave the country 
- Climate change proof the agricultural sector

- Develop and implement "climate screening guidelines" for the agriculture sector to identify and mitigate risks and exploit opportunities posed by climate change

- Improve capacity of agro-meteorology and communication with the farming community

- Ensure that the agricultural research agenda addresses climate change issues and generates recommendations to enhance resilience, including increased water capture and storage for irrigation, introduction of improved drought resistant seed varieties, improved dual purpose chicken and livestock with tolerance of climate extremes and climate change adapted cropping patterns

\section{- Reduce Market Risks}

- Explore the use of futures markets by the private sector to manage price volatility and encourage its use where feasible

- Identify options for agricultural insurance products

- Evaluate options to establish food reserves for food security and price management

- Promote integrated and sustainable development in rural areas

- Develop basic infrastructure to increase access to services and markets and strengthen linkages between rural and urban markets

- Promote integrated planning to establish linkages between agriculture and other sectors such as tourism, mining and small-scale manufacturing 
- Develop appropriate PPPs and regulatory frameworks to increase private initiatives where public goods and/or essential services and products are not accessible

- Enhance incentives and ICT based solutions to ensure placement and access to qualified personnel to provide services in rural areas

- Review human settlement policy to reduce isolation and cost of providing services while protecting cultural and other rights

- Promote the preservation of culture and beneficial traditional systems

\subsubsection{Manufacturing}

Employment in the Manufacturing Sector, which is mostly women, has increased dramatically over the past six years, from 39,762 in 2005 to 45,262 in 2008 and fluctuating around 43,000 in 2010. Most of these jobs result from foreign direct investment (FDI). The garments industry achieved very rapid growth up until 2004 through exports to the USA under AGOA but dropped in 2005 due to adverse exchange rate movements and increasing competition due to declining trade preferences in the US market. The greatest downturn was experienced in recent years due to the global financial and economic crisis. Textiles and Clothing contribute about $45 \%$ of total exports.

The manufacturing sector is severely affected by the inadequate industrial infrastructure, long lead times and high costs in exporting, erosion of preferences, and insufficient backward integration and limited product and market diversification. The net contribution (value-added) of the clothing sector to GDP, since it is CMT is small as the major part of the inputs are imported. This calls for more backward integration of the textiles sector. 
There is considerable potential to expand export-led growth in labourintensive manufacturing and assembly for the SACU/SADC market by building on our regional comparative advantage in labour and access to markets. Setting a supportive trade policy environment is an important element of this strategy. The objective is to utilise existing agreements, principally SACU and SADC and AGOA, EPAs, EFTA and others, which offer trade preferences temporary, to attract foreign direct investment and to diversifying markets.

The 2010 Land Act prevents foreigners from owning land outright. Instead, they must satisfy a local partnership requirement, which the Act reduced from $51 \%$ to $20 \%$. LNDC performs the role of partner by building factory shells which are then provided to foreign investors at a subsidised monthly rent. New factory shells require capital expenditure by Government ${ }^{26}$. There is a shortfall of space for potential investors and private firms cannot invest in factory shells since they are unable to secure land and/or compete with public subsidies. The Government is currently considering the costs and benefits of several options that could overcome the land and infrastructure problems that constrain FDI. The options to consider include allocation of resources from the capital budget for the provision of industrial infrastructure ${ }^{27}$ and instigating legal changes that would allow FDI to be invested directly in factory shells, within the confines of designated industrial zones.

Given that there are limited resources, the Government will identify and stimulate development in a few geographical rings/centres by causing an

LNDC cannot profitably finance the construction of factory shells as rents are subsidised through a rent ceiling set by MTICM. LNDC rents of $\mathrm{M} 10 / \mathrm{m} 2$ per month are substantially lower than the commercial alternatives. This results in an implicit annual subsidy which is the equivalent of $\mathrm{M} 1,400$ per worker (in the textiles subsector) and M6,000 per worker (in other manufacturing).

27 The cost of providing factory shells and associated transport and infrastructure is approximately $M$ 350 million for every 10,000 jobs to be created.
} 
expansion or progressive concentration of new activities. The objective is to facilitate concentration of related skills, building of networks and partnerships as well as attracting capital resources that will lead to the development of special economic zones and/or industrial hubs. These growth poles will require additional investments in infrastructure. It will be important to ensure that there are direct links between the established urban rings/growth poles with the agrarian economy and vice versa.

In order to improve productivity the Government will also ensure that there is support for Apparel Lesotho Alliance to Fight AIDS (ALAFA) programmes with extension to other industries and on-site clinics in mitigating the effects of HIV and AIDS on industrial workers.

\section{Strategic objectives and actions}

- Maintain the textiles hub by sustaining and increasing exports

- Identify niche markets and develop innovative linkage programmes to improve backward and forward linkages in the textiles sector

- Promote investment in the production of garments inputs

- Upgrade the textiles curriculum at Skills Development Centres to provide a full range of relevant factory floor skills;

- Integrate textile skills development needs in the vocational curriculum of Lerotholi Polytechnic and similar institutions;

\section{- Expand industrial infrastructure}

- In the short-term, fast-track ongoing building of factory shells and related industrial infrastructure

- For the long-term, prepare an industrial infrastructure development strategy including evaluation of legal changes that would allow FDI to 
invest directly in factory shells with $100 \%$ land ownership, within the confines of industrial zones

- Expedite provision of adequate utilities to industrial sites/estates/zones (electricity, water, ICT, waste disposal and management facilities, including roads)

- Upgrade and/or develop key infrastructure for trade facilitation including the dry port/refurbishment of Maseru Container Terminal, one-stop border posts and upgrading national roads and access roads to production sites

- Engage in bilateral talks with RSA to explore options for speeding up shipments in Durban and other ports

- Streamline import and export procedures and upgrade customs processing and clearance facilities to enable high speed cross-border transit

- Develop industrial clusters to diversify products and develop integrated supply chains

- Identify priority industries (e.g. furniture, leather, electronics, food processing) and areas of competitive advantage and develop industrial integration strategies and plans

- Promote investment into new high-tech/high-value products and agroprocessing

- Develop an incentives framework to encourage R\&D

- Increase local participation in manufacturing

- Provide information on manufacturing opportunities and markets 
- Establish industrial engineering and technology support services

- Explore options and develop a programme to facilitate linkages between MSMEs and large industry on a pilot basis

\subsubsection{Tourism}

Lesotho sits like a pearl in a shell - South Africa. Her formidable terrain is created by the sheer walls of the Maloti Mountains and the Drakensburg. This rugged country, with its majestic beauty and serene simplicity offers a very different tourism experience, rarely found in more commercialized destinations. The potential of the tourism sector lies in its natural beauty, rich flora and fauna, and absorbing prehistoric and cultural heritage. Mountains, valleys, and rivers provide memorable scenery for tourists. This is where the 'Kingdom in the sky' gets its crystal clear water. It is also a haven for back to nature adventures.

Lesotho has great potential for the development of a viable and strong tourism industry. Although there has been a substantial increase in the supply of accommodation over the last ten years (the number of establishments rose from 44 to $144^{28}$, and the number of beds almost doubled from 2,466 to $4,791)$, tourist arrivals increased by only $12 \%$ between 2000 and 2009 . This annual growth rate of $1.4 \%$ was slower than that of the economy as a whole, and has resulted in low bed-occupancy rates. ${ }^{29}$

Infrastructure remains the biggest challenge for tourism development. The existing accommodation facilities and attractions are not linked and there is no basic infrastructure on sites that have been identified for tourism investment.

A large number of these were Guesthouses and B\&Bs in the Maseru urban area.

The average bed occupancy rate was only $17.9 \%$ in 2009 .
} 
A national tourism marketing strategy that identifies Lesotho's unique sellingpoint and creates a distinctive brand to attract tourists in a number of niche areas - exploring traditional culture, pony-trekking, off-road biking, and others needs to be developed.

There is also limited protection of the rich cultural heritage from destruction, especially the physical assets, which threatens their existence for future generations to also inherit. Disparate efforts in packaging this product also limit the use of the product for viable tourism exploitation (museum, craft centres and theatres). Promotion and celebration of culture through spectacular events needs to be encouraged and developed, which also serves to unite the nation and infuse the experience of other cultures.

The main goal is to increase the number of tourist arrivals and spending in the country. Cooperation with SA tour operators could increase the number of international tourists who visit Lesotho as an 'add-on' destination. Tourism has been identified as one of the key sectors to drive growth and employment because of its labour-intensive nature and its potential to raise income in rural areas. It is necessary to find ways to develop tourism industry and encourage further private sector participation.

\section{$\underline{\text { Strategic objectives and actions }}$}

\section{- Develop tourism products and circuits to their full potential}

- Identify and develop tourism-related infrastructure to create circular routes linking tourism attractions and facilities

- Identify sites for tourism investment and declare as special development areas (SDAs) 
- Undertake research and create a platform for generating tourism innovations, especially for product development and investment promotion in line with the brand to be developed

- Develop strategies for increased participation of local communities within the tourism value-chain

- Develop comprehensive plans for amenities to complement the tourism product and invite private sector participation

- Protect, conserve and manage cultural heritage resources

- Develop a strategy for culture protection, conservation and effective use as a means of livelihood

- Identify, document and protect heritage sites and ecotourism destinations and facilitate the repatriation of objects of national significance

- Develop soft and hard infrastructure for conservation, preservation and proper management of heritage assets, including museums, archives and the use of relevant ICT platforms

- Promote documentation through art, writing, film and others and support the development of arts and crafts industry through creating platforms for innovation, product development and marketing

- Develop a programme for palaeontology and archaeology

\section{- Improve quality and standard of service}

- Implement accommodation star grading system

- In partnership with the private sector and institutions of higher learning, design an appropriate curriculum and delivery modalities for relevant 
sectoral skills development (tour guides, product development, marketing, etc.)

- Promote a culture of hospitality among the Basotho

- Facilitate quality service at the border posts

- Devise strategies for developing a more vibrant food and dining industry and other recreational activities

- Improve marketability and visibility of Lesotho as a destination of choice

- Develop a unique brand that will differentiate Lesotho from other destinations

- Establish tourist information centres and services at strategic locations

- Develop a marketing strategy and pursue it aggressively

- Forge linkages with tour operators in RSA and the Region

- Improve institutional framework and regulations

- Explore ways of easing visa application, processing, requirements where necessary and issuance to facilitate access into Lesotho for those eligible

- Develop a system for data collection to improve reliability and timeliness

- Update licensing procedures to create a regulatory environment conducive to investment (e.g. shorten the licence application processes)

- Review the institutional framework and skills mix in key institutions to strengthen capacity to support the tourism industry

- Strengthen capacity for event tourism promotion and management

- Review the legal frameworks to accommodate the required developments, including regulations that will give effect to the National Heritage Resource Act 2011 


\subsubsection{Mining}

The diamond mining industry has experienced strong growth over the last decade, its share of GDP increasing from $0.2 \%$ in 2000 to $7.3 \%$ in $2009 / 10$. The sector contributes significantly towards tax revenues and export earnings. However, the industry is very capital intensive and, despite substantial investment, the companies themselves will not significantly increase employment over the Plan period (approximately 1,500 additional jobs, double existing numbers), although the indirect increase in demand for goods and services should mean that there will be total additional employment of around 5,300. Diamonds could also create additional employment if private sector companies diversify downstream to turn Lesotho into an African jewellery hub. Average household income is expected to increase in line with employment and will be approximately M 970 higher by 2016/17.

Growth in mining is driven by the private sector and the main challenges for Government will be ensuring that the industry does not experience any unnecessary regulatory problems and to increase the skills base. Furthermore, impediments to the importation of unavailable skills should be removed.

There is a need to develop a consolidated mining policy and review legal frameworks including the development of mining tax code and adapting best international practices to enhance consonance with other policies such as Land use planning. It is also important to improve systems of authorisation for exploration and extraction as well as instituting measures to ensure due consideration of technical, social and environmental factors and augment mineral resource intelligence. 
Therefore, the Government will address issues related to geological information, value-addition, skills development and import, infrastructure (especially energy), trade and environment.

\section{Strategic objectives and actions}

- Provide information on natural resources wealth

- Complete geological mapping

- Develop database and website

- Improve the policy framework to address emerging issues and adopt best practices

- Prepare a consolidated policy, including alluvial mining to clarify key policy areas and adopt best practices including charges and taxation, labour, safety and security, domestic access and environmental sustainability

- Review the legal frameworks accordingly

- Promote value addition and marketing of mining products

- Facilitate the development of effective intermediaries for the local and international marketing of mined products, especially sandstone

- Promote investment in downstream industries (cutting, polishing and jewellery manufacturing for diamonds, and higher value alternative products for clay, sandstone and others)

- Improve mining companies access to infrastructure

- Explore options for improving access of mining companies to clean and cost effective energy

- Build and rehabilitate national roads in areas with major mineral sites 
- Explore use of carbon trading financing facilities for the sector

- Develop the necessary skills base

- Facilitate development of skills in which the industry has current or projected shortages

\section{- Enhance investment promotion and local participation/ownership}

- Develop mining investment promotion strategy

- Facilitate the establishment of vehicles for domestic private participation

\subsubsection{Micro, Small and Medium Enterprises (MSMEs)}

The estimated number of MSMEs operating in Lesotho is 100,000 with employment of over 300,000 people, including those in subsistence agriculture. MSMEs have great potential to contribute to Lesotho's economic growth, employment creation and poverty alleviation particularly youth employment. Development of a vibrant private sector and growth of MSMEs are hindered by inadequacies in: technical, management and entrepreneurial skills, competitiveness, access to appropriate infrastructure, poor regulatory framework and limited access to finance, markets and information. This results in stunting and low survival rates, poor quality of services and products.

The proposed reforms and interventions are expected to enhance the creativity of domestic entrepreneurs and to improve the efficiency with which they produce goods and services. This will have a big impact on employment and will encourage some self-employed people to make the transition from the informal cash-less sector to the more productive formal sector with better prospects and work conditions. Interventions to improve industry-specific skills are addressed in Section 5.9 (Skills and Technology and Innovation). 


\section{$\underline{\text { Strategic objectives and actions }}$}

- Improve entrepreneurship capacity

- Improve entrepreneurship training, business counselling, mentorship and incubation programmes, and accredit business development service providers

- Integrate entrepreneurship curriculum at secondary level in all schools and enhance teachers' skills

- Strengthen entrepreneurship capacity of youth groups, cooperatives and private sector associations

\section{- Improve competitiveness and productivity}

- Facilitate the establishment of industrial clusters and the development of supply and marketing intermediaries in order to improve logistical support and increase local value-addition

- Develop systems and services for quality management including certification of products and business processes and strengthen Government's institutional capacity to provide advisory services

- Establish enterprise and industrial development units to support MSMEs in industrial design and development

- Undertake enterprise audits and provide enterprise-specific technical and business management training

- Develop MSMEs related infrastructure and improve access to technology

- Reform the regulatory environment to make it easier to formalise MSMEs 
- Provide MSME property solutions including improvement (with necessary utilities and storage facilities) of market centres in all districts

- Establish technology hubs and industrial parks to facilitate linkages within the value chain and improve access to markets

- Create an information centre with web-based information dissemination solution

- Develop policy to promote research and development by industry

- Review intellectual property rights (IPRs) legislation to protect innovations/IPRs

\subsection{Develop Key Infrastructure}

Prospects for economic growth are maximised if the nation has a comprehensive network of high-quality infrastructure. Improvements in Lesotho's basic infrastructure and utility services are essential in order to ensure adequate market access, trade and enable key industries, such as agriculture, tourism, mining and manufacturing to achieve sustainable growth. Thus, we must invest in developing and maintaining good physical infrastructure, including Transport, Water and Sanitation, Energy, Information, Communications and Technology (ICT), Housing and Sports.

The benefits of physical infrastructure are only realised if there is integrated planning and the network of assets receive adequate recurrent resources to allow them to be properly operated and maintained and maximise opportunities for integration of physical infrastructure (ICT, Water and/or energy). New investments in infrastructure will be prioritized to high-growth, high-potential areas on the basis of greatest contribution to our growth objectives. Funds will be allocated on a multi-year basis to ensure that assets 
are not only acquired but also maintained. Project selection and design will focus on achieving value-for-money, equity, environmental protection, economic diversification and security.

\subsubsection{Transport}

The transport system in Lesotho is dominated by road transport as the main mode of transport and transport services are predominantly provided by private sector operators. Road transport is complemented by international rail and air transport services, and domestically by ferry services at river crossings, animal transport and pedestrian travel, especially in the less developed and sparsely populated mountainous areas. The over-arching strategic goal is to develop an integrated transport system.

The Ministry of Public Works and Transport is responsible for most infrastructure provision and maintenance and for creating the necessary enabling environment for the private sector to provide efficient, cost-effective and safe transport services within Lesotho, regionally and internationally. A strong transport system contributes to sustainable growth of the economy, the provision of social services and the welfare of the general population. The over-arching objective is to develop well-planned, efficient and integrated transport system. Lesotho's transport infrastructure consists of:

- A road network of 7,437 km, $16 \%$ of which are paved, $51 \%$ are gravel and $33 \%$ are earth and other forms of roads

- The Moshoeshoe I International Airport near Maseru and 12 operational airstrips throughout the country

- A $2.5 \mathrm{~km}$ railway line from Maseru industrial area to the Maseru Bridge border 
- A network of footpaths, including 221 footbridges providing river crossings particularly in the highland areas

Although the lowlands of Lesotho are relatively well served with the existing road network, about $25 \%$ of the population live in the mountains, with poor access to basic services and commodities, as well as limited market opportunities. Government will continue to provide infrastructure but will also encourage private sector participation in terms of commercial contracting and service provision.

Most public passenger transport services are provided by the private taxi and bus transport industries. However Government is responsible for two transport services:

a. Lesotho Freight and Bus Services Corporation, responsible for a very small percentage of public road passenger transport services, mainly in areas and on routes where volumes are low and the private sector is unable to provide profitable services

b. Approximately 44 ferryboats at river crossings owned and operated by MOPWT

\section{$\underline{\text { Strategic objectives and actions }}$}

- Improve access to main towns and key border posts

- Maintain and improve major national corridors that link main towns and key border posts

- Improve border crossing by creating high speed transit/one-stop border posts to link Lesotho to RSA and the rest of the world

- Develop a dry port (cargo handling facility and the railway station) 
- Explore the possibility of establishing a Lesotho hub/commercial presence at one of the RSA ports

- Improve and develop integrated rural and urban transportation systems

- Develop and maintain access roads in rural and urban areas

- Promote efficient labour intensive construction projects

- Develop policy and relevant legislation (e.g. standards) for water transport

- Promote private participation in water transport

- Explore different financing strategies to accelerate road infrastructure development and options for increasing revenue

- Undertake futures analysis to prevent congestion especially in major towns and reduce pollution and inform town planning

- Develop plans for integrated/inter-modal transport system, including well developed bus stations and/or inter-changes

- Explore options for improving public transport system

- Improve transport safety and reduce road accidents

- Assess the quality and safety level and of existing infrastructure and upgrade infrastructure and standards

- Install quality road safety furniture (e.g. roads signs)

- Improve and enforce speed and drink and driving regulations

- Improve air transport competition, efficiency and coverage

- Attract other airline operators and explore possibility of creating a regional hub 
- Upgrade Moshoeshoe I international Airport in line with the planned developments in air transport in Lesotho

- Rehabilitate selected strategic airstrips

- Revitalize air cargo facility project through cooperation with RSA and other members

\subsubsection{Water and Sanitation}

Water is Lesotho's most important natural resource as it lies in the wetter and uppermost part of three main river systems - the Senqu, Mohokare/Caledon and Makhaleng. Completion of Phase IA of the Lesotho Highlands Water Project (LHWP) in the mid-1990s and Phase IB in the early 2000s involved substantial construction activity and generated royalties. ${ }^{30}$ Lesotho was able to install hydroelectric generating plant at 'Muela and this satisfies most of the current electricity demand.

Around $77 \%$ of households have access to improved water sources and only $25 \%$ have access to improved sanitation. However, severe water access problems are experienced in the lowlands where about two thirds of the population live. Provision of water and sanitation infrastructure remains crucial to exploit our economic potential and prevent water borne diseases. Currently, improved supplies are essential, particularly to Maseru and its surrounding areas, where most textiles and light manufacturing are based in order to sustain the continued contribution of export industries (principally textiles). The growth of the garment industry has stimulated an increase in urban migration and the urban population has been growing rapidly, creating

30 LHWP is a complex programme of engineering works that transfers water that would otherwise flow down the Orange River into South Africa into the Vaal catchment area, where is can be used more productively 
additional demands for reliable residential supplies. Metolong Dam and Water Supply Programme (MDWSP) were identified as the least-cost, long-term solution for bulk supply to Maseru and the surrounding lowlands areas. This will make available $75,000 \mathrm{~m}^{3}$ of treated water per day by 2014 , enabling Maseru to meet domestic and industrial requirements for at least the next 40 years. Additional investments to the residential distribution network will also be needed to accommodate new households in peri-urban areas. There is need to promote investment in water related economic activities which include irrigation projects, fisheries, water sports and bottling.

\section{$\underline{\text { Strategic objectives and actions }}$}

- Expand water and sanitation distribution services to industries, commercial centres, households and other institutions

- Develop water infrastructure for communities that have no access to water, including installation of communal taps and protection of the wells

- Develop financing instruments to fast-track the connectivity of water and sanitation infrastructure to industry, commercial centres and households in rural and urban areas

- Enforce standards for construction of Ventilated Improved Pit latrines (VIP) and treatment of industrial waste and other effluent

- Build main lines for sanitation infrastructure for connection by industries, commercial centres, households and other institutions

- Facilitate and/or develop pre-treatment and wastewater recycling infrastructure for industries and domestic sources 
- Review the institutional framework to improve coordination and accountability (Rural Water Supply, WASCO, Ministry of Natural Resources and other agencies)

\section{- Expand water harvesting infrastructure}

- Build water harvesting infrastructure including LHWP and lowlands bulk water supply projects

- Facilitate the development of household and community level water harvesting infrastructure for irrigation, fisheries and others

\subsubsection{Energy}

Lesotho generates 72 Megawatts (MW) from Muela hydropower station and imports about $67 \mathrm{MW}, 40 \mathrm{MW}$ from Mozambique and $27 \mathrm{MW}$ from South Africa. Household access to electricity is estimated at $20 \%$ and concentrated in the lowlands and Senqu river valley. $77 \%$ of Basotho use biomass as the main source of energy.

The energy sector will be an important growth driver, if investment can be mobilised to tap the established potential of about 6,000 MW of wind power and 4,000MW of pumped storage plus $80 \mathrm{MW}$ of conventional hydropower. This presents a great opportunity to export electricity in the region, increase energy security and reduce imports of alternative sources of energy which should be coupled with the promotion of electricity use in sectors that require high consumption of fuel, such as transport.

Innovative solutions are required to accelerate connectivity to commercial centres and households. Furthermore, the use of bio-fuels will not decline significantly in the medium-term, therefore, afforestation and diffusion of 
appropriate technology for use of bio-fuels needs to improve. There is also room to improve energy efficiency and conservation.

\section{Strategic objectives and actions}

- Increase clean energy production capacity to attain self-sufficiency and export

- Evaluate renewable power generation options and negotiate financing arrangements to expand national generation capacity

- Explore opportunities and negotiate regional power pool linkages

- Develop small-scale electricity generation models that are viable for communities, where connection to the national power grid is not costeffective

- Expand electricity access to industry, commercial centres, households and other institutions

- Maintain the existing power generation infrastructure.

- Extend transmission and distribution networks and increase connectivity rates through community initiatives and by reviewing the tariff policy and terms for connections

- Evaluate the rural electrification programme for technical and cost efficiency and implement recommendations

- Increase energy conservation, security and distribution efficiency of alternative sources

- Raise awareness and promote use of energy efficient technology

- Develop and disseminate guidelines for specific industries and types of firms to increase energy conservation/efficiency 
- Promote appropriate technology for bio-fuel use

- Promote forest/tree planting and regeneration of other important biofuel species

- Undertake research to assess market and distribution efficiency of other sources of energy

- Develop and implement medium - long-term energy security strategy, including alignment with land and mining rehabilitation policy

- Promote research in solar and other potential niche energy markets

\subsubsection{Information and Communications Technology (ICT)}

ICT can play a great role in increasing competitiveness of a country through increased efficiency in the production processes (reduction of transaction costs) and improving access to information, markets and facilitating the establishment of global social networks. ICT can also be used to improve coverage and efficiency of service provision such as in health, education and general trade in services (e-commerce).

For the ICT sector to develop and for a country to realise the benefits, an appropriate ecosystem and infrastructure should be developed. The ecosystem includes competitive business/investment environment, competitive and/or contestability of markets through appropriate legal framework and reduced burden of regulation and capacity for knowledge assimilation and generation as well as innovation development. ICT Infrastructure comprises the requisite connectivity infrastructure and international access, significant density of computers, telephones and mobiles and electricity connections. For Lesotho to benefit fully from the infrastructure developed, the required technical skills and systems to manage the infrastructure should be developed. 
Access to high-speed broadband communication technology can transform the way services are delivered. Potential cost savings in health, education, energy and transport can justify investment in broadband networks. Lesotho has signed up to the East and Southern African Optic Submarine Cable System project, which will provide access to broadband infrastructure that allows cost competitive, high speed downloads and uploads of digital content. Access to high-speed digital subscriber line (DSL) broadband is currently constrained by limited fixed line infrastructure. In addition, limited bandwidth, which is the range of frequencies with which voice, data and internet traffic is transmitted, inhibits internet usage and uptake and consequently delays developments in electronic services. Broadband expansion is therefore likely to involve wireless technologies such as WLAN (wireless local area networks) and WiMAX (Worldwide Interoperability for Microwave Access), which implies leapfrogging traditional access technology. Currently, internet bandwidth is sourced from RSA and there are six internet service providers in Lesotho.

The key issues are: building primary infrastructure to access high speed broad band, increasing cost competitiveness of services, improving computer and internet connectivity to diversify and increase coverage of e-services, development of requisite capacities including ICT literacy, capacity for regulation and policy development and skills to develop innovations and provide services required by both the private and public sector and addressing cyber-security issues.

\section{$\underline{\text { Strategic objectives and actions }}$}

- Improve ICT infrastructure and access

- Facilitate connectivity to the East and Southern African Optic Submarine Cable System 
- Identify options for reconstitution of national backbone ICT infrastructure

- Promote investment to facilitate installation of advanced communications networks to make voice and data distribution services accessible across the country

- Facilitate infrastructure sharing among network operators so as to optimise scarce resources

- Identify and implement measures to enhance competition in the ICT sector so as to increase customer choice, quality and competitive pricing of services

- Facilitate use of ICT and widen ICT literacy

- Develop ICT roll out strategy and plan for schools and informal education programmes and facilitate implementation

- Create community education and information programmes

- Improve coverage and quality of postal services with integration of ICT services

- Promote integrated private service provision (e.g. internet shops), especially in remote areas

- Undertake market research to identify new solutions in banking, health, public service delivery and promote and/or facilitate their adoption

- Promote innovation and develop niche ICT sub-sectors

- Undertake industrial competitive analysis, regulatory review and develop a national ICT industry development strategy and plan 
- Develop research and development agenda and strategy to promote research in the ICT sector (align with Skills and Innovation section)

- Facilitate smooth migration from analogue to digital

- Install appropriate technology

- Develop and implement public education programmes

- Improve cyber security

- Develop cyber security strategy and programme for surveillance

- Enhance e-Government services

- Consolidate/update e-Government strategy, including, alignment at central and local level

- Undertake institutional review and improvement to facilitate accelerated and efficient implementation of the e-Government strategy

- Develop implementation plan and multi-year budget

\subsubsection{Shelter and Property Development}

Overtime, significant spatial developments are noticeable in Lesotho especially in Maseru and the main towns. The construction of rural roads and bridges has also opened up areas that were isolated and difficult to reach. The collage of schools, hospitals and retail services has changed the rural and per-urban landscape.

In terms of housing, owner occupied dwellings dominate the sector. Real estate accounts for about $9 \%$ of GDP, though annual growth is just above $1 \%$. This suggests that housing and other property development is not growing rapidly. 
However, rapid urbanization and inadequate capability to cope with the increasing housing needs in urban areas have contributed to the development of informal settlements and/or unsafe human habitats. Living in these settlements often poses significant health risks due to poor quality of drinking water and sanitation, cooking and heating facilities that lead to excessive exposures to indoor pollution and overcrowding that can contribute to stress, violence and other social ills. Industrial sites are quickly encroached by human settlements and there is shortage of office space. Marketing infrastructure is also underdeveloped leading in friction between the vendors and the related law enforcement agencies.

Problems that need to be addressed include, access to finance or promotion of housing and property development solutions that enable households and entrepreneurs to own or rent at acceptable terms, regularised and/or law enforcement of property rental markets, especially to ensure safety and orderliness, improved access to basic services such as, water, sanitation, roads, and education and health services especially in rural areas, recreation facilities and other services as well as security of tenure. There are some vulnerable groups including those in slums/squatter settlements, elderly and OVCs and the poor that need to be assisted to live in decent dwellings. There is also need to reduce urban sprawl.

Further expansion of the sector has potential to increase job creation in both construction and materials production. Property can serve as collateral for households seeking financial assistance to establish business ventures which can help alleviate poverty. Alignment of physical and economic medium to long-term plans is also critical. 


\section{Strategic objectives and actions}

- Improve and develop well-planned and serviced human settlements

- Identify appropriate and cost-effective ways of re-planning and accelerating integrated infrastructure roll-out to human settlements

- Develop a national land-use plan and implementation strategy

- Promote urban densification both by reducing the average size of plots, as this will make housing more affordable by cutting capital costs and bring people closer to essential infrastructure and social services, and by constructing more multi-story residential buildings

- Improve access and quality of housing

- Facilitate acquisition of land parcels for housing developments and well developed land/housing market

- Facilitate access to housing finance (e.g. establish low income housing fund, encourage financial institutions to design instruments for different segments of the market and develop a housing resource mobilisation strategy)

- Establish effective monitoring and control measures to improve standards

- Evaluate and empower the public housing development agencies (such as Lesotho Housing and Land Development Corporation (LHLDC)) and explore ways of increasing private participation in housing development

- Regularise housing rental market 
- Promote and expand production of local building materials

- Conduct research and encourage development of domestic materials and promote their use

- Train and capacitate local producers in entrepreneurial, managerial and competitiveness skills and enable them to improve quality of products

- Align Property development Initiatives with the Physical and Economic plans

- Develop growth poles development strategy and medium to long-term budget and financing strategy

- Review and/or develop town and area physical plans and implementation strategies

\subsubsection{Sports Infrastructure}

The aim is to provide opportunities for participation in sport for all sections of the community. The infrastructure developed should also be supported by programmes for institutional capacity building, promotion of sports, club development and training and coaching for those who want to participate for fun and those who are interested in competition at all levels, from very local levels to national and international competition. The importance of sports for health, crime prevention and social inclusion, especially of people with disability, women and the rural communities is recognized. Sports infrastructure development plan needs to be developed and to encourage private sector participation. Lesotho also needs to identify niche sports sectors to focus resources in building international competitiveness. 


\section{Strategic objective and actions}

- Increase sports participation and its contribution to economic growth

- Develop and implement sports and recreation development strategy and plan

- Develop sports and recreation infrastructure maintenance, development and management policy and plan

- Identify new opportunities for private sector investment

- Identify national priority sports activities and effective means for talent search and development so that resources can be concentrated on building international competitiveness.

- Rationalise and enhance capacity of sports institutions to promote, manage programmes and organise local and international events

\subsubsection{Public Asset Development and Management}

A significant proportion of capital budget goes into infrastructure development and the Government has to establish effective systems of developing, upgrading, maintaining and operating the assets cost-effectively. To this end that Government will improve and enforce quality standards in infrastructure development and ensure climate change proofing; Improve planning and coordination in acquisition of assets, including to enhance access and reduce time and costs to acquire services through one stop centres and public administration clusters at central, district and local levels.

The Government should have a framework that guides changing the use of facilities, property disposals, where the property is in surplus and market conditions are right and maintenance of assets. Coordinated planning and management of public infrastructure development is also necessary. This will 
also serve to implement the Public Financial Management and Accountability Act 2011 (PFMAA), with respect to accrual accounting provisions.

\section{Strategic objective and actions}

- Improve public asset management

- Develop public sector asset management policy/strategy

- Develop a comprehensive asset register, use and maintenance plans for all levels of government.

- Develop public infrastructure development plan

\subsection{Enhance Skills Base, Technology adoption and Foundation for Innovation}

\subsubsection{Skills}

Though labour is abundant and literacy rates are high at $85 \%$, there is high unemployment, relatively low productivity and limited technical skills for performing skilled blue collar jobs in leading sectors. High end skills are also limited partly due to brain-drain and there is a mismatch between the available skills and labour market requirements.

The base for skills development is improving but not at the rate required to sustain high and shared economic growth sectors. The introduction of free and compulsory primary education has improved enrolment (net enrolment is above $80 \%$ ) and the completion rate is high at $87.5 \%$ (2010). However, the quality of education in many primary schools is poor, mainly because of the relatively low level of qualified teachers (48\% in 2008). Secondary level enrolment is improving over time, though still low, at just above $30 \%$. Enrolment remains low, partly because few families are able to finance tuition 
costs and bursaries are limited relative to demand. Low enrolment at secondary and high school levels limits the flexibility of manpower to acquire industry-specific skills and their ability to move between sectors in line with changing economic opportunities. About $40 \%$ of the education budget finances higher education (budgets of public higher education institutions, student tuition fees and subsistence expenses). This suggests a systemic regressive bias, given that the majority of students entering the university system come from middle- and high-income households rather than from low-income households.

Tertiary institutions also need to be transformed so they can provide world class competencies and entrepreneurial skills. Particular attention will be given to the technical and vocational training institutions to produce learned-to-do individuals. It is important to ensure that individuals are equipped with skills that are in demand and where labour scarcity has resulted in skills gaps or a reliance on imported labour. Priority skills development areas include key growth and social sectors which are manufacturing and related engineering, agriculture and agro-industry, tourism, mining and entrepreneurship, business development and management which cuts across all sectors. Education and health skills shortages should also be addressed. This challenge will require the preparation of a manpower development strategy and a plan, based on a comprehensive needs assessment, including tapping the potential for trade in services.

The Plan will build on the achievements of Government's current efforts to ensure universal literacy and numeracy by strengthening the foundation for skills development through: improving the quality and coverage of Early Childhood Care and Development (ECCD); improving the quality of basic education and access to secondary and high school education; improve 
teaching capacity and infrastructure for science and mathematics at all levels; and facilitate transformation of skills development institutions. High end professional skills (Professors, Doctor/PhD) also need to be increased to be able to move to a knowledge-based economy.

\section{Strategic objectives and actions}

- Improve relevance and applicability of skills

- Undertake medium to long-term manpower needs assessment and prepare a national human resource development plan

- Revise the programmes offered in different institutions and align curricula with national development needs and sector/industry specific needs

- Develop strategies to increase and institutionalise industry-led work experience schemes such as apprenticeships, attachments, and mentoring

- Develop bursary policy that supports priority skills development needs and is equitable

- Expand and upgrade TVET institutions to support growth sectors

- Improve skills of trainees in vocational schools by making the curriculum more relevant and deploying qualified trainers

- Create/transform some of the existing facilities into vocational secondary/high schools

- Make more effective use of the textiles and manufacturing skills centre

- Establish Lesotho Skills Agency that will have responsibility for coordinating and managing the TVET system 
- Develop TVET financing strategy that also promotes private sector or employers and financial sector participation

- Rationalise and reform technical training institutions and skills training centres

- Reform the regulatory framework through development of the TVET qualification structure, supported by new assessment and accreditation policies and procedures

- Promote private sector participation in the provision of TVET

- Design short-term, community level agricultural and other vocational training programmes targeted at adults, herders, initiation schools leavers and others

- Transform institutions of higher education to become world class in selected subjects

- Identify areas of specialisation or priority areas in which Lesotho has the potential to become world class and reform academic programmes and institutions accordingly

- Develop a transformation plan to improve governance and management and increase the available pool of talent for teaching and research at higher learning institutions

- Modernise and improve facilities and equipment for learning and research

- Review curriculum and increase capacity for distance learning

- Institutionalise appropriate quality assurance systems, including accreditation of programmes by the Council of Higher Education 
- Promote enrolment and improve infrastructure and quality of curriculum and teaching of maths and science at all levels

- Improve teacher training programmes in mathematics and science

- Establish incentive schemes for mathematics, science for teachers and to increase student enrolment

- Upgrade laboratories and availability of Maths and Science teaching materials in schools

- Improve the foundation for skills development through the improvement of access and quality of education and infrastructure, including ICT literacy

- Develop ECCD policy and establish a multi-sectoral approach for ECCD to improve children's development (e.g. coordinating nutrition, immunisation, socialisation and education support)

- Fast-track construction and/or rehabilitation of schools/classrooms and extend coverage of reception classes

- Strengthen curriculum and quality of teaching at primary, secondary and high school levels to improve competencies of learners and reduce wastage (drop out and repetition), especially in rural Lesotho

- Develop, expand and/or improve e-learning programmes (radio and TV programmes)

- Identify and implement measures to increase secondary and high school enrolment

- Mainstream special education at all levels and/or introduce programmes so that people with special needs can enrol and excel 
- Develop effective monitoring mechanisms to ensure that vulnerable groups (such as children with disabilities, herd boys and young female domestic workers) can exercise their right to free and compulsory primary education

- Extend the coverage and/or provision of text books to secondary and high school levels

- Improve access to educational material, knowledge and information

- Strengthen the library system through automation, networking and better access to up-to-date materials

- Promote the establishment of ICT services centres (internet cafes) in all localities to facilitate access to information, e-books and materials and networking

- Promote the culture of reading and writing, especially at the early age

- Transform institutions for business and entrepreneurship development and training of public sector employees

- Review and rationalise entrepreneurship and business development programmes offered by different agencies to improve effectiveness and efficiency

- Reform LIPAM to offer necessary and quality programmes for the public sector

- Promote collaboration in the region

- Reduce Brain Drain

- Develop sector specific retention strategies and mechanisms to use skills in the diaspora 
- Promote partnerships between locals, Basotho in the diaspora and other international players to limit total out-migration

- Identify opportunities and negotiate favourable agreements on trade in services in potential export markets

\subsubsection{Technology and Innovation}

Technical change and economic growth depend not so much on being the first in the world in developing radical innovations but more on efficient diffusion of innovations.

However, research and innovation is a lynch pin for progressing to a knowledge based economy. In the medium term, the focus of R\&D in Lesotho should be on industrial and adaptive research. Lesotho has a limited foundation for research and development, with very few institutions involved in scientific research. Furthermore, negotiating licences to conduct research on appropriate and environment-friendly technology can be complicated and expensive. However, the proposal of Least Developed Country forum to establish and host a technology license bank that would maintain a database of available technologies, with details of suppliers, and a clearing house for buyers and sellers would increase opportunities for Lesotho to import appropriate technology.

Lesotho needs to make the transition to an information-oriented society and to build a culture of innovation. Cost-effective mechanisms involving the private sector need to be explored to promote scientific research, development of innovations and operation of productivity centres. This process can be facilitated by positioning ourselves to tap international innovation funds. Knowledge sharing and collaborative research is critical. The case of Quality Chemicals (India) - Cipla venture (Uganda) producing ARV and 
malaria drugs present a good example of South-South technology transfer for improving local production capacity. These cases could be emulated in other sectors. For environment and climate change, ways and means will have to be found to improve the scientific capacity to assess climate change vulnerabilities and adaptation, and generate and communicate information that is useful for adaptation planning and action. It should also be noted that innovation in other areas, other than science, should also be pursued.

\section{Strategic objectives and actions}

- Enhance technology transfer, diffusion and use

- Develop a local intellectual property rights (IPRs) information database, that would include international IPRs that are in the public domain and develop robust dissemination mechanisms

- Strengthen the Appropriate Technology Services (ATS) of the Ministry of Communications, Science and Technology for development of appropriate technology and training of artisans

- Establish a unit(s) that is responsible for technology research and dissemination in non/-scientific areas

- Develop capacity for industrial engineering design and enterprise development support

- Establish Science, Technology and innovation centres

- Develop innovation culture and capacity for scientific research

- Establish Science and Technology Council

- Develop a national research and development agenda and implementation strategy covering priority sectors such as water, energy, manufacturing, ICT, indigenous plants and traditional knowledge 
- Improve infrastructure and facilities for science and technology in tertiary institutions and forge networks with other research institutions

- Develop a resource mobilisation strategy for establishment of research and innovation fund and prepare the related legal framework

- Reform relevant curricula to inculcate a culture of innovation, including non-scientific disciplines

- Undertake institutional review for social and economic research and enhance coordination, efficiency and effectiveness of relevant institutions

\subsection{Improve Health, Combat HIV and AIDS and Reduce Vulnerability}

\subsubsection{Health}

Deteriorating trends in morbidity and mortality depreciate our human resource capital, thereby reducing productivity, savings and growth. High and increasing mortality rates cause a reduction in the labour force, increasing numbers of orphans, and deepening and spreading poverty. The significant drivers are high HIV and AIDS prevalence, limited accessibility of essential maternal and preventive health care services, poor quality of services and access to essential drugs. Generally, there is good access to health facilities and this should improve with the opening of a new national referral hospital (with three filter clinics) in Maseru.

There has been a dramatic increase in the Crude Death Rate: the 2006 Census estimates that the CDR was 26.5 deaths per 1000 people in 2006, doubling 
from 12.8 in 1996. This has contributed to a significant decline in life expectancy at birth: this had increased from 51.0 years in 1976 to 59.0 in 1996 but fell to only 41.2 in 2006 (for females, the fall was from 60.2 to 42.9 whereas for males it was from 58.6 to 39.7). The main factor in the high adult mortality rate is the prevalence of HIV at 232 per 1000 adults aged $15-49$ years (and associated opportunistic illnesses, such as tuberculosis). Although it only accounts for approximately $1 \%$ of all deaths, there has been a disturbing increase in the maternal mortality rate at an estimated rate of 939 per 100,000 live births (2006 Census) and increased to 1.115 (LDHS 2009). This has occurred even though $92 \%$ of pregnant women made at least one visit to a professional ante-natal care provider (and $70.4 \%$ made $4+$ visits) and $58.7 \%$ gave birth in a health facility (LDHS 2009).

The Infant Mortality Rate was 74 per 1000 live births in 1996 but the 2006 Census shows that had increased to 94 (102.5 for males, 83.9 for females). Combined with a Child Mortality Rate of 23.7 (26.5 for males, 21.1 for females), this gives an under-five mortality rate of $116 / 1000$. The main causes of deaths under five years are: prematurity; birth asphyxia; pneumonia; neonatal sepsis; and diarrhoea.

The 2009 Demographic and Health Survey indicates that the percentage of children aged 12-23 months who have received all basic vaccinations is $61.7 \%$, down from $67.8 \%$ recorded in 2004 . However, coverage for each individual vaccine range from $74.9 \%$ to $95.7 \%$ and is adequate to provide general immunity. Malnutrition has stagnated over this five-year period at around $40 \%$. Currently, $39.2 \%$ of children are stunted (short relative to their age), $3.8 \%$ are wasted (inadequate weight relative to height) and $13.2 \%$ are underweight (low weight for age). There is a high deficiency of micronutrients among children of 6 to 59 months which recorded $47 \%$ in 2009. 
Non-communicable diseases such as hypertension, obesity and alcohol and drug abuse related illnesses are increasing. Human resources are limited, with the ratio of doctors to population at 0.5 per 10,000 and of nurses and midwives at 6.2 per 10,000. Both ratios are far below the WHO AFRO Region averages of 2.4 and 10.9 respectively. Traditional medicine, is also an integral part of Basotho's health system, and needs to be documented, researched and developed, especially nutritional and medicinal plants.

\section{Strategic objectives and actions}

- Reduce infant and child morbidity and mortality rates

- Eliminate mother-to-child transmission of HIV by scaling up Prevention of Mother-to-Child Transmission (PMTCT) services

- Scale-up cost-effective health interventions (such as immunization, essential new-born care, case management of pneumonia and diarrhoea) with proven high impact on child survival

- Introduce community-based case management system for common childhood illnesses

\section{- Reduce Malnutrition (stunting, Wasting and Underweight)}

- Strengthen implementation of minimum health package with special emphasis on the first 1000 days.

- Strengthen implementation and management of Acute malnutrition programme

- Improve community health and nutrition programmes, growth monitoring and promotion, nutrition education, infant and young child feeding practises 
- Develop and implement a national nutrition policy and its implementation strategy.

- Develop and enforce implementation of national food fortification legislation.

- Integrate nutrition monitoring in Health Management Information Systems (HMIS).

- Enhance capacity of the national nutrition coordinating body

- Reduce maternal mortality rate

- Deploy skilled health/birth attendants at all health centres

- Improve access to emergency obstetric care services

- Provide maternal health education to communities and develop specific programmes for males

- Reintroduce ante-natal shelters

- Scale-up reproductive health education and services, including promotion of greater use of contraception. Establish comprehensive outreach health services

- Increase awareness and improve facilities for cervical cancer testing

- Scale-up essential nutrition package for pregnant and lactating mothers

- Improve skills through capacity building and provide appropriate incentives to retain skilled health professionals

- Develop a transformation and capacity building programme for local health training institutions

- Improve linkages with external institutions on human resource development through bilateral agreements 
- Review and implement retention strategy

- Explore viable options for establishing a medical school

- Reinvigorate the Village Health Worker system through training and a revamp of supervision mechanisms

- Develop a strategy for continuous medical education and an implementation action plan

- Improve procurement and dispensing systems for pharmaceuticals and essential supplies

- Implement pooled procurement and payment systems for drugs and medical supplies

- Expand integrated electronic Drug Supply Management system

- Attain full coverage and access to health services

- Develop infrastructure in under-served areas

- Implement the essential health package, including health infrastructure, human resources, medicines and health supplies plus appropriate technologies, transport and communication systems

- Improve performance of and expand the integrated delivery system for prevention, treatment, care and support of communicable and noncommunicable diseases, including mental health

- Strengthen emergency health services

- Explore options for the introduction of a sustainable social health insurance scheme 
- Strengthen the management and accountability of health facilities and systems

- Develop performance and accountability systems for management of all health facilities and services

- Upgrade the health management information system and produce national health accounts

- Improve public finance management systems and build technical capacity to operate them

- Undertake an outcome-based public expenditure review for health

- Prepare a Health Sector Development and Investment Programme, following a sector wide approach with common planning, financing, accounting and M\&E procedures

- Strengthen partnerships with the private sector, NGOs, churches and development partners

- Use lessons learned from the PPP with Tsepong to assess further opportunities for collaboration to improve health infrastructure

- Improve quality and access to laboratory services

- Establish a national health laboratory system

- Enhance public education on blood transfusion

- Promote research and documentation traditional medicine

- Develop a policy for the partnership between traditional and conventional medicine in the context of Basotho culture

- Promote documentation of available traditional medicines to inform future studies on efficacy and safety. 


\subsubsection{HIV and AIDS}

HIV prevalence seems to be stabilising at a high prevalence of $23 \%{ }^{31}$ with an annual incidence of 21,000 new infections in adults and 1,300 in children ${ }^{32}$. The epidemic has a gender bias with women having higher prevalence (26.7\%) than men (18\%). Prevalence is lowest (3.5\%) among young people aged 15-19 years but is higher among women aged $35-39$ years (42.3\%) and men aged $30-$ 39 years (40\%).

High HIV and AIDS prevalence is attributed to high incidence of unprotected sex in high risk sexual acts, including multiple and concurrent partners and transactional sex. The main drivers for unprotected sex are cultural practices that perpetuate gender inequality and gender based violence such that women relent to unprotected sex, alcohol and drug abuse and limited access to condoms on a consistent basis. Early sexual debut, increasing intergenerational sex, childbearing (Mother-to-child transmission) and low/full circumcision in males also increases the risk of exposure to HIV and AIDS. Exposure is especially high for migrating populations and child-bearing age groups.

\section{$\underline{\text { Strategic objectives and actions }}$}

- Reduce new infections through intensification of HIV prevention and integration with treatment

- Intensify comprehensive condom programming (logistic management, condom promotion, distribution and procurement) and attain $100 \%$ rollout

\footnotetext{
31 MOHSW (2009): Demographic and Health Survey, Ministry of Health and Social Welfare.

32 NAC, UNAIDS (2009) Modes of Transmission Report, National AIDS Council, United Nations Joint Programme on HIV and AIDS.
} 
- Promote circumcision of males and effectively communicate associated risk profiles

- Intensify communication to influence behaviour change on key HIV and AIDS drivers and promote adherence to treatments

- Promote 'know your status', HIV testing and maintain counselling capacity, focusing on community levels

- Implement measures to enhance safety of the blood transfusion system

- Explore options for incentivising people, especially the youth to stay HIV negative

- Undertake research to improve the targeting of structural, behavioural and biomedical interventions to provide understanding of knowledge, attitudes and practices

- Increase coverage and quality of treatment, care and support services and facilities

- Increase coverage of ART treatment by finding innovative ways to encourage uptake and adherence to appropriate regimes, especially for women in the reproductive age group

- Integrate nutrition support in treatment, care and support programmes

- Increase coverage of Pre-ART treatment and encourage uptake and adherence to the appropriate regime

- Strengthen capacity to implement home-based care in line with the existing guidelines

- Facilitate co- management of TB/HIV which should include the integration of the TB/HIV services in the Health Services 
- Improve efficiency and sustainability of mitigation programmes

- Consolidate support and empowering mechanisms for OVCs and other vulnerable groups

- Promote workplace programmes and strengthen inspection to improve enforcement of HIV and AIDS policies and laws

- Promote self-sustaining and livelihoods networks at community levels

- Improve institutional effectiveness and coordination

- Undertake a sector-wide HIV and AIDS institutional review to improve attainment of results, coordination, management, cost efficiency and promote integration of services

- Strengthen capacity to mainstream HIV and AIDS in plans, policies and programmes

- Improve capacity and modalities for mobilisation of funds for HIV and AIDS interventions

- Undertake regular National AIDS Spending Assessments and implement recommendations to improve the efficiency and effectiveness of spending

- Enhance capacity of organisations supporting people living with HIV and involve them in policy development and decision-making

- Upgrade the HIV and AIDS M\&E system by consolidating linkages with other data collection and M\&E systems (e.g. Health Management Information System and Lesotho Output Monitoring System for HIV and AIDS) and roll out the integrated system at national, district and community levels 


\subsubsection{Social Protection}

The high rates of poverty, HIV and AIDS and unemployment indicate that there is high vulnerability in Lesotho. The Government implements several major programmes to address these concerns, including the old age pension to approximately 75,000 people who are over 70 years, the school feeding programme, bursaries for orphans and vulnerable children, food and cash for work, food aid, social assistance for people with disability and OVCs. The 2006 Census indicated that there were 221,000 orphans, while about 70,000 people are living with disabilities. The primary goal is to prevent and reduce the economic and social vulnerabilities of the most disadvantaged and socially excluded segment of the society. Therefore, we need to develop a social protection system that promotes prevention and reduction of exposure and enhances the management of risks and is well co-ordinated.

\section{$\underline{\text { Strategic objectives and actions }}$}

- Consolidate and improve efficiency of social protection systems and enhance coverage of selected interventions

- Develop a comprehensive social protection policy and review the legal framework

- Strengthen organizational capacity for social protection programmes design, resource mobilization and service delivery to the poor and marginalized populations

- Establish social protection coordination body and undertake institutional review to reform and strengthen inter-agency coordination

- Establish central registry system and improve Management Information Systems (MIS) for individual interventions and facilitate consolidation of 
social grant schemes/safety nets while enhancing coordination and efficiency

- Undertake impact assessments and evaluations of existing programmes

- Increase capacity of able bodied persons to deal with vulnerability

- Promote food and cash for work programmes

- Identify and implement sustainable livelihood strategies and programmes for vulnerable able-bodied persons to graduate from receiving social grants and reduce vulnerability

- Explore options for export of manpower

- Explore options to establish a comprehensive contributory social security scheme

- Improve work safety and ease job search

- Develop guidelines and standards to promote decent and safe work in different sectors

- Establish registries for job seekers and vacancies in all the districts

- Increase capacity for disaster risk management at household, community and national level

- Consider options for establishing a Disaster Risk Management and Climate change Fund

- Explore the viability and/or alternatives to building infrastructure for strategic commodity reserves and implement viable options

- Educate the public to strengthen capacity to manage disasters and establish more effective early warning systems, design of appropriate responses and effective communication with target groups 
- Enhance capacity to increase national water and energy security

\subsection{Reverse Environmental Degradation and Adapt to Climate Change}

Sound environmental policies, adaptation to climate change and physical planning, are necessary for sustainable long-term economic growth while preserving our country for future generations. Climate change models indicate that Lesotho will experience higher temperatures and more erratic rainfall patterns in future. Our current dependence upon rain-fed agriculture makes the country highly vulnerable to such changes, which will exacerbate existing issues of environmental degradation, increase the risk of vector and waterborne diseases and have the potential to slow economic performance and threaten our achievements in social development.

There is compelling evidence that the measures that are currently being taken, (including tree planting, donga reclamation, protection of wet lands and other biodiversity conservation programmes) are not adequate to reverse environmental degradation. The damage and loss of critical habitats, such as wetlands, and degradation of forest and vegetation cover significantly reduce the capacity of catchments to capture and store water and, paradoxically, this contributes to both floods and water shortage. The main causes of environmental degradation include ploughing on steep slopes and/or marginal lands by crop farmers (54\% of croplands are exposed to sheet erosion), overgrazing of rangelands (an estimated 50\% over-stocking of livestock) and unregulated encroachment of human settlements onto prime agricultural lands. 
Inadequate physical planning and poor implementation of plans also result in inappropriate land use, urban sprawl and building on areas that are prone to natural disasters.(e.g. exposed to high winds or in flood plains). Appropriate planning is required to cater for spatial development required for future industrial and social developments. Spatial planning efforts should cater for growth pole developments.

There is also inadequate infrastructure and systems to prevent pollution through solid and hazardous waste, generated by activities in the agriculture, industry and construction sectors. Effective measures are also required to reduce environmental health hazards posed by inadequate water supply and sanitation. Moreover, poor construction and operational practices of some industrial and commercial operations lead to inefficient use of resources such as energy and water and preventable environmental pollution.

Lesotho is a minor emitter of greenhouse gases. Nonetheless, adopting a low carbon development route would allow Lesotho to develop a higher degree of energy security, improved competitiveness through lower energy costs and, potentially, access to international climate finance.

There are multiple policies and plans that address the key environmental and climate change challenges. However, delivery has been weak because of institutional fragmentation, duplication of efforts, insufficient cross-sectoral coordination within the Government and non-governmental sectors, weak implementation and enforcement of policies and legislation. 


\section{Strategic objectives and actions}

- Reduce land degradation and protect water sources

- Evaluate and, as appropriate, scale-up programmes to address sustainable land and water management and the rehabilitation and protection of rangelands, wetlands, forests and agricultural lands

- Develop integrated land and water resource management programmes

- Increase biodiversity conservation and promote sustainable use

- Identify areas to be put under protection and develop innovative models for communities and/or private establishments to manage the areas

- Support entrepreneurs in developing viable and bankable eco-projects

- Promote preservation of flora and fauna through education and improving the capacity of the existing Botanical Garden(s)

- Enact the Biodiversity Bill

- Strengthen range management institutions and range carrying capacity

- Promote and strengthen capacity of Range Management Area (RMAs) associations and other groups

- Explore other range management models

- Facilitate reseeding of range lands

- Develop incentives and strategies for de-stocking including resuscitation of auction sales yards and explore the feasibility of introducing a grazing levy

- Improve national resilience to climate change

- Undertake or review vulnerability assessments and review sector plans and programmes to improve mainstreaming 
- Consolidate the national climate change strategy and agenda

- Upgrade standards for infrastructure development to climate-proof investments

- Develop mechanisms to improve access to climate change technology and use

- Promote and increase the greening of the economy

- Promote cost-effective and clean energy generation

- Promote foreign and domestic investment in the production and use of environment friendly technology

- Promote research and private participation in "green" technology

- Explore options for carbon trading and tapping different international funds

- Improve land use, administration and management

- Develop national, town and local level land use plans

- Facilitate the development of a transparent and efficient land market

- Provide training to enhance national and local capacity to prepare sustainable plans for human settlements

- Promoting ring-fencing of towns and densification in designated urban areas to reduce encroachment on agricultural land, fragile ecologies and costs for provision of basic infrastructure

- Improve the delivery of environmental services

- Improve regulation of EIA services to make them more accessible, affordable and efficient, thereby minimising any adverse effects on the investment climate 
- Develop a strategy for waste and sanitation services with a sustainable financing model

- Develop an appropriate model for landfills and facilitate their construction and operation

- Develop models for waste recycling and support communities and/or private sector for their adoption

- Improve environmental health education programmes and coverage

- Improve environment and climate change governance

- Harmonise policies and legal frameworks and undertake an institutional review and implement the recommended reforms to improve coordination, efficiency, policy implementation and service delivery

- Build relevant skills, including undertaking policy analysis and physical plan development and in operating geographic information systems

- Establish environment and climate change registry and build capacity to compile statistics (such as "green" accounts), undertake vulnerability assessments and utilise them for medium to long-term forecasting, policy and planning

- Enhance capacity of institutions to share information domestically and internationally

- Enhance public education on environment and climate change and create incentives for communities to be more aggressive on the issues 


\subsection{Promote Peace, Democratic Governance and Effective Institutions}

Sustained levels of investment, whether domestic or foreign, cannot take place in a politically unpredictable and socially unstable environment. Peace and stability are therefore sine qua non for accelerated economic and social development. Lesotho needs a clear and predictable legal and regulatory environment that is characterized by the rule of law, respect for human rights, efficient law enforcement agencies and an independent judiciary that dispenses justice quickly and impartially.

It also requires strong and efficient institutions that are capable of policy formulation, execution and monitoring and which contribute to economic and business competitiveness and the creation of an investor-friendly environment. The Government's goal is to create a public service that sees its role as serving the public and enabling Basotho to help themselves through a stronger private sector and increased private initiative.

\subsubsection{Stability and Democracy}

Lesotho is a relatively stable country with a young multi-party democratic system. It is ranked above the average of Sub-Saharan African (SSA) countries in political stability. Both national and local democratic elections are held periodically and have been declared free and fair. However, the main threats to political stability are conflicts that arise between political parties and intraparty clashes. Poverty and high unemployment, especially among the youth, are also regarded as threats to stability.

Several institutions are responsible for oversight but their capacity is limited. In particular, the Directorate of Corruption and Economic Offences (DCEO) need 
to be strengthened to address public perceptions of corruption in the public sector. Civic education, strengthening social dialogue and tri-partism as well as celebration and preservation of culture also improve cohesion and stability.

\section{Strategic objectives and actions}

- Improve capacity of oversight bodies to promote accountability and deal effectively with corruption

- Build capacity of oversight bodies to perform their functions

- Review legal frameworks to align mandates and procedures with institutional responsibilities and to attain the expected effectiveness

- Improve capacity for conflict resolution and promote social cohesion

- Develop a comprehensive capacity development programme and robust peace architecture (institutions and systems) to resolve conflicts

- Promote participation of all sections of society, including disadvantaged groups such as youth, women and people with disabilities, in decision-making processes

- Introduce programmes for conflict resolution from primary school level

- Introduce leadership training programmes for different sections of society

- Establish effective social dialogue mechanisms

- Promote cultural events and other mechanisms for cultural preservation as a way of promoting social cohesion 
- Enhance the capacity of private sector and non-state actors organisations to participate effectively in policy development and promote tri-partism

- Develop a policy for non-state actors engagement with the Government and institutionalise mechanisms for consultation and dialogue

- Enhance capacity of trade unions to participate in policy development and negotiations

- Promote and support professional associations to act as think tanks and engage in policy development

- Develop and implement a robust civic education programme

- Promote effective corporate social responsibility programmes

- Provide capacity development support to private sector and civil society organisations

\subsubsection{Human Rights}

Human rights are enshrined in the Constitution and Lesotho has a good record for observing them. Lesotho is also a state party to the majority of the international human rights conventions, but has limited human capacity for domestication of international treaties and conventions and their implementation. In some cases, cultural traditions and practices play a role in perpetuating discrimination especially against women.

\section{$\underline{\text { Strategic objective and actions }}$}

- Enhance the protection and fulfilment of human rights

- Facilitate operation of the National Human Rights Commission to promote, protect and monitor human rights 
- Develop a Human Rights Action Plan to coordinate the efforts of institutions and civil society in the furtherance of human rights

- Align policy and legislation with Government's commitments to human rights as expressed in international and regional treaties

- Institutionalise mechanisms to address the issues/concerns of minority and vulnerable groups

- Introduce formal street law programmes targeted at high school students and communities to equip them with essential legal information, including procedures and rights, which could reduce incidences of crime

- Undertake public awareness campaigns on human rights with a particular focus on the needs of vulnerable groups (women, children, people with disabilities, people living with HIV and AIDS and elderly)

\subsubsection{Law Enforcement and Administration of Justice}

The rule of law, equitable access and efficient administration of justice are prerequisites for social and economic development. Progress has been made in the number of areas within the justice system, particularly in reducing the backlog of court cases and introducing alternative dispute resolution mechanisms. However, a number of challenges still exist. Cases still take long to be concluded due to systems that are weak, with limited transparency and poor record handling. In addition, rehabilitation centres are over-crowded, vulnerable groups do not have adequate access to the justice system as a result of low capacity of legal aid unit and limited skills to deal with disabled and juvenile cases in particular. Crime is increasing, but the police fail to respond promptly to crimes and make relatively few arrests and convictions are even fewer. 
Several laws are also out-dated which leads to poor application. Moreover, even when laws have been reviewed, it takes a long time to get amendments through Parliament due to limited capacity for drafting bills. These concerns impose substantial social and economic costs: cases drag on for a long time; the process of summoning witnesses often fails so other parties attend court without resolution; prisoners are held on remand for long periods and rehabilitation centres are unable to perform their rehabilitation function.

In addition, several competitiveness indices show that Lesotho has a high regulatory burden, which constrains investment. Furthermore, the full operation of the commercial court and training of the legal professionals in handling commercial cases needs to be expedited to improve the business climate and to ensure speedy and transparent processing of cases.

The crime rate is not high by regional standards, but some crimes appear to be increasing (e.g. cash heists, burglary, organised theft of vehicles and livestock) and perpetrators are rarely prosecuted. This is mainly attributed to limited technical capacity, corruption, limited accountability of enforcement agencies and the cross-border nature of some criminal activity.

\section{Strategic objective and actions}

- Enhance the justice system to be more equitable, effective and efficient and significantly reduce crime

- Develop and implement effective measures to combat major and organised crimes, including stock theft and improve coordination with RSA to reduce cross-border crime

- Facilitate the smooth operation of the commercial court and training of judicial personnel 
- Facilitate the establishment of small claims court

- Improve case management by developing policy, establishing transparent systems for movement and tracking of dockets, training justice personnel and establishing complaints mechanisms to deal with cases that have not been handled satisfactorily

- Roll out the local courts infrastructure (Tsefa-li-Mali Model)

- Strengthen the legal aid system by reviewing the current legal frameworks with the objective of improving protection for vulnerable groups, building capacity of staff and assessing options for decentralising legal aid services so that indigent Basotho have access to justice

- Promote and build capacity for alternative dispute resolution mechanisms, thereby reducing the backlog of cases in higher courts

- Improve rehabilitation programmes of offenders through provision of basic educational and high quality vocational skills and a phased programme for rehabilitation and/or development of correctional services infrastructure

- Develop an effective system for monitoring ex-offenders and promote alternative rehabilitation programmes

- Enhance the juvenile case management system and the capacity of probation unit services

- Institute measures to improve coordination between all stakeholders in the justice sector 
- Develop and implement effective measures for the protection of natural resources and enforcement of laws that provide for the protection of heritage

- Identity options to accelerate training of police and National Security forces to deal effectively with crime and national security threats.

- Improve concept or model of community policing

- Modernise and harmonise laws

\subsubsection{Policy, Planning and Public Financial Management}

Lesotho has a comprehensive set of planning documents, including Vision 2020, medium-term plans, sector policy papers, plans and programmes, project memoranda and some district plans. However, there are inconsistencies between these planning frameworks, trade-offs between policies are not explicitly analysed, action plans are not linked to realistic assessment of available implementation capacity and the resource envelope and it is not easy to assess their implementation status. There is also limited capacity for regular policy updates based on rigorous analysis. The engagement of the private sector and civil society in policy development needs to be strengthened through capacitating associations/organisations, policy research institutions and institutionalising mechanisms for engagement.

In relation to statistics, users require timely publication of relevant and accurate statistics in order to conduct policy analysis, market analysis and evidence-based decision-making. A national strategy for development of statistics has been prepared. Implementation of this strategy will contribute to improvements in: efficiency of data collection; functioning of quality assurance procedures; accuracy, credibility and timeliness of publications. In addition monitoring and evaluation of programmes will improve. Public awareness and 
education also needs to be heightened on the available statistics and their interpretation.

The Government has implemented a far-reaching package of public financial management (PFM) reforms in recent years. Core responsibilities and procedures are defined in the Public Financial Management and Accountability Act 2011. The medium-term expenditure framework (MTEF) approach was introduced in order to improve fiscal discipline, targeting of resource allocations, operational cost efficiency and to promote greater certainty over resource flows in the medium-term. These objectives have not yet been fully realized due to capacity constraints. The new integrated financial management information system (IFMIS) was implemented to improve accountability, minimize fraud and improve efficiency for settlement of payments. The system has improved transparency and discipline; however its functionality is constrained by capacity gaps due to loss of trained personnel to other institutions. A thoroughly revised procurement system was introduced in 2007 and is expected to generate significant efficiency gains. Nonetheless, the 2009 assessment conducted using the Public Expenditure and Financial Accountability methodology demonstrated that further reforms and improvements in implementation are necessary.

Although Government has established mechanisms for aid coordination and management, there is still duplication of effort and some programmes do not necessarily address national development priorities. In addition, even though our main development partners support the principles of the Paris Declaration on Aid Effectiveness, there is poor reporting of donor activity as some programmes are implemented outside Government's budgeting, accounting and monitoring systems. An aid policy is under preparation which should contribute to improved aid management. 


\section{Strategic objectives and actions}

- Strengthen statistics, policy development, planning and public expenditure and financial management

- Develop and implement the PFM reform agenda based on local and international policy and institutional assessment

- Facilitate the implementation of the National Strategy for the Development of Statistics

- Undertake institutional review and capacity development to improve Government procurement management and oversight

- Improve policy analysis and planning capacity at central and local level including project cycle management

- Institutionalise regulatory impact assessment

- Develop medium - long-term sector wide investment programmes with periodic reviews

- Develop Public Private Partnership policy, guidelines and related legal frameworks

- Improve aid mobilisation, effectiveness, management and coordination

- Finalise aid policy and the appropriate institutional framework to operationalise aid and development effectiveness principles and agenda (Busan agenda)

- Identify and implement measures to improve resource mobilisation and build absorptive capacity especially for donor funds 


\subsubsection{Public Administration and Service Delivery}

There is a general perception that public service delivery is poor, while the private sector complains that it imposes a high regulatory burden with excessive compliance costs. Various reforms have been initiated, but implementation has been generally weak. Despite having a relatively large public sector, there is generally a poor culture of service as a result of an inadequate legal framework, weak administration and management, weak technical capacity and accountability and inefficient business processes. There might be need to outsource some of the services, however, before services are contracted out, the private sector will need to demonstrate that it can perform better.

The key objective, integral to improving Lesotho's democratic institutions and traditions, is improving the overall efficiency of Government, the administration of public services, and effective oversight.

\section{$\underline{\text { Strategic objective and actions }}$}

- Improve public service delivery and strengthen the integrity of the public administration

- Develop comprehensive public sector improvement and reform programme, including right-sizing strategy and improvement of legal frameworks, internal controls, accountability, business processes and performance management systems and technical capacity development

- Establish and monitor achievement of appropriate service delivery standards 
- Identify service delivery functions that can be outsourced, review and implement divestiture programme

- Develop/consolidate and implement retention strategy

- Create and build capacity to conduct policy analysis and research

- Upgrade LIPAM infrastructure and training capacity to deliver key training programmes for all government ministries

\subsubsection{Decentralisation}

Lesotho has a two-tier Government system. The first local authority elections for 128 Community Councils and the Maseru Municipal Council were held in 2005. The second local authority elections were held in 2011 and the Community Councils were reduced to 65 and 11 Urban Councils created. Representatives of the Community and Urban Councils constitute the 10 District Councils. Significant progress has been made in the transfer of responsibility from national to local institutions but the process is still ongoing.

Decentralisation has involved devolution of power to the elected councils. In several areas, technical staff has been transferred from national agencies to the councils to enable them to perform their mandates. Councils remain accountable to the Ministry of Local Government and Chieftainship.

In parallel, there has been de-concentration of several functions from national agencies to the office of the District Administrator. The DA is the representative of central Government at the district level and is accountable to the Minister for Local Government. Technical staff is responsible to the DA administratively and on professional matters to their line ministries. 
Issues to be addressed include: improvement of local capacity for planning, budget management and project cycle management; underemployment of staff due to limited resources for operational expenses; poor service delivery due to limited capacity of DA office and local councils; and consensus among all stakeholders on policy direction and vision for decentralisation, including functions to be delegated to district councils from DA and Ministries and fiscal decentralisation.

\section{Strategic objective and actions}

- Deepen decentralisation

- Enhance systems and capacity of local authorities for planning, budgeting, monitoring and evaluation of projects and accountability

- Build consensus on policy direction and vision for decentralisation

- Determine functions to be delegated to district councils from District Administrator and ministries at central level and transfer them in tandem with capacity building

- Develop decentralisation plans for all ministries

- Develop fiscal decentralisation framework

\subsubsection{Regional Integration, International Relations and Cooperation}

Regional agreements such as SACU, SADC and AU offer great opportunities for cooperation and trade. The policies and programmes adopted at the regional and international levels need to be domesticated through adaptation and integration into national policies, plans and legislation. Lesotho has to ensure that it participates effectively in the negotiations on regional trade and other international policy making processes, such as those of the WTO and the UN 
system, and makes full use of the established channels to other political and economic configurations such as the EU, USA and the Commonwealth.

It is important to establish an appropriate institutional structure with the capacity to contribute effectively to tariff and trade policy negotiations within SACU and to the domestication of integration plans adopted at SADC and AU. This will ensure that Lesotho benefits from regional and international trading arrangements.

Lesotho has strong economic links with RSA as our only neighbour and the largest economy in the region. However, Lesotho has not adequately exploited the opportunities offered by this location. Approximately, 120,000 Basotho live in South Africa. Less than 50,000 are mineworkers while many of the others are skilled workers. While recognising that remittances make a major contribution to GNI, these skills could be deployed for the economic development of Lesotho. Since traditional sources of employment for Basotho in RSA, such as mining, are declining, it is desirable to reach a bilateral agreement on updated manpower policies and industrial integration. The cultural similarities and ties between Basotho and the larger Sotho community offer enormous opportunities for cultural cooperation in art, writing, films and tourism including religious tourism. There are also opportunities for regional cooperation over a number of natural resources and products, notably water and energy.

Lesotho is a member of a number of multilateral organisations and has diplomatic relations across the world. Although it is important to maintain these relations, the need for embassies has to be reviewed and rationalised, whilst ensuring that our strategic objectives are met. In particular, we need to 
identify innovative ways to promote Lesotho as an attractive destination for foreign investment, trade and tourism.

\section{Strategic objectives and actions}

- Increase effectiveness and stakeholder participation in regional and international policy making

- Institutionalise mechanisms (such as inclusive national networks) to increase participation of stakeholders in the development of Lesotho's policy positions in regional and international negotiations

- Provide public education and ease access to international treaties and other instruments through the creation of an electronic depository and facilitate domestication

- Develop and implement capacity building programmes for trade policy analysis and negotiations, investment and trade promotion and diplomacy in local institutions

- Increase cost-effectiveness and efficiency in dealing with international affairs and cooperation

- Review the architecture of foreign missions, institutional capacity and coordination and rationalise and/or improve as required

- Strengthen bi-lateral cooperation including Joint Bilateral Commission of Cooperation (JBCC) programmes, particularly in respect of infrastructure development, cargo handling at the ports, industrial and tourism development, skills development, transformation of local institutions, movement of persons and cross-border crime

- Improve mechanisms to ease international travel by Lesotho citizens and tourists

- Strengthen prevention and effective handling of human trafficking 


\subsubsection{Media}

The media industry is relatively large with 65 newspapers, periodicals and magazines, 2 state run radio stations and 8 private stations, 3 of which are owned by churches. Radio is still the dominant platform for public debate. State television, South African Broadcasting Corporation and other international channels are available through satellite. The key challenges include: delays in adopting and subsequently implementing the media policy which would result in the establishment of the relevant institutional infrastructure and legal framework that would systematically address issues related to professionalism, ethics and conduct as well as improvement of media content and coverage.

\section{$\underline{\text { Strategic objective and actions }}$}

- Enhance the capacity of the media sector to play an effective role in promoting democracy and development

- Facilitate the adoption of the media policy

- Review related laws and regulations in line with the media policy

- Establish the recommended institutional structures by the media policy, including ombudsman and Media Council

- Review and update the media studies curriculum of local training institutions

- Establish clear procedures for media interaction with Government ministries and policy makers to improve access to accurate information 


\section{Cross-cutting issues}

This section highlights the critical issues to be addressed in the Plan period for a number of cross-cutting themes. Government interventions for these critical topics will be implemented by integrating them into relevant chapters and action programmes.

The Government will promote gender equality, protect the interests of children and youth, people with disabilities and the elderly. General challenges that will be addressed for all cross-cutting thematic areas include the generation of disaggregated data and development of effective mechanisms for improved coordination and mainstreaming into policies, programmes and budgets.

\subsection{Gender}

The population of 1.89 million is evenly distributed between females and males. Lesotho has made significant progress in terms of gender equality and, as noted in Section 4.2.1, it ranks better on the Gender Inequality Index than on the Human Development Index. Females participate in education more than males. With the introduction of quotas, there has been an increasing number and proportion of females in Parliament and Cabinet as well as in local councils. However, women have long been disadvantaged by cultural traditions and there are still challenges ahead, notably to maintain levels of political participation, to facilitate their contribution to economic activities, to improve maternal health and to empower females in respect of reproductive health. This plan should facilitate the implementation of the Legal Capacity of Married 
Persons Act 2006 and the gender policy framework. In order to promote gender equality and mainstreaming, the following key strategic actions will be pursued:

\section{Strategic objective and actions}

- Promote Gender equality and empowerment of women

- Strengthen institutional, policy and legislative frameworks to ensure effective mainstreaming of gender into national development programmes.

- Create awareness and advocate for male involvement in gender and sexual and reproductive health programmes.

- Enhance economic empowerment of Basotho men through targeted vocational (artisan) and entrepreneurship training and business counselling to be delivered at community level and combat stock theft and/or increased recovery

- Enhance training on sexual and reproductive health targeted at men and women. Implement programmes for reduction of child and maternal mortality as indicated in the health chapter

- Enhance political empowerment of women through implementation of policies that will strengthen female participation in politics, including leadership training

- Identify and implement measures to reduce cost of living for industrial work force, including housing solutions with the participation of the private sector

- Increase dissemination of legal frameworks that promote gender equality and develop guidelines to facilitate implementation 
- Support non-formal education and skills development programmes for herd-boys and domestic workers

- Improve the capacity of supporting agencies (CGPU/police, social welfare, health and the justice system) to respond adequately to gender-based violence

\subsection{Children and Youth}

The key issues for children and youth, which leads to their being vulnerable and in need of support, include: orphan-hood as a result of the high mortality rate, limited access to health services, poor nutrition, trafficking in persons, children living on the street, herd boys, early pregnancy, forced marriages, substance and drug abuse, child abuse (physical, emotional and sexual), childheaded households, child carers, property dispossessions and children out of school. In addition to the above, there is high unemployment among youth, which is caused by limited technical skills and being out of school early, frictional constraints, including limited work experience opportunities though employers prefer experienced labour force and mismatch between labour market needs and available skills.

The Census 2006 showed there were 221,000 orphans, not including other categories of vulnerable children. This represents a significant increase from the estimate of 180,000 orphans for 2004 (UNAIDS 2004). It is clear that there are a large number of orphans who are in need of care and support. On a positive note, educational enrolment data suggests that approximately 180,000 orphans aged $5-19$ years are attending primary and secondary school. 


\section{Strategic objectives and actions}

- Promote children development and protection of rights

- Step up education and immunisation of children

- Provide quality free universal primary education and nutrition

- Provide effective means for protection from abuse, by improving the capacity of service providers (CGPU/police, social welfare, health and the justice system) to respond adequately to cases of violence, abuse and exploitation of children, including child labour and developing prevention measures, especially at community level

- Scale-up and improve efficiency of the programmes of support for orphans and vulnerable children

\section{- Promote youth participation development}

- Strengthen the capacity of the Youth Council to promote the interests of youth

- Improve employment opportunities for youth by delivering demanddriven community level youth livelihood training programmes at local youth training centres and incorporate training in entrepreneurship skills

- Identify strategies to increase secondary and high school enrolment

- Improve services for job information and search

- Promote apprenticeship programmes to give experience and increase employability

- Improve access to finance through grants and risk guarantees for high potential projects

- Develop programmes to increase computer literacy and competency 
- Develop young farmers' training programmes to be delivered at FTCS and establish mechanisms for financial support for graduates to increase self-employment

- Increase quality of and access to distance learning by making e-services available at local level

- Create educational radio and TV programmes in pedagogic and life skills (ICT, HIV and AIDS, Environment) in collaboration with regional countries and promote community voluntary education programmes

- Develop a programme for sports facility roll out

- Identify a limited number of sports in which to develop professional players of international standards

- Promote youth friendly/driven sexual and reproductive health programmes such as adolescent health corners following a review and rationalisation of current Government and non-government interventions

- Promote the culture of reading and writing

\subsection{Disability}

According to the Lesotho Census Report carried out in 2006, about 70,000 people $(3.7 \%$ of the population) had some form of disability that required a service. While some people are born with a disability, other common causes of impairment and disability include illness, road traffic accidents, domestic accidents and mine accidents. The most prevalent type of disability was reported to be blindness (19.3\% of all disabled persons), with prevalence 
slightly higher among females than among males. Other common disabilities include amputation of foot/leg, deafness, lameness/paralyzed limb, mental illness and mental retardation.

\section{Strategic objective and actions}

- Prevent disability and facilitate persons with disability (PWD) to lead healthy and productive lives

- Promote preventive health measures to reduce disability through improved quality health services.

- Increase the number of trained facilitators for the education of children with specific needs, such as Braille, sign language, and specific skills for profoundly disabled children.

- Facilitate access to formal education through targeted measures for PWDs.

- Utilise domestic, regional and international experience to develop teaching aids and materials for persons with disabilities.

- Conduct public education campaigns to de-stigmatise disability at all levels.

- Encourage the recruitment of PWD to positions that they can perform successfully within the public and private sector.

- Promote programmes targeted at reducing the number of preventable disabilities, especially road and workplace accidents.

- Promote programmes targeted at rehabilitating, integrating and mainstreaming PWDs into society.

- Improve the capacity and sustainability of vocational training for PWDs, and provide business support

- Develop and enforce standards to facilitate accessibility of public buildings, transport services and social services by PWDs. 
- Take steps to improve access for persons with disabilities to appropriate health, legal and other social services.

- Review disability grant policy especially to improve targeting and access to basic needs by the beneficiaries

- Develop strategies for effective inclusion and efficient participation of PWDs in planning, policy development and related legal reforms

\subsection{Elderly}

The Census 2006 recorded approximately 147,000 residents ( $7.8 \%$ of the total) aged 60 years and over. Those aged 60 - 69 years accounted for $49 \%$ of the elderly $(72,000)$ while those aged $70-79$ represented $37 \%(54,000)$ and those over 80 years were only $14 \%(21,000)$. The Government provides an old age pension to all citizens over the age of 70 years as well as to survivors and eligible dependents of the African Pioneer Corps receive a monthly pension. There are also occupational pension schemes, of which the largest is for public servants. There is a limited population benefiting from private pension schemes.

\section{$\underline{\text { Strategic actions }}$}

- Provide key services at community level, including health, psycho-social support and provision of grants, extension services for economic empowerment and protection of the rights of the elderly, especially those playing a parental role towards children

- Expand the Old Age Pension scheme in line with the performance of the economy 


\section{Implementation Strategy}

The purpose of this Plan is to make a break with the past by transforming the economy. The plan objectives will be achieved if the expected investments take place and the Government implements the key reforms thereby improving allocative and absorptive capacity. The main external risks are the uncertain global economic recovery and climate change impacts. The Government will address low administrative capacity and weakness of the domestic private sector. Implementation excellence will also be built through ensuring local ownership of the Plan by all stakeholders, effective mobilisation of resources and developing timely and robust monitoring and evaluation systems. The Government will use the projected benign economic circumstances in the early Plan period as a window of opportunity to implement reforms and targeted, cost-effective interventions that will encourage faster, broad-based growth.

The key drivers for change, implementing reforms and facilitating the implementation of this Plan are:

\section{Plan and Budget Integration}

- Facilitating NSDP integration into MTEF and annual budget process. Resource allocation priorities for each sector will be guided, as the first principle, by their contribution on growth and employment and/or crowding in private investment to be able to deliver on the growth targets

- Development of implementation plans by all ministries and encouraging other stakeholder groups such as the private sector and civil society organisations to develop their implementation agenda 
- Adopt Sector Wide Approaches (SWAPs) to define medium-term investment needs and rolling NSDP Part II: Public Investment and Development Programme annually.

- Undertake annual Public Expenditure Reviews (PERs) for selected subsectors and districts to enhance allocation efficiency

- Develop district economic strategies and flagship projects to exploit different comparative advantages

\section{Monitoring and Evaluation}

- Preparation of the Monitoring and Evaluation Framework with targets for each strategic area

- Establishment of the National Planning Advisory Board to allow independent and high level monitoring and evaluation

- Creating an institutionalised platform for non-state actors participation in policy dialogue and monitoring results

- Promoting results oriented leadership and management system

\section{Private Sector Participation}

- Use the established private sector platforms such as private sector foundation/Business Council, Business Chambers and agri-business associations for high level dialogue and creating avenues for greater private sector participation in implementing the growth agenda

- Identify new investment opportunities that translate into bankable projects for investment promotion locally and internationally

- Offer effective entrepreneurship training and support services 


\section{Financing Strategy}

- Resources will be mobilised primarily through the creation of vehicles that will direct domestic resources and remittances towards investment in high potential areas that have been identified in the plan, promote FDI and investment by the diaspora, especially in RSA. The Government has to develop more effective strategies to mobilise additional Official Development Assistance (ODA) from traditional and new sources and use available space to contract concessional external debt whilst ensuring that macroeconomic stability is maintained

- Mobilising general and sector budget support by ensuring that the Government meets her obligations or agreed targets

- Facilitating the alignment of Country Assistance Strategies/Frameworks with the NSDP

- Negotiation of Bilateral Framework agreements such as Millennium Challenge Account II and financing of Joint Bilateral Commission for Cooperation

- Promoting further south-south cooperation

This will have to be supported by the implementation of aid policy and mutual accountability framework between the Government and development partners, public sector improvement and reform programmes, including smart PPPs and outsourcing of services to the private sector and capable NGOs. 